\title{
The Sustainable Development Goals Report 2017
}

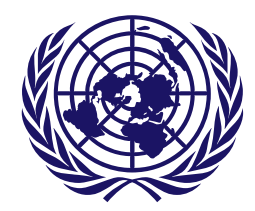

United Nations

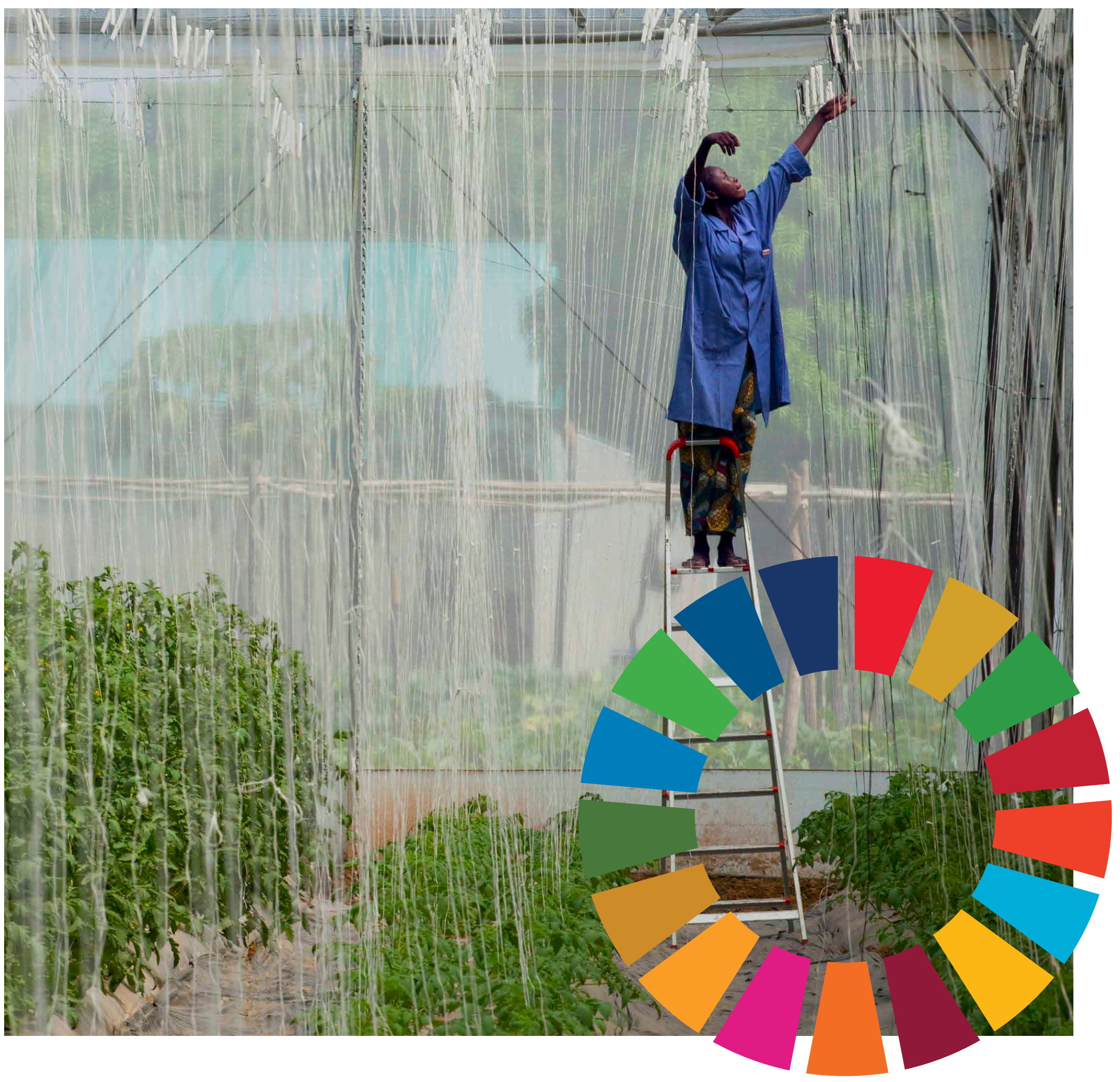




\section{Contents}

Foreword

Overview

Harnessing the power of data

16

Goal 1: No poverty

18 Goal 2: Zero hunger

20 Goal 3: Good health and well-being

24 Goal 4: Quality education

26 Goal 5: Gender equality

30 Goal 6: Clean water and sanitation

32 Goal 7: Affordable and clean energy

34 Goal 8: Decent work and economic growth

36 Goal 9: Industry, innovation and infrastructure

38 Goal 10: Reduced inequalities

40 Goal 11: Sustainable cities and communities

42 Goal 12: Responsible consumption and production

44 Goal 13: Climate action

Goal 14: Life below water

48 Goal 15: Life on land

50 Goal 16: Peace, justice and strong institutions

54 Goal 17: Partnerships for the Goals

58 A note to the reader

Regional groupings 


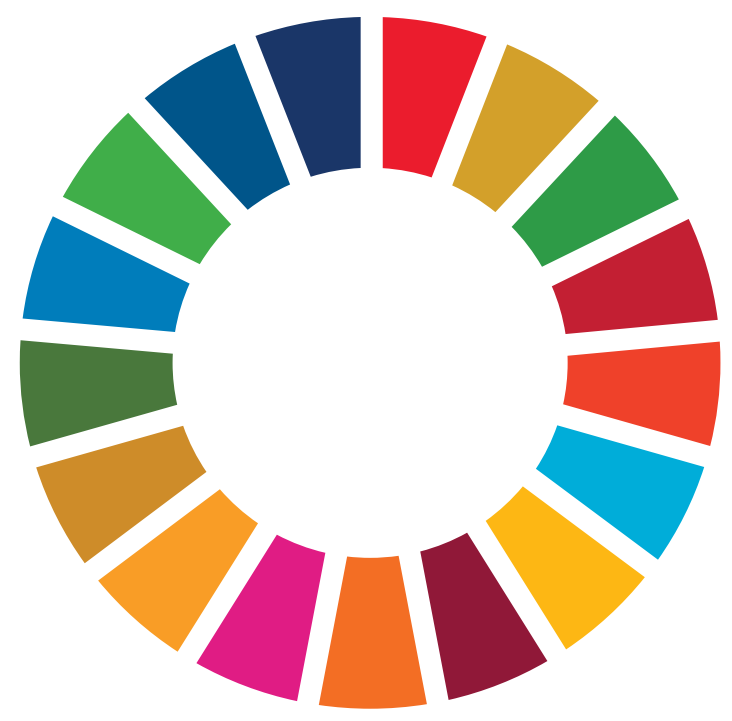

\section{The Sustainable Development Goals Report 2017}

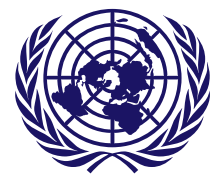




\section{Foreword}

In adopting the 2030 Agenda for Sustainable Development, world leaders resolved to free humanity from poverty, secure a healthy planet for future generations, and build peaceful, inclusive societies as a foundation for ensuring lives of dignity for all.

This collective journey has at its heart a promise to leave no one behind. The 2030 Agenda is deliberately ambitious and transformational, with a set of 17 integrated and indivisible Sustainable Development Goals and targets to guide us. Crucially, it is a universal agenda, applying to all countries; even the richest have yet to fully ensure women's rights, conquer inequality or safeguard the environment.

Implementation has begun, but the clock is ticking. This report shows that the rate of progress in many areas is far slower than needed to meet the targets by 2030 .

Focused actions are needed to lift the 767 million people who still live on less than 1.90 US dollars a day, and to ensure food security for the 793 million people who routinely confront hunger. We need to double the rate at which we are reducing maternal deaths. We need more determined progress towards sustainable energy, and greater investments in sustainable infrastructure. And we need to bring quality education within reach of all; if all children in low-income countries completed upper secondary school by 2030, per capita income would increase by 75 per cent by 2050 and we could advance the fight to eliminate poverty by a full decade.

Gender inequality is still deeply entrenched, as manifested in the slow progress in women's representation in political life, in decision-making within their own households, and in the violence, most often with impunity, that women and girls face in all societies. Young people continue to face alarmingly high rates of unemployment, and their voices are yet to be sufficiently included in the deliberations affecting their lives and futures.

More than 2 billion people are living in countries with excess water stress. Nine out of 10 city dwellers are living in cities where air pollution is a health hazard. Planetary warming continues unabated, setting a new record of about 1.1 degrees Celsius above the preindustrial period and contributing to an increased frequency of extreme weather events.
Sustainable development also depends fundamentally on upholding human rights and ensuring peace and security. Leaving no one behind also means reducing inequalities within and among countries, reaching those most at risk, and strengthening our resolve to prevent conflict and sustain peace.

This report provides a snapshot of our efforts to date. It stresses that high-level political leadership and new partnerships will be essential for sustaining momentum. It also underscores the need for reliable, timely, accessible and disaggregated data to measure progress, inform decision-making and ensure that everyone is counted.

The 2030 Agenda for Sustainable Development aims to improve the lives and future prospects of everyone, everywhere. Along with the "Sustaining Peace" resolutions adopted by the General Assembly and Security Council, the world now has, in its hands, roadmaps for reducing vulnerability, increasing resilience and averting armed conflict. Indeed, sustainable and inclusive development is both a goal in its own right and the world's best form of prevention.

Our challenge now is to mobilize action that will bring these agendas meaningfully and tangibly to life. I call on Governments and stakeholders to recognize the gaps that have been identified in this report-in implementation, financing and political will-and to now join hands to fulfil this vision and keep this promise. For my part, I will do my utmost to make the United Nations itself more effective and efficient so that it can deliver coherent support on the ground, on one agenda. Together, we can make the full, transformative ambition of the 2030 Agenda a reality for all.

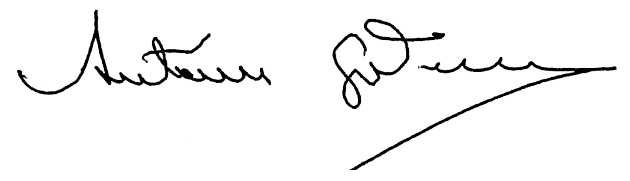

ANTÓNIO GUTERRES

Secretary-General, United Nations 


\section{Overview}

The Sustainable Development Goals Report 2017 reviews progress made towards the 17 Goals in the second year of implementation of the 2030 Agenda for Sustainable Development. The report is based on the latest available data. It highlights both gains and challenges as the international community moves towards full realization of the ambitions and principles espoused in the 2030 Agenda.
While considerable progress has been made over the past decade across all areas of development, the pace of progress observed in previous years is insufficient to fully meet the Sustainable Development Goals (SDGs) and targets by 2030. Time is therefore of the essence. Moreover, as the following pages show, progress has not always been equitable. Advancements have been uneven across regions, between the sexes, and among people of different ages, wealth and locales, including urban and rural dwellers. Faster and more inclusive progress is needed to accomplish the bold vision articulated in the 2030 Agenda.

\section{Goal 1: End poverty in all its forms everywhere}

Giving people in every part of the world the support they need to lift themselves out of poverty in all its manifestations is the very essence of sustainable development. Goal 1 focuses on ending poverty through interrelated strategies, including the promotion of social protection systems, decent employment and building the resilience of the poor.

- An estimated 767 million people lived below the extreme poverty line in 2013, down from 1.7 billion people in 1999. This represents a reduction in the global rate of extreme poverty from 28 per cent in 1999 to 11 per cent in 2013.

- Almost 10 per cent of the employed population worldwide lived with their families on less than 1.90 US dollars per person per day in 2016. Vulnerability was much higher for younger workers: 9 per cent of adult workers and their families lived in extreme poverty compared to 15 per cent of youth workers.

- In 2016, only 22 per cent of the unemployed worldwide received unemployment benefits, 28 per cent of people with severe disabilities collected a disability pension, 35 per cent of children were covered by social protection, 41 per cent of women giving birth received maternity benefits, and 68 per cent of people above retirement age collected a pension.

- Economic losses from natural hazards are now reaching an average of 250 billion to 300 billion US dollars a year, with a disproportionate impact on small and vulnerable countries.
Number of people living in extreme poverty fell significantly

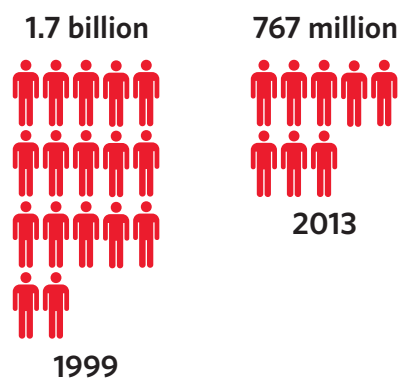

Proportion of vulnerable populations covered by social protection systems is still low

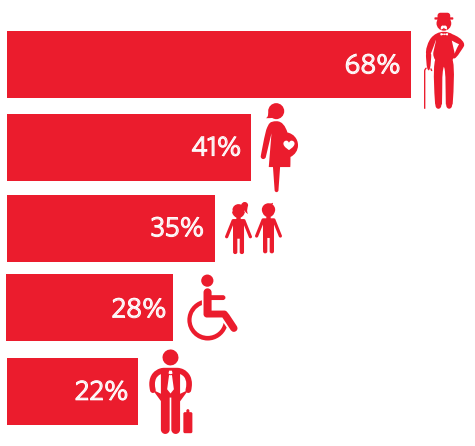


Almost two thirds suffering from hunger live in sub-Saharan Africa and Southern Asia
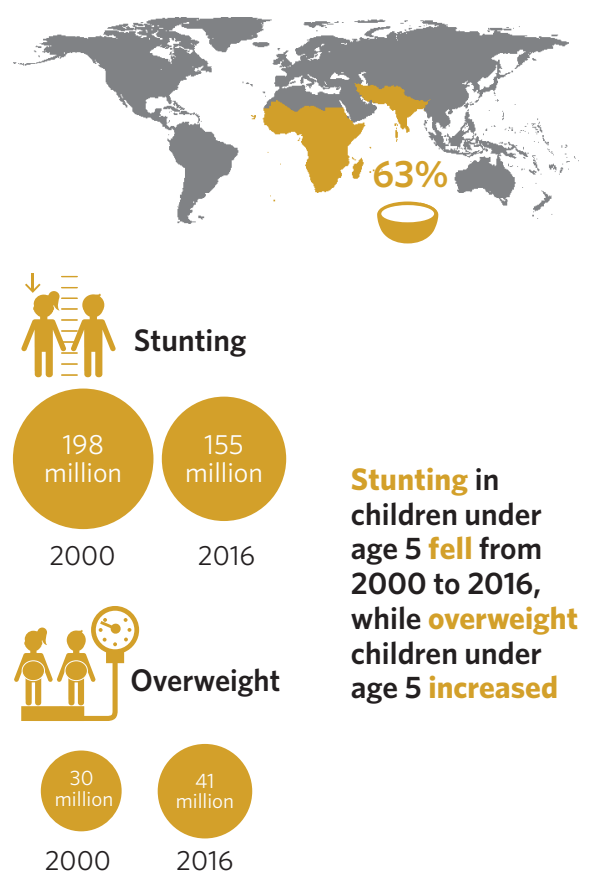

Goal 2 addresses a fundamental human need-access to nutritious, healthy food, and the means by which it can be sustainably secured for everyone. Tackling hunger cannot be addressed by increasing food production alone. Well-functioning markets, increased incomes for smallholder farmers, equal access to technology and land, and additional investments all play a role in creating a vibrant and productive agricultural sector that builds food security.

- The proportion of undernourished people worldwide declined from 15 per cent in 2000-2002 to about 11 per cent in 2014-2016. Globally, about 793 million people were undernourished in 2014-2016, down from 930 million in 2000-2002.

- Southern Asia and sub-Saharan Africa accounted for 63 per cent of undernourished people worldwide in 2014-2016.

- In 2016, an estimated 155 million children under age 5 were stunted (low height for their age), 52 million were suffering from wasting (low weight for their height), and 41 million were overweight. Globally, the stunting rate fell from 33 per cent in 2000 to 23 per cent in 2016.

- The share of aid to agriculture in sector-allocable aid from member countries of the Development Assistance Committee of the Organisation for Economic Co-operation and Development fell from nearly 20 per cent in the mid-1980s to 7 per cent in 2015.

\section{Goal 3: Ensure healthy lives and promote well-being for all at all ages}

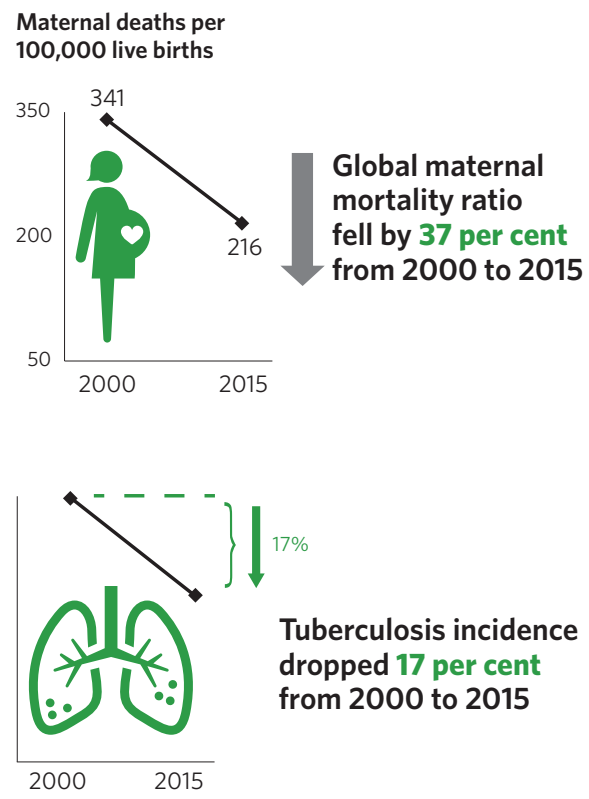

Risk of dying between ages of 30 and 70 from one of these four NCDs fell from 2000 to 2015

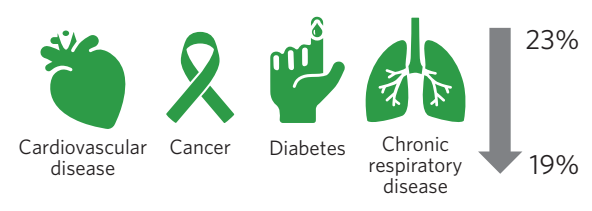

Goal 3 addresses all major health priorities and calls for improving reproductive, maternal and child health; ending communicable diseases; reducing non-communicable diseases and other health hazards; and ensuring universal access to safe, effective, quality and affordable medicines and vaccines as well as health coverage.

- Between 2000 and 2015, the global maternal mortality ratio declined by 37 per cent, and the under- 5 mortality rate fell by 44 per cent. However, 303,000 women died during pregnancy or childbirth and 5.9 million children under age 5 died worldwide in 2015. Most of these deaths were from preventable causes.

- The period between 2000 and 2015 saw a 46 per cent reduction in HIV incidence; a 17 per cent decline in the incidence of tuberculosis; a 41 per cent decrease in the incidence of malaria; and a 21 per cent drop in people requiring mass or individual treatment and care for neglected tropical diseases.

- The risk of dying between the ages of 30 and 70 from one of four main non-communicable diseases (NCDs) - cardiovascular disease, cancer, diabetes or chronic respiratory disease-fell from 23 per cent to 19 per cent between 2000 and 2015, not rapidly enough to meet the 2030 target.

- Nearly 800,000 suicides occurred worldwide in 2015, with men about twice as likely to die by suicide as women.

- In 2013, around 1.25 million people died from road traffic injuries, an increase of 13 per cent since 2000 .

- Globally in 2012, household air pollution from cooking with unclean fuels and inefficient technologies led to an estimated 4.3 million deaths; another 3 million deaths were attributed to ambient air pollution from traffic, industrial sources, waste burning and residential fuel combustion. 


\section{Goal 4: Ensure inclusive and equitable quality education and promote lifelong learning opportunities for all}

Goal 4 aims to ensure that all people have access to quality education and the opportunity for lifelong learning. The Goal goes beyond school enrolment and looks at proficiency levels, the availability of trained teachers and adequate school facilities, and disparities in education outcomes.

- In 2014, 2 out of 3 children worldwide participated in pre-primary or primary education in the year prior to the official entrance age for primary school, compared to only 4 in 10 children in the poorest countries.

- Despite considerable gains in primary school enrolment between 2000 and 2014, 9 per cent of primary-school-aged children worldwide were out of school in 2014, with little progress since 2008.

- Surveys undertaken between 2007 and 2015 in selected countries show that children and adolescents from the richest 20 per cent of households achieved greater proficiency in reading than those from the poorest 20 per cent of households, and urban children scored higher in reading than rural children.

- Data for 2011 indicate that only about one quarter of schools in sub-Saharan Africa had electricity, less than half had access to drinking water, and only 69 per cent had toilets (with many lacking separate sanitation facilities for girls and boys).

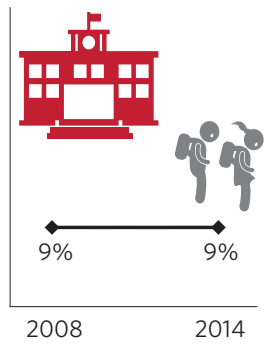

Proportion of primary school age children out of school has stagnated at about 9 per cent since 2008

In 2011, only around one quarter of schools in sub-Saharan Africa had electricity and less than half had access to basic drinking water
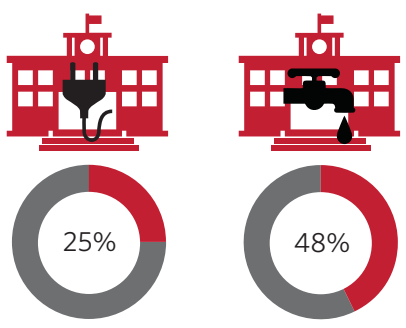

\section{Goal 5: Achieve gender equality and empower all women and girls}

Gender inequality persists worldwide, depriving women and girls of their basic rights and opportunities. Achieving gender equality and the empowerment of women and girls will require more vigorous efforts, including legal frameworks, to counter deeply rooted gender-based discrimination often resulting from patriarchal attitudes and related social norms.

- One in five girls and women (aged 15 to 49) who have ever been married or in union reported they had been subjected to physical and/or sexual violence by an intimate partner in the previous 12 months, according to surveys undertaken between 2005 and 2016 in 87 countries.

- Around 2000, nearly one in three women between 20 and 24 years of age reported that they were married before age 18; around 2015, the ratio had declined to roughly one in four.

- According to surveys undertaken around 2015 in 30 countries where the practice of female genital mutilation is concentrated, over a third (35 per cent) of girls between the ages of 15 and 19 had been subjected to the procedure.

- On average, women spent almost triple the amount of time on unpaid domestic and care work as men, based on data from 2000 to 2016.

-Women's participation in single or lower houses of national parliaments worldwide reached only 23.4 per cent in 2017. In the majority of the 67 countries with data from 2009 to 2015 , fewer than a third of senior- and middle-management positions were held by women.
1 in 5 ever-partnered women and girls were subjected to physical and/or sexual violence by an intimate partner
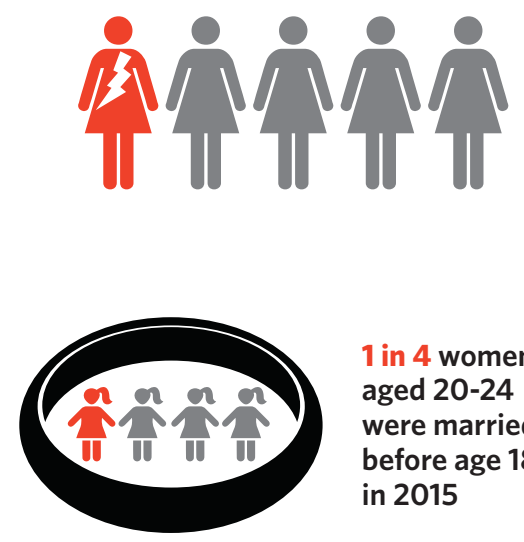

1 in 4 women aged $20-24$ were married before age 18 in 2015

Fewer than 1 in 3 senior- and middlemanagement positions were held by women in the majority of 67 countries

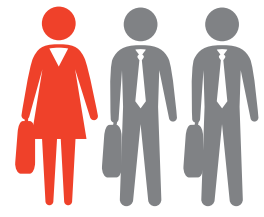




\section{Goal 6: Ensure availability and sustainable management of water and sanitation for all}

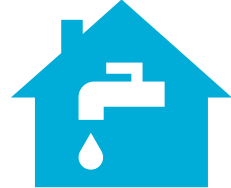

5.2 billion people used a "safely managed" drinking water service in 2015

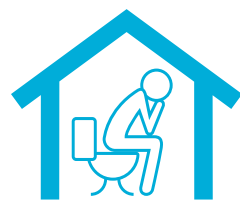

2.9 billion people used a "safely managed" sanitation service in 2015

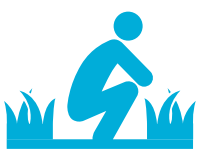

892 million people still practised open defecation in 2015

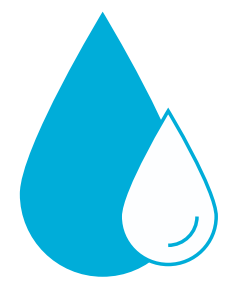

More than 2 billion people are affected by water stress
Goal 6 aims to tackle challenges related to drinking water, sanitation and hygiene for populations, as well as to water-related ecosystems. Without quality, sustainable water resources and sanitation, progress in many other areas across the SDGs, including health, education and poverty reduction, will also be held back.

- In 2015, 5.2 billion people (71 per cent of the global population) used a "safely managed" drinking water service-an improved source located on premises, available when needed and free from contamination.

- In 2015, 2.9 billion people (39 per cent of the global population) used a "safely managed" sanitation service-a basic facility that safely disposed of human waste.

Open defecation, practised by 892 million people (12 per cent of the global population) in 2015 , continues to pose serious health risks.

- More than 2 billion people globally are living in countries with excess water stress. Northern Africa and Western Asia, as well as Central and Southern Asia, experience water stress levels above 60 per cent, indicating the strong probability of future water scarcity.

\section{Goal 7: Ensure access to affordable, reliable, sustainable and modern eneroy for all}

Electricity access in rural areas is lower than in urban areas
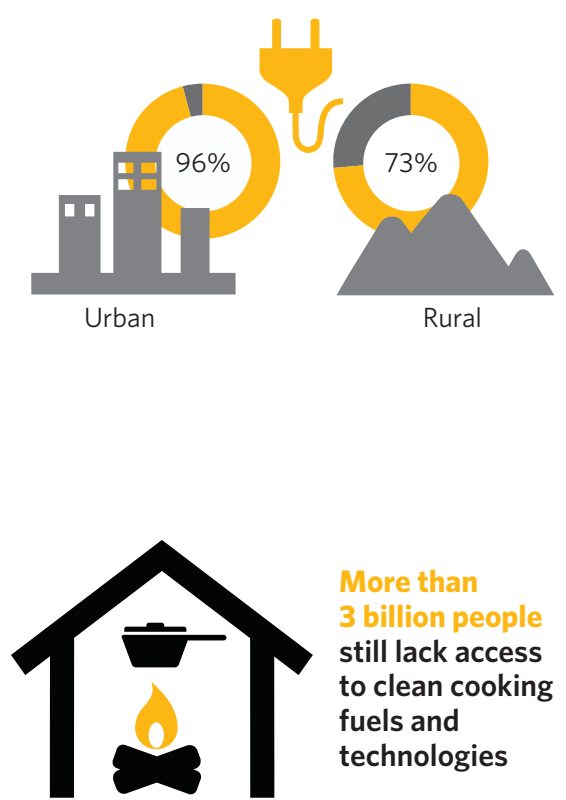

More than

3 billion people

still lack access

to clean cooking

fuels and

technologies
Universal access to affordable, reliable and sustainable energy services requires expanding access to electricity and clean cooking fuels and technologies, as well as improving energy efficiency and increasing the use of renewable energy. To achieve this Goal, bolder financing and policies will be needed, along with the willingness of countries to embrace new technologies on a much more ambitious scale.

- In 2014, 85.3 per cent of the global population had access to electricity, up from 77.6 per cent in 2000 . However, 1.06 billion people still lived without this basic service.

-While 96 per cent of urban residents could access electricity in 2014, the share was only 73 per cent in rural areas.

- Access to clean fuels and technologies for cooking climbed to 57 per cent in 2014, up from 50 per cent in 2000. Still, more than 3 billion people, most of them in Asia and sub-Saharan Africa, lack access to clean cooking fuels and technologies and are exposed to high levels of household air pollution.

The share of renewable energy in final energy consumption grew modestly from 2010 to 2014-from 17.5 to 18.3 per cent. Water, solar and wind power generation accounted for most of the increase.

Globally, primary energy intensity improved by 2.1 per cent a year from 2012 to 2014. However, this pace is insufficient to double the global rate of energy efficiency improvements as called for in the target. 


\section{Goal 8: Promote sustained, inclusive and sustainable economic growth, full and productive employment and decent work for all}

Economic growth is a principal driver of sustainable development. When this growth is sustained and inclusive, more people can escape poverty as opportunities for full and productive employment expand. To allow future generations to benefit from today's economic growth, such growth should be environmentally sound and not the result of unsustainable exploitation of resources.

- The average annual growth rate of real gross domestic product (GDP) per capita expanded from 0.9 per cent over the period 2005-2009 to 1.6 per cent in 2010-2015. Real GDP growth in the least developed countries (LDCs) averaged 4.9 per cent in 2010-2015, short of the target of at least 7 per cent annually.

- Growth in labour productivity-measured by GDP per worker-slowed sharply after the financial crisis of 2008-2009. It grew at an average annual rate of 1.9 per cent between 2009 and 2016, compared to 2.9 per cent between 2000 and 2008.

- The global unemployment rate fell from 6.1 per cent in 2010 to 5.7 per cent in 2016. Despite progress overall, youth (aged 15 to 24 years) were nearly three times more likely than adults to be without a job, with unemployment rates of 12.8 per cent and 4.4 per cent, respectively.

- The number of children aged 5 to 17 engaged in child labour declined from 246 million in 2000 to 168 million in 2012. Still, around 1 in 10 children worldwide were engaged in child labour in 2012; more than half of them (85 million) were exposed to hazardous forms of work.
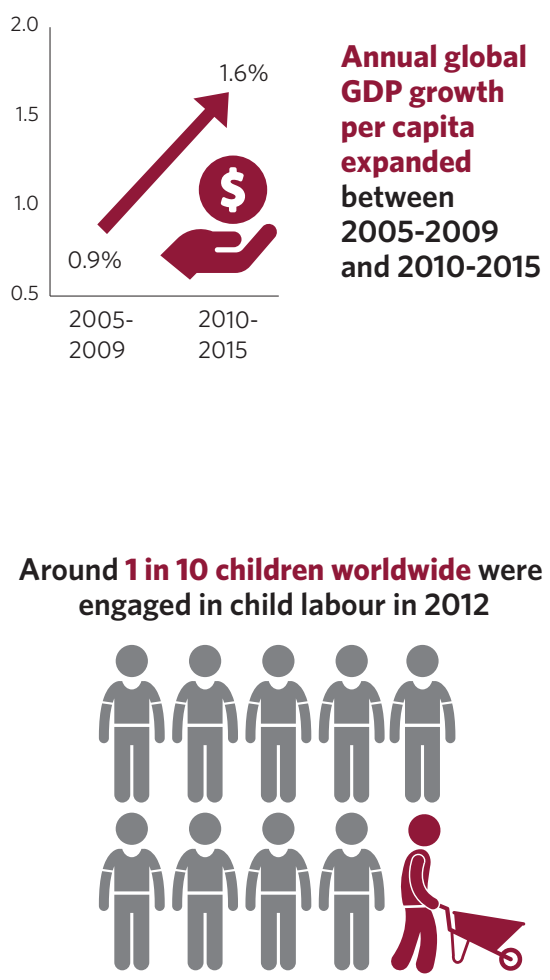

\section{Goal 9: Build resilient infrastructure, promote inclusive and sustainable}

industrialization and foster innovation

Infrastructure, industrialization and innovation are three drivers of economic growth. When inclusivity, resilience and sustainability are factored into the implementation of these driving forces, economic growth can support sustainable development.

- In 2015, the economic impact of air transport was 2.7 trillion US dollars (3.5 per cent of global GDP). The least developed countries (LDCs), landlocked developing countries (LLDCs) and small island developing States (SIDS) accounted for limited air travel and freight volumes-each country group comprised only a small fraction (1 to 2.7 per cent) of the global total.

- Between 2005 and 2016, manufacturing value added (MVA) per capita increased by almost 59 per cent in LDCs, yet was still only about 2 per cent of that in Europe and Northern America.

- Between 2000 and 2014, steady reductions were observed in carbon dioxide $\left(\mathrm{CO}_{2}\right)$ emissions from manufacturing per unit of MVA in most regions of the world and in all 10 of the largest manufacturing countries.

- Global investment in research and development increased at an average annual rate of 4.5 per cent between 2000 and 2014. It reached 1.8 trillion US dollars (purchasing power parity) in 2014-1.7 per cent of global GDP.

- Coverage by a mobile cellular signal has become almost universal. In 2016, 95 per cent of the world's population was in range of at least a second-generation (2G) signal and 84 per cent received at least a third-generation (3G) signal.

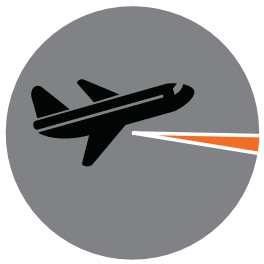

LDCs, LLDCs and SIDS each accounted for 1 to 2.7 per cent of global air travel and freight volumes

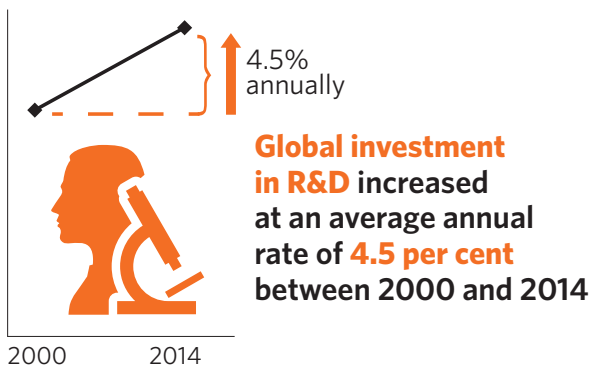




\section{Goal 10: Reduce inequality within and among countries}

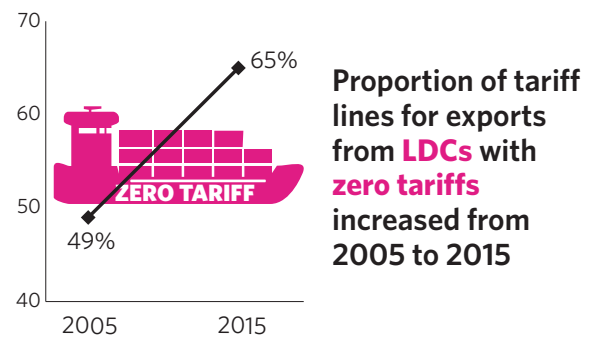

Global cost of sending remittances averaged above 7 per cent

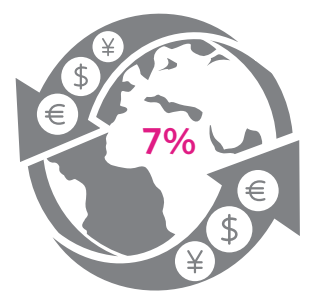

Goal 10 calls for reducing inequality within and among countries, ensuring safe, orderly and regular migration, and strengthening the voices of developing countries in international economic and financial decision-making.

- In 49 of 83 countries with data for the period 2011-2015, the per capita incomes of the poorest 40 per cent of the population grew more rapidly than the national average, leading to a reduction in income inequality.

- Reforms at the International Monetary Fund have led to increased voting shares for developing countries, yet in many international organizations their voting shares remain far below their overall membership levels.

- The international trade community continues to grant more favourable access conditions to LDCs: the proportion of tariff lines for exports from LDCs with zero tariffs increased from 49 per cent in 2005 to 65 per cent in 2015.

- On average, the cost of sending remittances home is above 7 per cent of the amount remitted, significantly higher than the 3 per cent target. New and improved technologies, such as prepaid cards and mobile operators, helped reduce these fees to between 2 per cent and 4 per cent, but are not yet widely available or used in many remittance corridors.

\section{Goal 11: Make cities and human settlements inclusive, safe, resilient and sustainable}

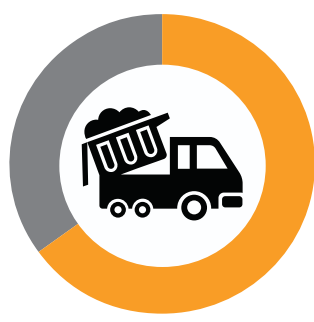

Coverage of municipal waste collection was 65 per cent in cities in 101 countries
The pace of urban growth has been unprecedented. More than half the world's population, or nearly 4 billion people, lived in cities in 2015. However, while cities are incubators of innovation and help foster increased employment and economic growth, rapid urbanization has brought with it enormous challenges, including inadequate housing, increased air pollution, and lack of access to basic services and infrastructure.

- The proportion of the urban population living in slums worldwide fell from 28 per cent in 2000 to 23 per cent in 2014. However, in sub-Saharan Africa, more than half (56 per cent) of urban dwellers lived in slum conditions.

From 2000 to 2015, in all regions of the world, the expansion of urban land outpaced the growth of urban populations, resulting in urban sprawl.

- According to data from cities in 101 countries from 2009 to 2013, approximately 65 per cent of the population was served by municipal waste collection.

- In 2014, 9 in 10 people living in urban areas breathed air that did not meet the World Health Organization's air quality guidelines value for particulate matter (PM 2.5).

-As of May 2017, 149 countries had fully or partially implemented national-level urban policies, most of which are aligned with priority areas identified in the SDGs. 
Sustainable consumption and production patterns enable efficient resource use and can reduce the impact of economic activities on the environment. To that end, this Goal focuses on decoupling economic growth from resource use, and ensuring that hazardous chemicals and wastes are managed in a way that minimizes their impact on human lives and the environment.

- Globally, the material footprint of human beings increased from 48.5 billion metric tons in 2000 to 69.3 billion metric tons in 2010. The material footprint per capita increased from 8 metric tons per person to 10 metric tons per person over the same period.

- In 2010, Australia and New Zealand had the highest material footprint per capita (35 metric tons per person), followed by Europe and Northern America (20 metric tons per person); sub-Saharan Africa had the lowest (2.5 metric tons per person).

- Eastern and South-Eastern Asia accounted for 42 per cent of global domestic material consumption (DMC), reflecting rapid industrialization in the region.

- Almost all United Nations Member States are party to at least one global environmental agreement on chemicals and hazardous waste. However, between 2010 and 2014, only 51 per cent of Parties to the Stockholm Convention, 57 per cent of Parties to the Basel Convention, and 71 per cent of Parties to the Rotterdam Convention fully met their reporting commitments under these agreements.
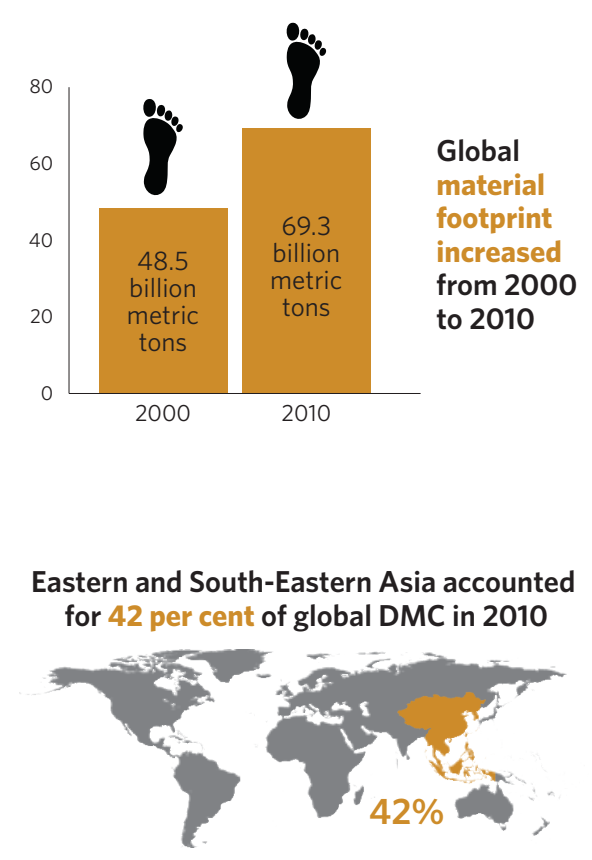

\section{Goal 13: Take urgent action to combat climate change and its impacts}

Planetary warming continued in 2016, setting a record of about 1.1 degrees Celsius above the pre-industrial period. The extent of global sea ice fell to 4.14 million square kilometres in 2016, the second lowest on record. Mitigating climate change and its impacts will require building on the momentum achieved by the Paris Agreement on Climate Change. Stronger efforts are also needed to build resilience and limit climate-related hazards and natural disasters.

- The Paris Agreement entered into force on 4 November 2016, marking a shift in focus towards implementation of action for the climate and sustainable development.

- As of 7 June 2017, 148 Parties had ratified the Paris Agreement; of these, 142 Parties (141 countries and the European Commission) had communicated their first nationally determined contributions to the United Nations Framework Convention on Climate Change Secretariat.

- The number of deaths attributed to natural hazards continues to rise, despite progress in implementing disaster risk reduction strategies. From 1990 to 2015, more than 1.6 million people died in internationally reported natural hazards.

- Many countries have begun implementing national and local disaster risk reduction strategies. In 2014-2015, most reporting countries indicated that environmental impact assessments, legislation on protected areas, climate change adaptation projects and programmes, and integrated planning played a major role in reducing underlying risk factors.

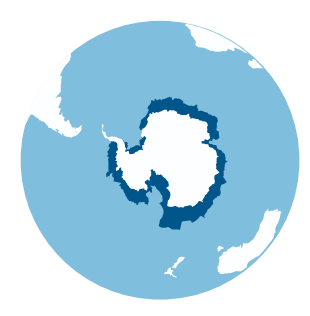

Global sea ice fell in 2016 to its second lowest extent on record
Record was set in 2016 for warming at 1.1 degrees Celsius above pre-industrial period

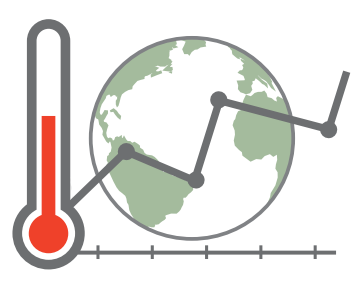




\section{Goal 14: Conserve and sustainably use the oceans, seas and marine resources}

for sustainable development

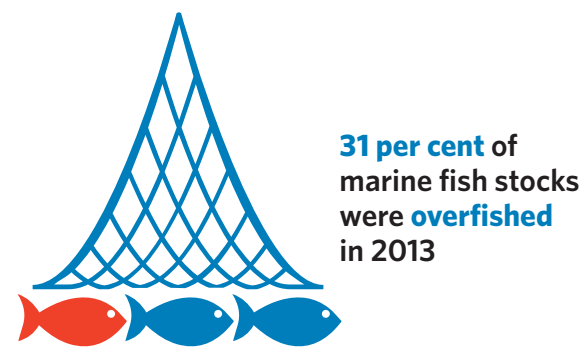

As atmospheric $\mathrm{CO}_{2}$ levels increase, estimates indicate that oceans could be nearly 150 per cent more acidic by 2100

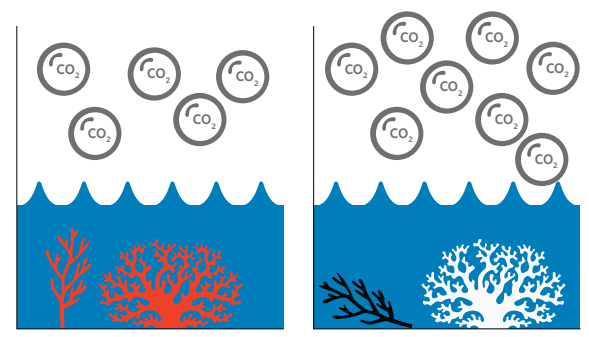

Oceans cover almost three quarters of the planet, comprising the largest ecosystem on Earth. The increasingly adverse impacts of climate change (including ocean acidification), overfishing and marine pollution are jeopardizing recent gains in protecting portions of the world's oceans.

- In 2017, protected areas cover 13.2 per cent of the marine environment under national jurisdiction, 0.25 per cent of the marine environment beyond national jurisdiction, and 5.3 per cent of the total global ocean area. The average coverage of marine key biodiversity areas (KBAs) by protected areas has risen from 32 per cent in 2000 to 45 per cent in 2017.

- The proportion of marine fish stocks worldwide that have been overfished-that is, are at biologically unsustainable levels-increased from 10 per cent in 1974 to 31 per cent in 2013.

- Oceans absorb up to 30 per cent of the annual emissions of $\mathrm{CO}_{2}$ generated by human activity. However, the absorbed $\mathrm{CO}_{2}$ also leads to an increase in the acidity of seawater, which weakens the shells and skeletons of many marine species, such as corals. As atmospheric $\mathrm{CO}_{2}$ levels rise, estimates indicate that oceans could be nearly 150 per cent more acidic by 2100 .

- Of the 63 large marine ecosystems evaluated under the Transboundary Waters Assessment Programme, 16 per cent are in the "high" or "highest" risk categories for coastal eutrophication. By 2050, it is estimated that coastal eutrophication will increase in 21 per cent of these large ecosystems.

\section{Goal 15: Protect, restore and promote sustainable use of terrestrial ecosystems, sustainably manage forests, combat desertification, and halt and reverse land degradation and halt biodiversity loss}

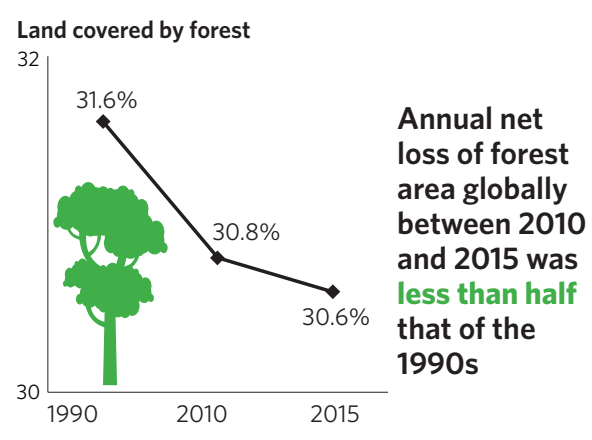

Average worldwide coverages of terrestrial, freshwater and mountain KBAs have increased

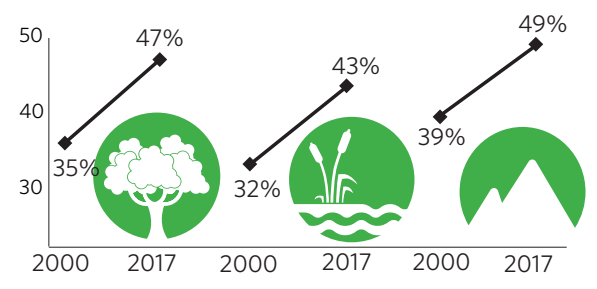

Protected and restored ecosystems and the biodiversity they support can help mitigate climate change and provide increased resilience in the face of mounting human pressures and natural disasters. Healthy ecosystems also produce multiple benefits for communities that rely on them. Goal 15 focuses on preserving and sustainably using the Earth's terrestrial species and ecosystems.

- From 2010 to 2015, the annual net loss of forest area globally was less than half that of the 1990s. The proportion of land area covered by forest decreased from 31.6 per cent in 1990 to 30.8 per cent in 2010 and 30.6 per cent in 2015.

- From 2000 to 2017, average worldwide coverage of terrestrial, freshwater and mountain KBAs by protected areas increased from 35 per cent to 47 per cent, from 32 per cent to 43 per cent, and from 39 per cent to 49 per cent, respectively.

- Biodiversity loss, however, continues at an alarming rate. Corals, amphibians and cycads are in serious decline due to distinct and worsening threats. Bleaching, driven by climate change and local impacts, has affected the health of coral reefs worldwide, which could disappear completely by 2050. Amphibians also face a high risk of extinction, with 41 per cent already threatened.

- Illicit poaching and trafficking of wildlife continues to thwart conservation efforts, with nearly 7,000 species of animals and plants reported in illegal trade involving 120 countries. In 2013, elephant ivory, rosewood, rhinoceros horn and reptiles comprised 70 per cent of total wildlife seizures. 


\section{Goal 16: Promote peaceful and inclusive societies for sustainable development, provide access to justice for all and build effective, accountable and inclusive institutions at all levels}

Peace, justice and effective, accountable and inclusive institutions are at the core of sustainable development. Progress in promoting peaceful and inclusive societies remains uneven across and within countries. Violent conflicts have increased in recent years, and a number of high-intensity armed conflicts are causing large numbers of civilian casualties and driving millions of people from their homes.

- In 2015, the intentional homicide rate in countries with high income inequality (Gini index $>0.45$ ) was nine times that of countries with low income inequality (Gini index $<0.35$ ).

- In 76 countries with available data from 2005 to 2016, about 8 in 10 children aged 1 to 14 years were subjected to some form of psychological aggression and/or physical punishment on a regular basis.

- More than 570 different human trafficking flows, which criss-cross the globe, were identified by law enforcement officers between 2012 and 2014. The large majority of identified trafficking victims in 2014 were women and girls (71 per cent), and more than a quarter were children.

- Globally, the proportion of people held in detention without being tried or sentenced for a crime was 31 per cent in 2013-2015.

- According to data from 2005 to 2016, over 18 per cent of firms worldwide reported receiving at least one bribery payment request. The share of firms in low- and lowermiddle-income countries was 25 per cent, versus 4 per cent in high-income countries.

- Data reported for 147 countries from 2010 to 2016 indicate that 71 per cent of children under age 5 worldwide have had their births registered; the birth registration rate in sub-Saharan Africa stands at just 46 per cent.

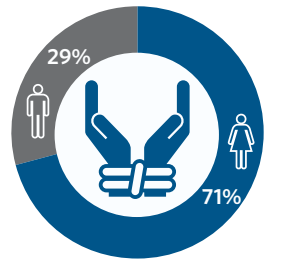

Over 70 per cent of victims of trafficking were women and girls in 2014

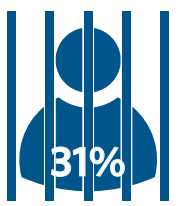

Almost 1 in 3 people were held in detention without being tried or sentenced for a crime in 2013-2015

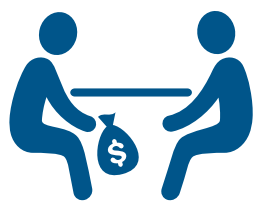

Over 18 per cent of firms worldwide reported receiving at least one bribery payment request

\section{Goal 17: Strengthen the means of implementation and revitalize the Global Partnership for Sustainable Development}

A stronger commitment to partnership and cooperation is needed to achieve the SDGs. Attaining the Goals will require coherent policies, an enabling environment for sustainable development at all levels and by all actors, and a reinvigorated Global Partnership for Sustainable Development. Meeting the means of implementation targets is key to realizing the 2030 Agenda, as is the full implementation of the Addis Ababa Action Agenda. Incremental progress has been made in these areas, but more is needed.

- From 2015 to 2016, official development assistance (ODA) rose by 8.9 per cent in real terms to 142.6 billion US dollars, reaching a new peak. Despite this progress, bilateral aid to LDCs fell by 3.9 per cent in real terms.

- Debt service is trending upwards. From 2000 to 2011, debt service in lower-middleincome countries fell from 12.9 per cent to 3.6 per cent, before rising slowly to 6.1 per cent in 2015 .

- In 2016, international remittances totalled 575 billion US dollars, 75 per cent of which (429 billion US dollars) flowed to developing countries. However, remittances to developing countries fell in 2016 for a second consecutive year, declining by 2.4 per cent over 2015.

- In 2016, about 80 per cent of the population in developed regions had Internet access, compared to 40 per cent in developing regions and 15 per cent in LDCs.

- In 2014, financial support for statistical capacity in developing countries (338 million US dollars) accounted for only 0.18 per cent of total ODA. From 2007 to 2016, 89 per cent of countries or areas around the world conducted at least one population and housing census; 25 countries or areas failed to conduct a census during this period.

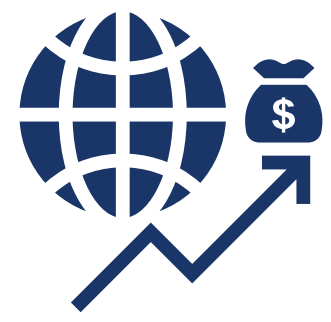

ODA rose by 8.9 per cent from 2015 to 2016, reaching a new peak

Proportion of the population with Internet access was lowest in LDCs in 2016

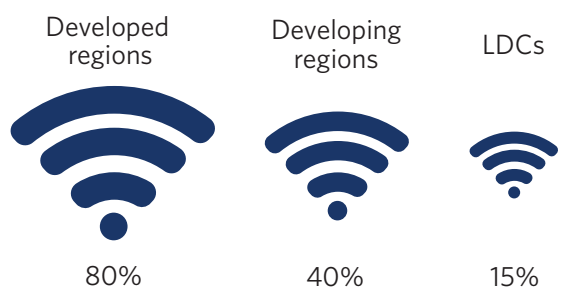




\section{Eradicating poverty and promoting prosperity in a changing world}

Eradicating all forms of poverty is at the core of sustainable development. Poverty encompasses deprivation in many domains, including income, hunger, poor health, social exclusion, discrimination and lack of access to basic services. At the same time, deprivations in any one of these domains can in turn exacerbate the depth or duration of deprivations in one or more of the others. Eradicating poverty and promoting prosperity in a changing world requires a holistic approach that takes into account the interlinkages across the different dimensions of sustainable development. This section provides a few highlights of these interconnections in the context of the theme and Goals under review at the High-Level Political Forum on Sustainable Development in July 2017.

\section{Increasingly, the extreme poor reside in fragile settings}

While nearly a billion people have escaped extreme poverty since 1999, about 767 million remained destitute in 2013, living on 1.90 US dollars or less a day. Half of the world's poor lived in sub-Saharan Africa, where 42 per cent of the population subsisted in conditions of extreme poverty in 2013. Another one third lived in Southern Asia. Those in extreme poverty are increasingly found living in fragile situations such as conflict zones and remote areas that are difficult to reach. And many of those who have climbed out of extreme poverty continue to live precariously, just above the poverty line, and are highly vulnerable to falling backwards. Economic volatility, natural disasters and other shocks put them at risk. About 80 per cent of the world's poor live in rural areas and 64 per cent work in the agriculture sector. Children are more likely to suffer poverty than adults: almost 385 million people living in extremely poor households were under 18 years of age in 2013. Adding to their vulnerability is the lack of adequate social protection systems, which, if well designed, can help prevent and reduce poverty and inequality at every stage of life. In 2016, only 45 per cent of the world's population were covered by at least one social protection cash benefit.

\section{Conflict and war exacerbate poverty}

Conflict has become the most insurmountable barrier to poverty eradication and sustainable development. War, violence and persecution worldwide led to the displacement of 65.6 million people from their homes by the end of 2016. This represents an increase of about 300,000 people since 2015, and the highest level recorded in decades. Of these, 22.5 million were refugees, 40.3 million were internally displaced, and 2.8 million were asylum seekers.

Children, who make up about half of the 17.2 million refugees under the responsibility of the United Nations High Commissioner for Refugees, are disproportionately affected by conflict. In fleeing to escape violence and persecution, children are often deprived of what they need most, including health care and education, safe water and shelter. In 2015, 50 per cent of refugee children of primary-school age were out of school. Many displaced children travel alone or are separated from their parents. Among the children making the dangerous passage from North Africa to Europe, the vast majority-92 per cent-of those who arrived in Italy in 2016 and the first two months of 2017 were unaccompanied.

\section{Women still face considerable structural disadvantages in escaping poverty}

Entrenched gender inequality continues to hold women back from achieving their full potential. In 2015, for instance, almost 27 per cent of women aged 20-24 were married before the age of 18-a practice commonplace in Southern Asia and sub-Saharan Africa. These two regions are also home to 80 per cent of the world's poor. Child marriage is closely linked to early childbirth and poor access to health and reproductive health care. Typically, marriage ends or severely limits girls' education, autonomy and economic potential.

Societal assumptions and expectations of women's roles as caregivers and mothers also curtail their income. Women spent almost three times as many hours on unpaid domestic work as men. Only half of women in 45 countries with available data make their own decisions about reproductive health. And women's and girls' lack of autonomy over their sexual and reproductive health-compounded by unintended pregnancies - tends to increase household poverty. In many parts of the world, women's access to land, property and financial assets remains restricted, which limits their economic opportunities, and their ability to lift their families out of poverty.

Around the world, one's home is a key asset for stored wealth. Preliminary analysis of data from selected countries finds that women possess less wealth in dwellings than men. In Uganda and Mongolia, for example, fewer women than men own dwellings, with women representing only 35 per cent and 37 per cent of homeowners, respectively. In KwaZulu-Natal Province in South Africa, nearly half of women own their own homes, but their dwellings have less monetary value than men's, accounting for only about one third of the total value of dwelling wealth.

Even in most European countries, poverty rates among older people are higher for women than for men. In more than half of the countries with available data, the gender gap is higher in one-person households compared to all households. This reflects women's heightened vulnerability when living by themselves.

All over the world, women continue to be largely underrepresented in parliaments and senior management positions, with less than one-third representation in either domain in most regions of the world. 


\section{Ocean degradation threatens progress on eliminating poverty}

Oceans cover almost three quarters of the planet. Close to 40 per cent of the world's population live in coastal communities, and about 61 per cent of the world's gross national product is produced within 100 kilometres of oceans. Sustainable use of oceans can provide countries with food and economic opportunities in fisheries, tourism and recreation, along with transport and trade, among others. Appropriate management of this priceless resource can help reduce poverty by enhancing food security and improving the livelihoods of millions of people. However, climate change and recent trends showing ocean acidification, eutrophication, environmental degradation of coastal land, and a reduction in marine biodiversity are together exerting mounting pressures on this resource. In 2013, nearly a third (31 per cent) of marine stocks were overfished; increasing ocean acidification levels endanger marine ecosystems worldwide; and, by 2050, coastal eutrophication will increase in 21 per cent of major marine ecosystems. And the decreasing extent of global sea ice as well as the increasing level of planetary warming indicate that climate change continues, increasing the adverse impacts on the oceans and many other ecosystems.

\section{Investment in infrastructure and technology can help poor rural farmers}

Sustainable agriculture, along with investments to improve agricultural productivity and enhance food security, are key to ending hunger and lifting millions of people, including small-scale farmers, out of extreme poverty. Improving farm productivity, increasing the value added in agriculture, and integrating markets are all important strategies. The role of infrastructure and technology in this regard cannot be overstated. Transportation infrastructure, for instance, can connect farmers with existing markets and create new ones. Where poverty rates are still very high-as in sub-Saharan Africa-air travel and freight transportation are very limited. The rapid expansion of mobile cellular service is, however, helping to overcome some barriers. By 2016, 2 G mobile cellular networks were almost universal, with 95 per cent of the world's population covered. Information and communication technologies can help farmers connect with buyers, transfer money and acquire valuable information, including about weather conditions and market prices.

\section{Eradicating poverty and promoting prosperity cannot be achieved without reaching the most vulnerable groups}

Empowering vulnerable groups is critical to ending poverty and promoting prosperity for everyone everywhere. Due to age, socioeconomic status, gender, ethnicity and geography, vulnerable groups tend to be excluded from access to good education, health care, electricity, safe water and other critical services. In 2016, for instance, 15 per cent of young workers and their families lived in extreme poverty, compared to 9 per cent of adult workers. Moreover, youth were nearly three times more likely than adults to be unemployed. In 2015, 85 per cent of the urban population used safely managed drinking water services, compared to only 55 per cent of the rural population. Exclusion extends to persons with disabilities as well. In 2016, only 28 per cent of people with severe disabilities collected a disability pension.

The lack of sound disaggregated data for many of these vulnerable groups-including children, youth, persons with disabilities, people living with HIV, older persons, indigenous peoples, migrants, refugees and those internally displaced-exacerbates vulnerabilities by masking the extent of deprivation and disparities. What's more, a lack of rigorous evidence and comprehensive data has long compromised the ability of governments and the international community to accurately document the discrimination faced by various groups. As a result, planning and budgeting for necessary services along with effective policymaking have suffered. Children living outside of family care, persons with disabilities and older persons, for example, have largely fallen off the statistical "map". While innovative approaches for bringing these hidden populations into focus have begun to emerge, more resources and capacity-building efforts are needed to ensure that vulnerable groups receive their long-overdue place in the development agenda.

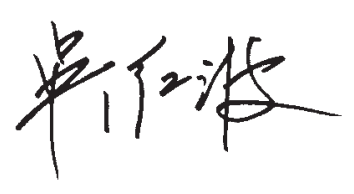

WU HONGBO

Under-Secretary-General for Economic and Social Affairs 


\section{Harnessing the power of data for sustainable development}

To fully implement and monitor progress on the SDGs, decision makers need data and statistics that are accurate, timely, sufficiently disaggregated, relevant, accessible and easy to use. Data availability and quality have steadily improved over the years. However, statistical capacity still needs strengthening and data literacy must be enhanced at all levels of decision-making. This will require coordinated efforts on the part of data producers and users from multiple data systems. It will also demand innovative ways to produce and apply data and statistics in addressing the multifaceted challenges of sustainable development.

\section{New approaches to capacity development for better data}

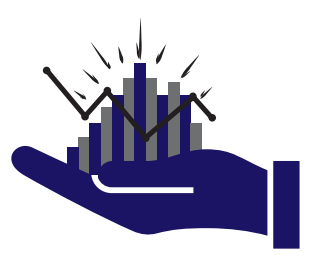

The scope of traditional statistical capacitybuilding is widening to nurture collaboration and synergies across increasingly complex data systems. The goal now is to mainstream data innovations into official statistical production processes and focus more sharply on users' needs. Efforts are also being made to ensure that statistical capacity-building initiatives are home-grown, long-term, and generated and managed collectively by those who benefit from them.

Many countries are making strides in this direction. For example, following the launch of its second National Strategy for the Development of Statistics in June 2016, Equatorial Guinea adopted an Advanced Data Planning Tool (ADAPT). Its purpose is to facilitate the budgeting and monitoring of development activities assigned to key department heads, allowing for direct ownership and reporting of progress. Similarly, in 2016, the heads of national statistical offices in 24 African countries participated in leadership training that emphasized the importance of active leadership and change management.

\section{Innovations and synergies across data ecosystems}

Increasingly, public-private partnerships are enabling the use of big data and other non-traditional data sources in policymaking by mainstreaming their use in official statistics. This is made possible through various institutional arrangements, including in-house production of statistics by data providers, direct transfer of private data to end users, the transfer of private data to a trusted third party and the outsourcing of certain functions. It is crucial that national statistical offices, supported by international organizations, continue to advance the design and implementation of incentives and business models that encourage effective partnerships for improving the availability and quality of data for sustainable development.
Data innovation projects are being implemented by a broad range of public and private actors in many parts of the world, including Africa, Asia and Latin America. The results are promising. For instance, crowdsourcing exercises are being employed for the collection and analysis of data for disaster risk management and data on climate change. That said, the use of innovative technologies and new data sources for the public good is not without risk. It also presents institutional challenges: merging new data sources with traditional ones requires the modernization of data governance and quality frameworks to ensure national ownership and the establishment of transparent mechanisms. Such mechanisms allow partners from the private sector, academia and civil society to contribute their data, expertise and technology to achieving the SDGs.

\section{Using innovative web-based technologies for health-data reporting}

A growing number of countries are implementing routine health information systems such as DHIS 2, a web-based facility reporting program developed by the World Health Organization. This has been a game changer for health data, since it improves real-time availability, use and analysis of facility-based statistics. Now in use in more than 50 countries, DHIS 2 is increasingly becoming the centralized health-data platform of choice. Over the past year, partners in the Health Data Collaborative have also been supporting the integration of disease-specific data (on HIV, tuberculosis and malaria programmes, among others) into DHIS 2 , to replace the inefficient use of parallel reporting systems.

\section{Leave no one behind}

National averages, even city averages, often mask wide disparities among population groups. The identification of people suffering from deprivation therefore requires sufficiently detailed data across multiple dimensions, including age, sex, geography and disability status, among others. Any global or national statistical system must ensure that the coverage and level of data disaggregation for the follow-up and review of the 2030 Agenda leaves no one behind.

Towards this end, national statistical systems need to invest in the technology and skills necessary to collect and integrate data from multiple sources, including integration of geospatial information with statistics and other data. This means making better use of traditional statistical surveys, censuses and administrative records. It also means harnessing the power of technology to leverage new sources of data, such as from cell phone records, Earth observations, other sensors and social media. More citizen-generated data are also being used to monitor the needs and progress of vulnerable groups. However, new methodologies need to be developed to ensure the quality and reliability of such data. 


\section{Improving data on difficulties faced by children with disabilities}

Tools to collect robust and comparable data on the barriers faced by persons with disabilities - and actions needed to help them gain more equitable participation in society-remain in short supply. In response, the United Nations Children's Fund (UNICEF) and its partners released, in 2016, a new module on child functioning for use in censuses and surveys, with the aim of producing internationally comparable data. The module covers children between 2 and 17 years of age, and assesses functional difficulties in the domains of communication, hearing, vision, learning, mobility and motor skills, behaviour and emotions.

\section{Understanding the world through data}

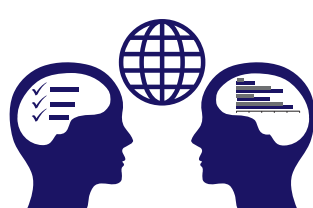

When properly designed, visual information facilitates data exploration and processing for evidence-based decision-making and advocacy. Data visualization and storytelling can connect users with data on sustainable development, enabling them to discover,

understand, and communicate patterns and interrelationships in the wealth of data and statistics that are now available.

Today, there is an explosion of commercial and open-source frameworks and tools for data visualization. To take advantage of them, national statistical systems need to engage with diverse communities of data scientists and analysts ready to put their expertise to the service of sustainable development.

Data users also need help in making sense of the overwhelming volume of data and information they are presented with every day. This can be accomplished by increasing collaboration across sectors and enhancing users' skills. In addition, policymakers and the public in general must improve their data literacy. The National Institute of Statistics of Rwanda and the Partnership in Statistics for Development in the 21st Century (PARIS21), for example, are partnering to provide training to journalists from local radio, television, print and online media along with the Executive Secretary of the Media High Council of Rwanda.

\section{Data principles and governance}

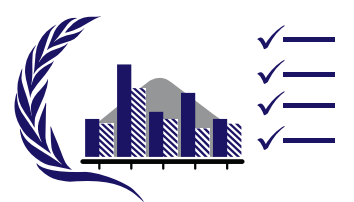

Data standards and best practices need to evolve in parallel with available technology and users' needs. Data developers and users must therefore engage on an ongoing basis, recognizing the policy context for the SDG data ecosystem. For instance, new open data management frameworks are needed to foster innovation, while providing continuity and facilitating interoperability among data providers, managers and users.
In recent years, a number of initiatives have reviewed ways to possibly expand existing data principles and standards to non-traditional data sources, such as big data. The focus has been on new data standards that would build upon existing ones to facilitate their adoption and rapid scale up among stakeholders from both public and private spheres.

\section{The way forward, starting in Cape Town}

The first United Nations World Data Forum, held in January 2017 in Cape Town, South Africa, has led to the launch of a number of related initiatives. It also provided a platform for the presentation and review of the Cape Town Global Action Plan for Sustainable Development Data. The plan was developed by members of the official statistical system and other data communities, including civil society, the private sector and academia; it was later adopted by the United Nations Statistical Commission at its forty-eighth session. The plan provides strategic guidance for the design and implementation of country-led statistical capacity-building needed to achieve the 2030 Agenda, and identifies six strategic areas for action listed below.

\section{Cape Town Global Action Plan for Sustainable Development Data}

Six strategic areas:

- Coordination and strategic leadership on data for sustainable development;

- Innovation and modernization of national statistical systems;

- Strengthening of basic statistical activities and programmes;

- Data dissemination and use;

-Multi-stakeholder partnerships;

- Resource mobilization and coordination.

The full text of the Cape Town Global Action Plan is available online at:

https://unstats.un.org/sdgs/hlg/Cape-Town-Global-Action-Plan. 


\section{Goal 1: End poverty in all its forms everywhere}

Giving people in every part of the world the support they need to lift themselves out of poverty in all its manifestations is the very essence of sustainable development. Goal 1 focuses on ending poverty through interrelated strategies, including the promotion of social protection systems, decent employment and the resilience of the poor. Although the global rate of extreme poverty has been reduced by more than half since 2000 , intensified efforts are required to boost the incomes, alleviate the suffering and build the resilience of those still impoverished, particularly in sub-Saharan Africa. Social protection systems need to be expanded and risks mitigated for disaster-prone countries, which tend to be among the world's poorest countries.

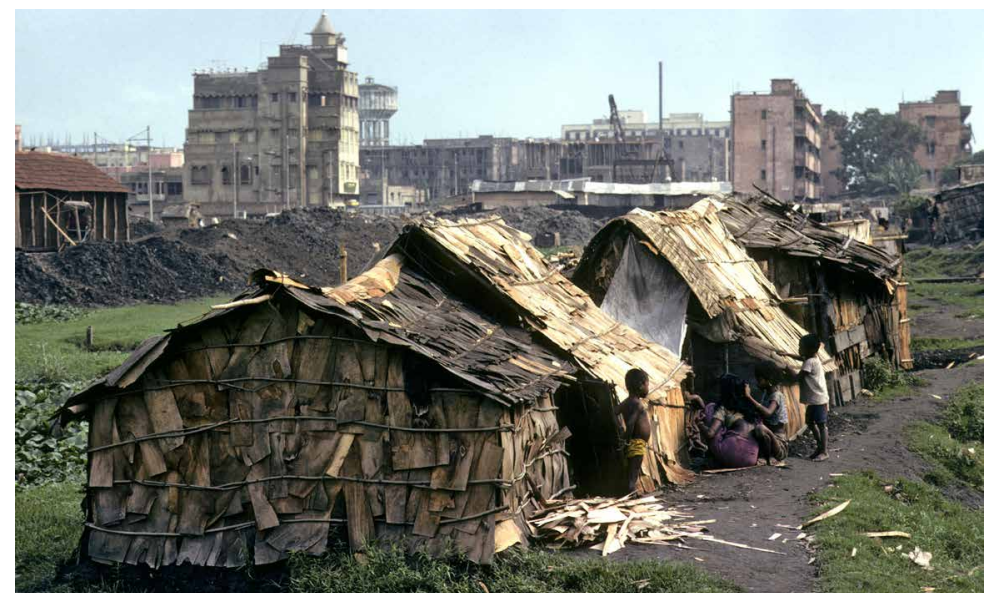

Proportion of the population living below 1.90 US dollars a day, 1999 and 2013 (percentage)
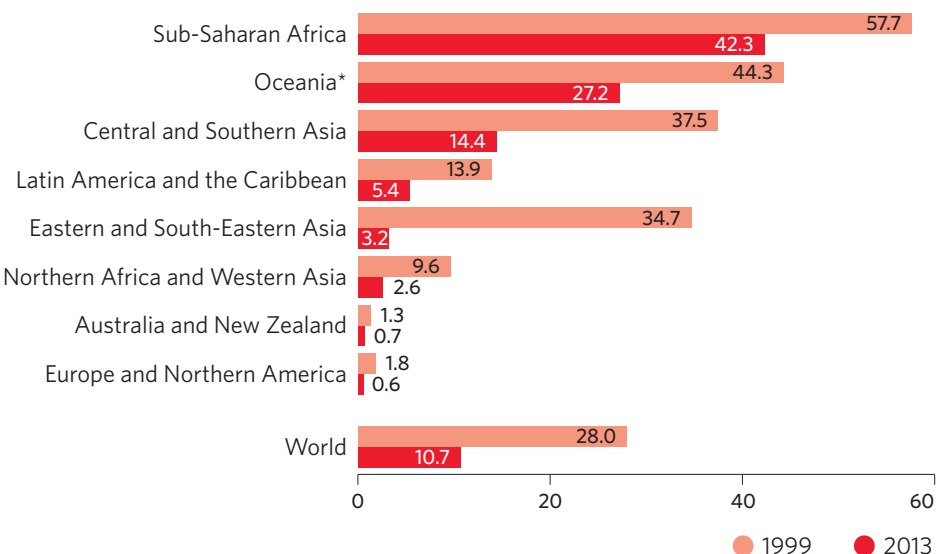

Note: Oceania* refers to Oceania excluding Australia and New Zealand throughout the publication.

\section{Nearly a billion people have escaped extreme poverty since 1999; three quarters of a billion remain in its grasp}

The international poverty line is currently defined as 1.90 US dollars per person per day using 2011 purchasing power parity (PPP). In 2013, an estimated 767 million people lived under the poverty line, down from 1.7 billion people in 1999. This represents a reduction in the global extreme poverty rate from 28 per cent in 1999 to 11 per cent in 2013. The fastest progress was observed in Eastern and SouthEastern Asia, where 3 per cent of the population lived in extreme poverty in 2013, down from 35 per cent in 1999. Despite a decline in the poverty rate in sub-Saharan Africa, 42 per cent of the population continued to subsist in conditions of extreme poverty in 2013. In fact, sub-Saharan Africa was home to about half of the world's poor. Combined with Southern Asia, the two regions accounted for over 80 per cent of the world's poorest people that year.
Proportion of employed population living below 1.90 US dollars a day, youth and adults, 2000 and 2016 (percentage)
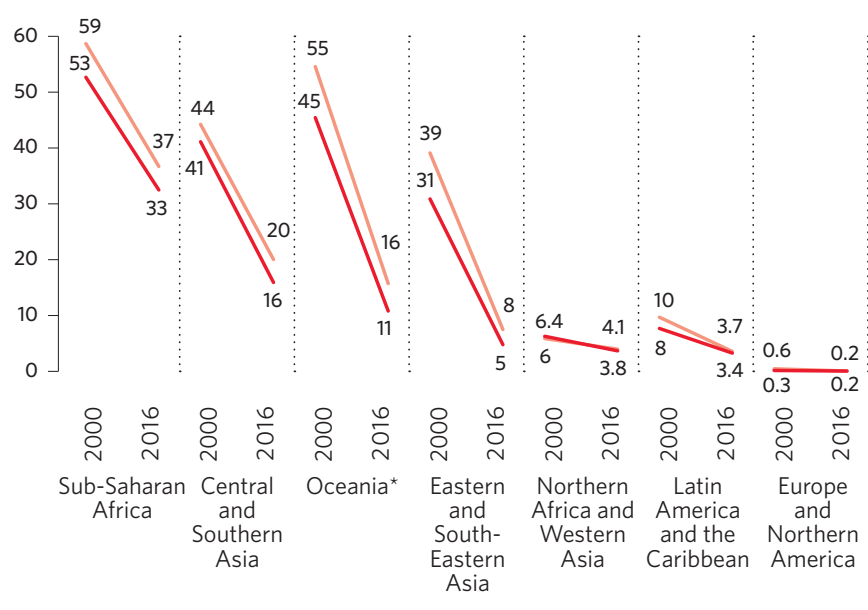

34

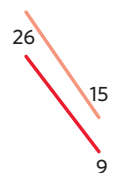

융ำำ World

- Adults

\section{Working poverty has decreased, but it is still pervasive in many regions and disproportionately affects the young}

Many of the world's workers live in extreme poverty due to a lack of decent work opportunities. Almost 10 per cent of the employed population globally lived with their families on less than 1.90 US dollars per person per day in 2016. While the percentage of the "working poor" has been cut by more than half since 2000-when it stood at 28 per cent-it remains pervasive in a few regions. In sub-Saharan Africa, 34 per cent of workers and their families continued to live in extreme poverty in 2016. Working poverty affects youth at a much higher rate than adults: in 2016, 15 per cent of young workers worldwide lived under the international poverty line, compared to 9 per cent of adult workers. This pattern holds true across almost all regions. 


\section{Less than half the world's population are covered by at least one social protection scheme}

Social protection systems have an important role in protecting the most vulnerable. They are fundamental to preventing and reducing poverty and inequality at every stage of people's lives. Benefits for children, mothers with newborns, persons with disabilities, older persons and those who are poor and without jobs help ensure that no one is left behind. Preliminary data show that in 2016, only 45 per cent of the world's population were covered by at least one social protection cash benefit, and that the proportion varied widely across countries and regions. Sub-Saharan Africa had the lowest coverage, with about 13 per cent of its population covered by at least one social protection benefit, versus 86 per cent of the population in Europe and Northern America.
Proportion of population covered by at least one social protection benefit, 2016 (percentage)

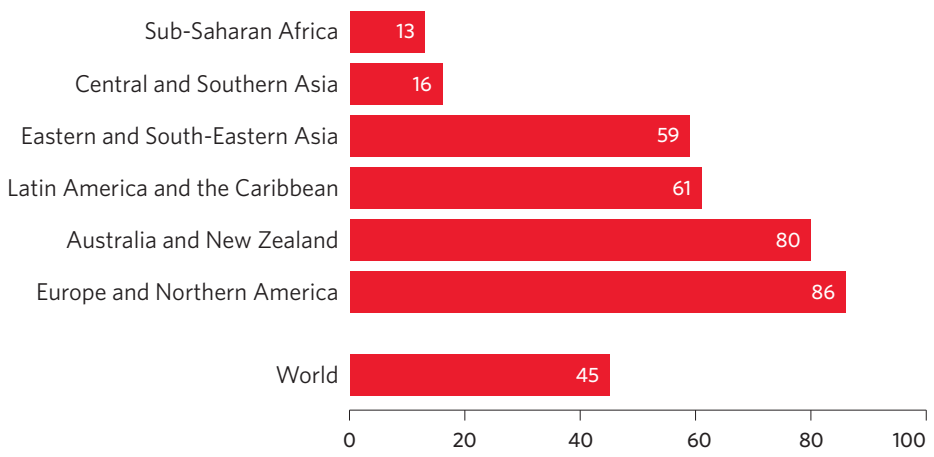

Note: Coverage corresponds to the sum of persons protected by contributory schemes and recipients of contributory and non-contributory benefits expressed as a percentage of the total population. Northern Africa and Western Asia and Oceania* data are not shown due to low population coverage of available data.

\section{Social protection coverage varies widely by type of benefit, with many vulnerable groups left behind}

In 2016, 68 per cent of people above retirement age received a pension. However, this global average masks large regional differences. In sub-Saharan Africa, only 22 per cent of people above retirement age received a pension in 2016, while in Europe and Northern America, pension coverage is almost universal. Other vulnerable groups also lack social protection. In 2016, only 22 per cent of the unemployed worldwide received unemployment benefits, 28 per cent of people with severe disabilities collected a disability pension, 35 per cent of children were covered by social protection, and 41 per cent of women giving birth received maternity benefits.
Proportion of the world's population covered by various social protection floors/systems, 2016 (percentage)

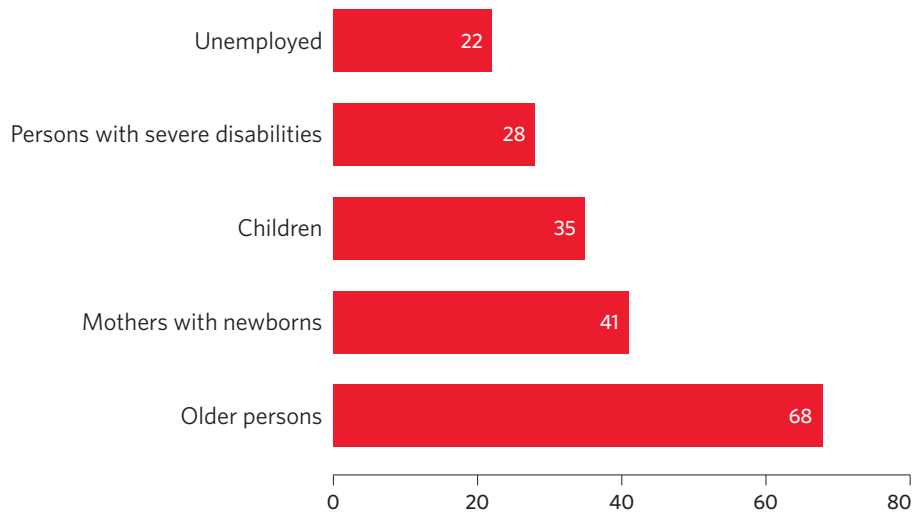

\section{Probabilistic models show that small island developing States are expected to bear disproportionately large economic losses attributed to disasters}

Building the resilience of the poor and strengthening disaster risk reduction are key strategies for ending extreme poverty in the most afflicted countries. Economic losses from natural hazards are now reaching an average of 250 billion to 300 billion US dollars a year. Based on estimated future loss-as measured by Average Annual Loss $(A A L)$ - the largest losses will be concentrated in bigger economies. However, smaller and more vulnerable countries, particularly the small island developing States, will bear a disproportionate impact in relation to the size of their economies. More efforts should be made to promote disaster risk reduction, particularly in these most vulnerable countries.
Average Annual Loss in relation to 2013 GDP (percentage)

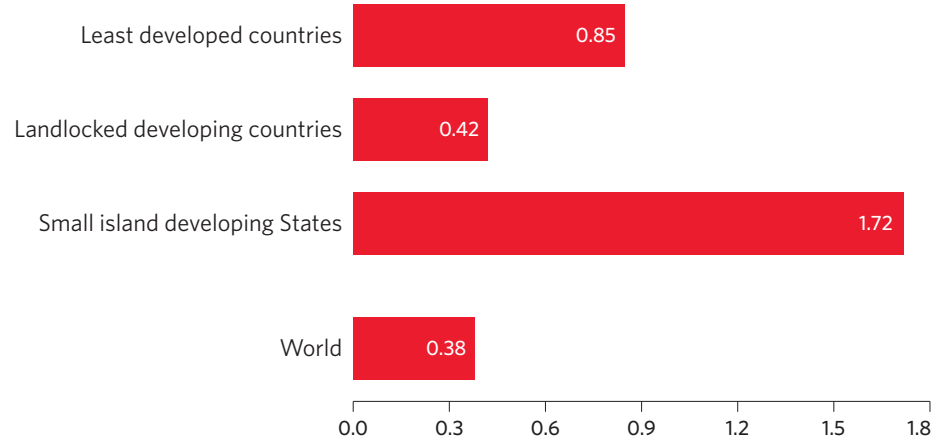

Note: Average Annual Loss is the expected (i.e., future) economic loss value normalized in annual terms considering all potential occurrence (both severity and frequency) of natural hazards (earthquakes, cyclonic wind, storm surges and tsunamis) over a long time frame using probabilistic hazard models. 


\section{Goal 2: End hunger, achieve food security and improved nutrition and promote sustainable agriculture}

Goal 2 addresses a fundamental human need-access to nutritious, healthy food-and the means by which it can be sustainably secured for everyone. Tackling hunger cannot be addressed solely by increasing food production. Well-functioning markets, increased incomes for smallholder farmers, equal access to technology and land, and additional investments all play a role in creating a vibrant and productive agricultural sector that builds food security.

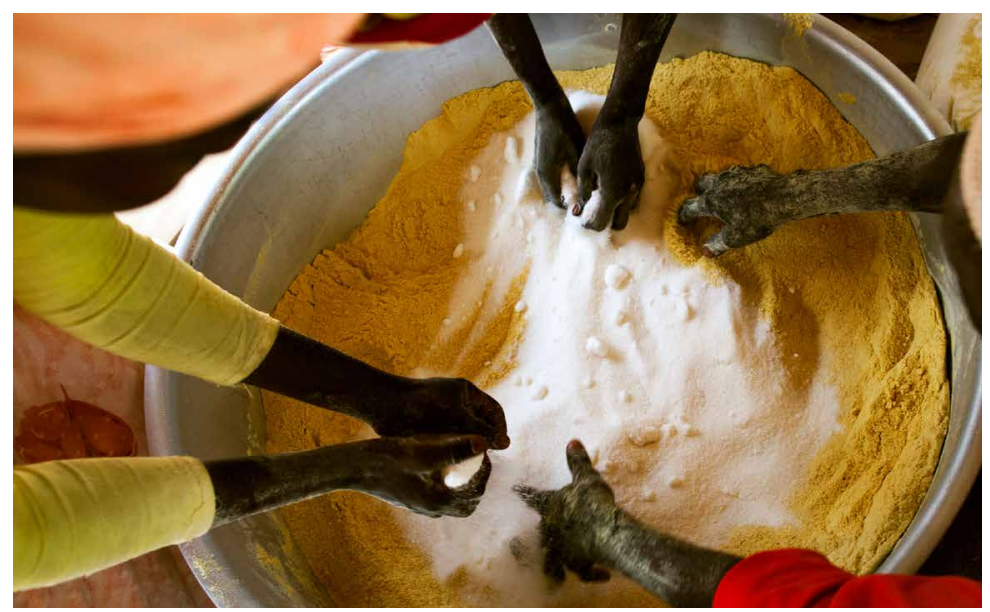

\section{Malnutrition affects an alarmingly high number of children under age $\mathbf{5}$}

Far too many children under age 5 are stunted, wasted or overweight-all of which are manifestations of malnutrition. These conditions put children at greater risk of dying from common infections, jeopardize their cognitive development, and increase their vulnerability to non-communicable diseases later in life.

In 2016, an estimated 155 million children under age 5 were stunted (low height for their age), down from 198 million in 2000. Globally, the stunting rate fell from 32.7 per cent in 2000 to 22.9 per cent in 2016. Southern Asia and sub-Saharan Africa accounted for three quarters of children under age 5 with stunted growth in 2016.
In 2016, an estimated 52 million children under age 5 worldwide suffered from wasting (low weight for their height). The global wasting rate in 2016 was 7.7 per cent, with the highest rate (14.9 per cent) in Central and Southern Asia. More than half of all children (27.6 million) suffering from wasting lived in Southern Asia. At the other end of the malnutrition spectrum is being overweight, which is increasing in many regions. The number of overweight children under age 5 worldwide increased from 30 million ( 5 per cent) in 2000 to 41 million ( 6 per cent) in 2016. The highest rates of overweight children under age 5 in 2016 were seen in Oceania excluding Australia and New Zealand (9.6 per cent), Northern Africa and Western Asia (9 per cent), and Northern America (7.8 per cent).

Proportion of children under age 5 who are overweight or stunted, 2000 and 2016 (percentage)
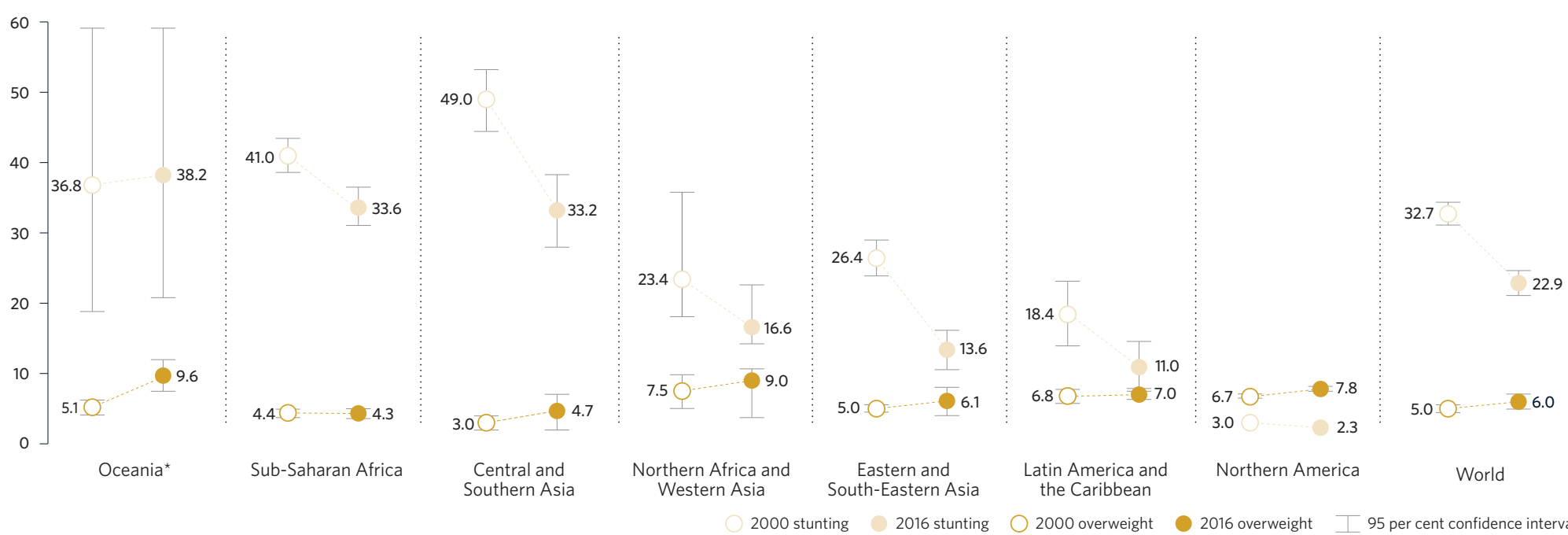

Note: Central and Southern Asia 2016 overweight data had consecutive low population coverage. Northern America regional average for stunting is based only on United States data; hence, confidence intervals are not available. 


\section{Without accelerated progress, hunger will persist beyond 2030}

At the current rate of progress, the world will not meet the zero hunger target by 2030, despite major advances since 2000. The proportion of undernourished people worldwide declined from 15 per cent in 2000-2002 to about 11 per cent in 2014-2016. The least developed countries and landlocked developing countries made the most progress. However, about one in four persons still suffer from hunger in those countries.

Globally, about 793 million people were undernourished in 2014-2016, down from 930 million in 2000-2002. Southern Asia faces the greatest challenge with about 281 million undernourished people. In sub-Saharan Africa, the hunger rate has fallen by 7 percentage points since 2000 . Still, the number of undernourished sub-Saharan Africans has increased by 16 millionreaching 218 million-reflecting the region's high population growth rate. These two most affected regions accounted for 63 per cent of undernourished people globally in 2014-2016.
Proportion of undernourished people, 2000-2002 and 2014-2016 (percentage)

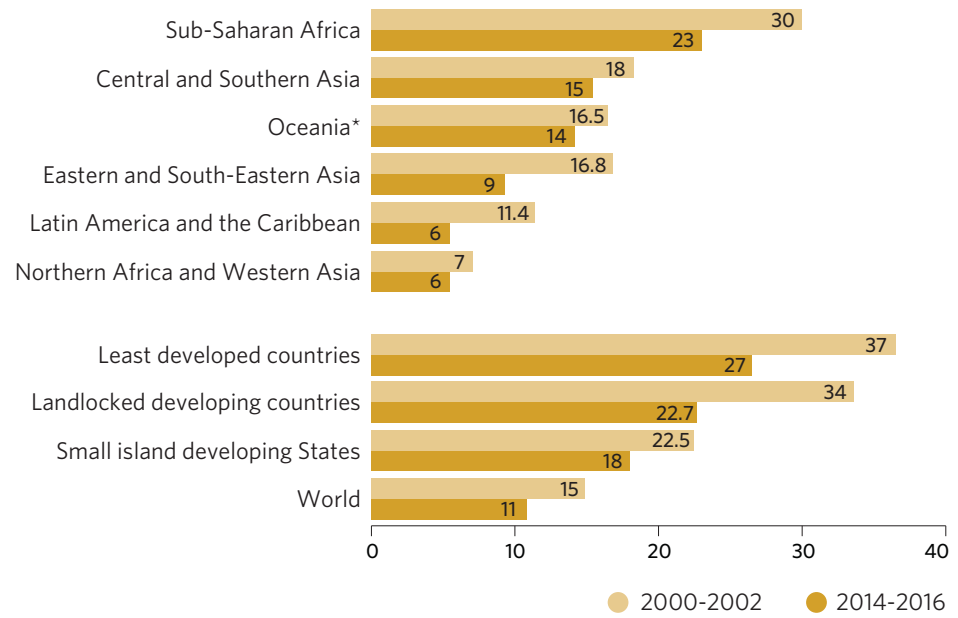

Note: In Australia and New Zealand and Europe and Northern America, the prevalence of hunger is less than 5 per cent.

\section{Increased efforts are needed to achieve the $\mathbf{2 0 2 0}$ target on maintaining genetic diversity}

Plant and animal genetic resources are essential for improving breeds and crops and their ability to adapt to changing environments and human needs. Moreover, maintaining and conserving genetic material from existing plants and animals could counter extinctions.

By the end of 2016, 4.7 million samples of seeds and other plant genetic material had been conserved in 602 gene banks across 82 countries and 14 regional and international centres. Over the past 11 years, the rate of increase in gene-bank holdings has slowed. Genetic material from animals has been cryoconserved for 15 per cent of national breed populations, according to information received from 128 countries. However, the stored material is sufficient to reconstitute only 7 per cent of the national breed population. Therefore, accelerated progress is needed to conserve genetic resources from plants and animals in order to achieve the SDG target.
Number of accessions of plant genetic resources secured in conservation facilities under medium- or long-term conditions, 2006-2016 (millions)

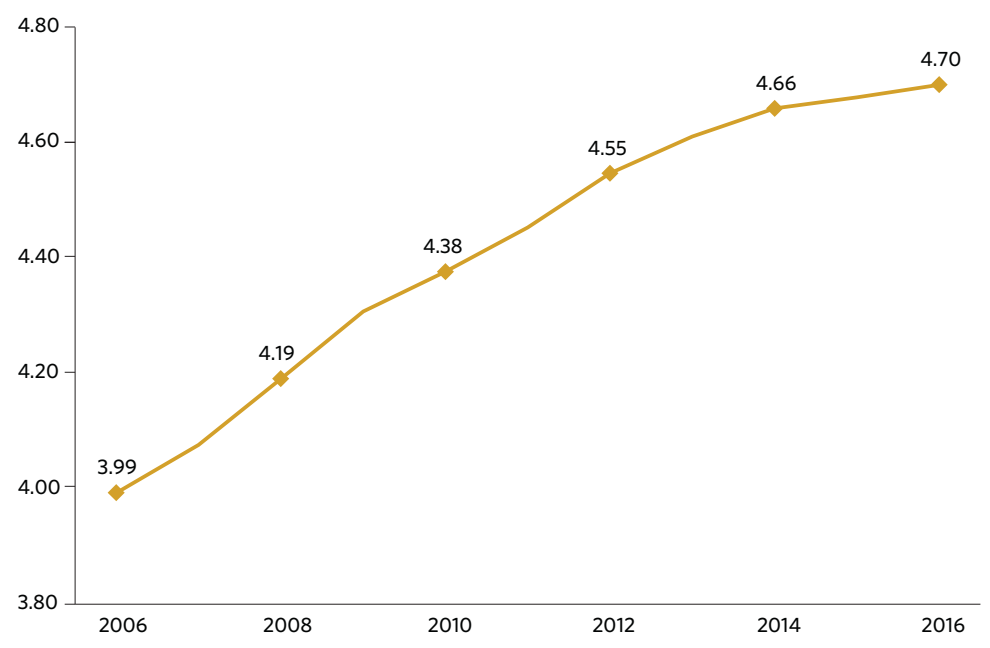

\section{Foreign and domestic official investments in agriculture are lagging}

Investing in agriculture is widely recognized as one of the most effective ways to alleviate poverty, improve food security and reduce hunger and malnutrition. However, both foreign and domestic official investment in agriculture has been declining. The share of aid to agriculture in sector-allocable aid from member countries of the Development Assistance Committee of the Organisation for Economic Co-operation and Development (OECD-DAC) has fallen from nearly 20 per cent in the mid-1980s to only 7 per cent in 2015. It has remained at this level since the late 1990s, reflecting a shift away from the financing of infrastructure and production towards a greater focus on social sectors. Government spending on agriculture has not been proportional to the sector's share of gross domestic product (GDP) either. The global agriculture orientation index-defined as agriculture's share of government expenditures divided by the sector's GDP-fell from 0.38 in 2001 to 0.24 in 2013 and to 0.21 in 2015.
Share of aid to agriculture in total sector-allocable aid from OECD-DAC, mid-1980s and 2015 (percentage)
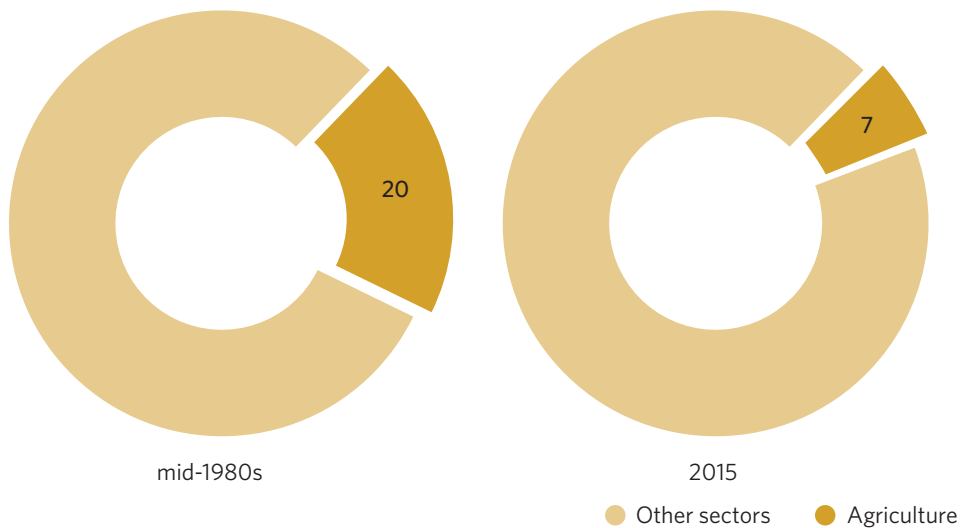


\section{Goal 3: Ensure healthy lives and promote well-being for all at all ages}

Over the past 15 years, reproductive, maternal and child health have improved greatly. The incidence of communicable diseases has declined, as have premature deaths from non-communicable diseases. Health services have been upgraded through better maternal and reproductive care, targeted disease elimination and control programmes, including broader treatment and vaccination coverage, and increased funding to support medical research and basic health in developing countries. To meet the 2030 targets, however, these interventions need to be expanded, particularly in regions with the highest burden of disease.

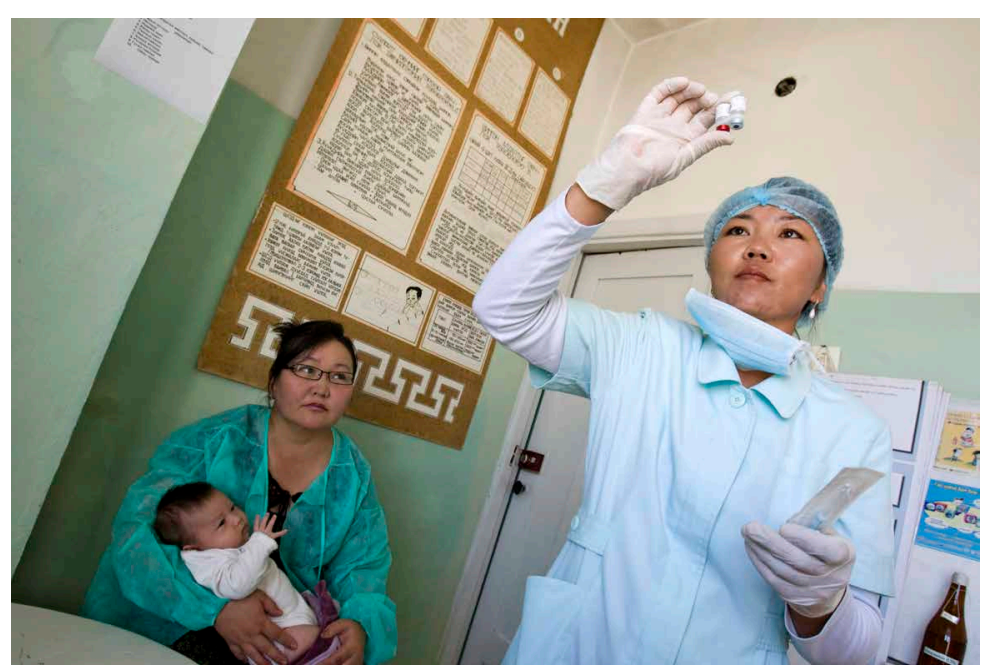

Child mortality has declined rapidly since 2000, but reductions in neonatal mortality need to accelerate

Significant progress has been made in reducing child mortality. In 2015, the mortality rate for children under age 5 worldwide was 43 deaths per 1,000 live births-a 44 per cent reduction since 2000. This translates to 5.9 million under-5 deaths in 2015 , down from 9.8 million in 2000. But despite progress in every region, wide disparities persist. Sub-Saharan Africa continues to have the highest under-5 mortality rate, with 84 deaths per 1,000 live births in 2015about twice the global average.

Children are most vulnerable in the first 28 days of life (the neonatal period). To reduce child deaths even further, greater attention must be focused on this crucial period, where progress has not been as rapid. In 2015, the global neonatal mortality rate was 19 deaths per 1,000 live births, a 37 per cent reduction since 2000 . This means that, in 2015, about 2.7 million children died in the first month of life. Neonatal mortality remains highest in Central and Southern Asia and in sub-Saharan Africa: 29 deaths per 1,000 live births in 2015 in both regions.

The share of newborn deaths in all under- 5 deaths grew from 40 per cent in 2000 to 45 per cent in 2015, due to the slower pace of progress among newborns. It is estimated that 40 per cent of neonatal deaths could be prevented by providing high-quality care for both mother and baby around the time of birth. 


\section{To reach the 2030 target, the pace of progress in reducing maternal mortality needs to double}

In 2015, an estimated 303,000 women worldwide died due to complications during pregnancy and childbirth. This translates into a global maternal mortality ratio of 216 deaths per 100,000 live births in 2015, a 37 per cent reduction since 2000. Achieving the global target of less than 70 maternal deaths per 100,000 live births by 2030 requires a global annual rate of reduction of at least 7.5 per cent, more than double the rate achieved between 2000 and 2015 .

Most maternal deaths can be prevented by providing antenatal care during pregnancy and skilled care during childbirth, as well as care and support in the weeks after childbirth. In sub-Saharan Africa, only half of live births benefitted from skilled care during delivery in 2016.
Maternal mortality ratio worldwide, 2000-2015 (maternal deaths per 100,000 live births)

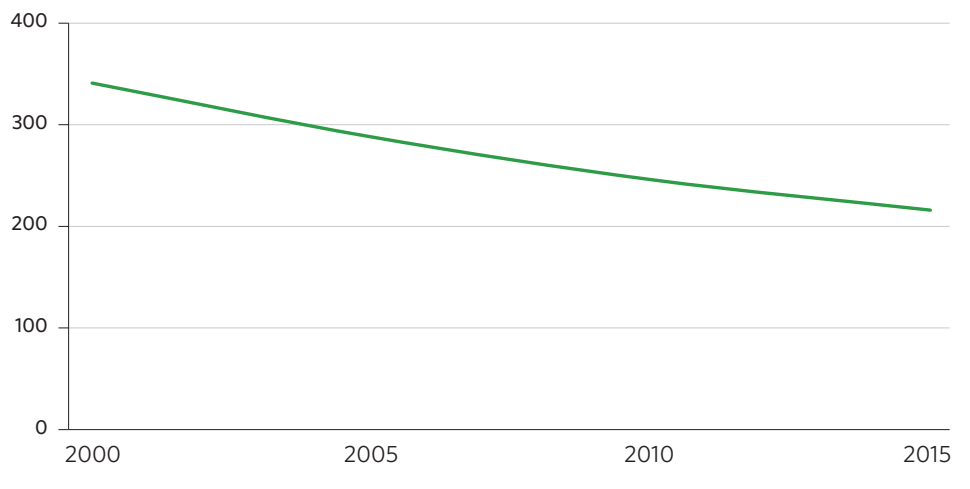

\section{Despite progress, only half of married women in sub-Saharan Africa and Oceania* satisfy their need for family planning with modern methods}

Preventing unintended pregnancy through universal access to family planning is critical to further improvements in the health and wellbeing of women and children. Based on estimates, in 2017, 78 per cent of girls and women of reproductive age (15 to 49 years) worldwide who are married or in union have their need for family planning satisfied through modern contraceptive methods. This global average masks wide regional disparities: in 2017, an estimated half of women married or in union in sub-Saharan Africa and in Oceania excluding Australia and New Zealand who have a need for family planning are not using modern contraceptive methods. In sub-Saharan Africa, at least, this still represents substantial progress: since 2000, an additional 19 per cent of women married or in union have had their need for family planning satisfied through modern methods.

Proportion of women aged 15-49, married or in union, who have their need for family planning satisfied through modern methods of contraception, 2000 and 2017 (estimated) (percentage)

$$
\text { Sub-Saharan Africa }
$$

Oceania*

Northern Africa and Western Asia Central and Southern Asia Europe and Northern America

Latin America and the Caribbean

Australia and New Zealand Eastern and South-Eastern Asia

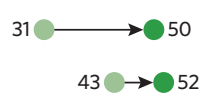

$57 \bigcirc \rightarrow 65$ $64 \bigcirc \rightarrow 72$

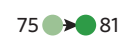

$77 \nrightarrow 83$ $83.7 \bigcirc 84.1$

$89 \bigcirc 89$

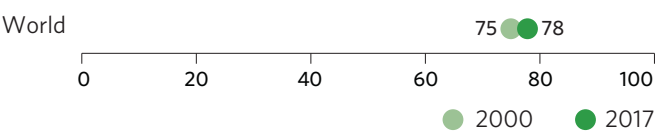

\section{Targeted disease elimination and control programmes are reducing new infections of communicable diseases}

In 2015, an estimated 2.1 million people worldwide were newly infected with HIV. This translates to 0.3 new infections per 1,000 uninfected people, a reduction of 46 per cent since 2000 . The rate of new HIV infections among children under age 15 declined by 72 per cent between 2000 and 2015 due to the rapid expansion in access to antiretroviral drugs for preventing mother-to-child transmission. In sub-Saharan Africa, the rate of new HIV infections has dropped by 62 per cent since 2000 . However, this region continues to have the highest HIV incidence, at 1.5 new infections per 1,000 uninfected people in 2015.

Targeted disease elimination and control programmes have also helped to reduce the incidence of other communicable diseases. In 2015, there were 142 new tuberculosis cases per 100,000 people, a decline of 17 per cent since 2000 . The global malaria incidence rate in 2015 was 94 per 1,000 people at risk, representing a 41 per cent decrease since 2000. In 2015, 1.6 billion people required mass or individual treatment and care for neglected tropical diseases, a 21 per cent decline from 2010 .
HIV incidence rates, 2000 and 2015 (new cases per 1,000 uninfected population)

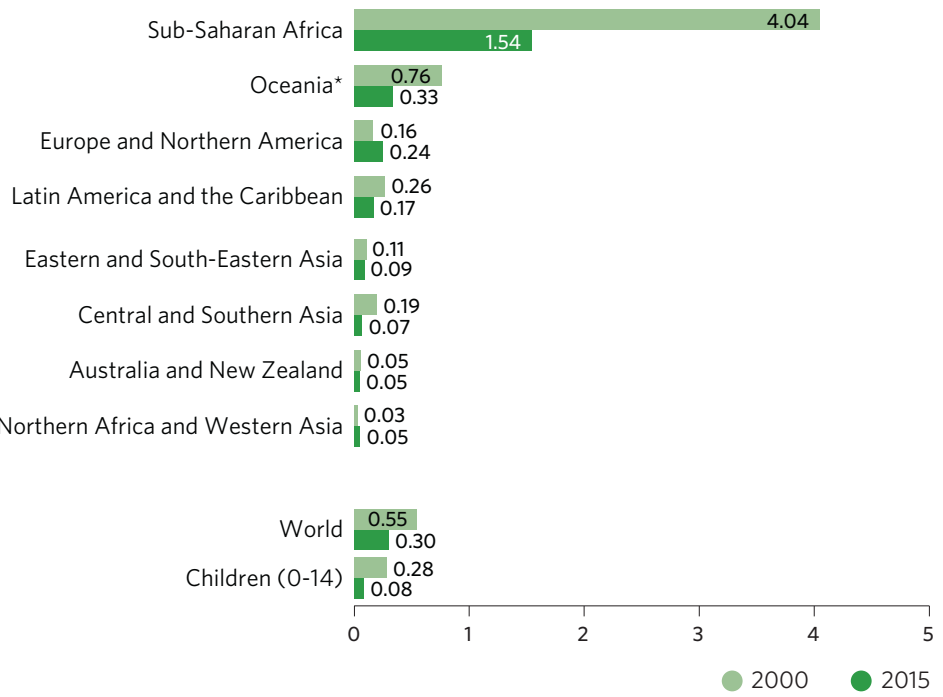


Number and proportion of deaths attributed to hepatitis viral infections, 2015 (millions and percentage)

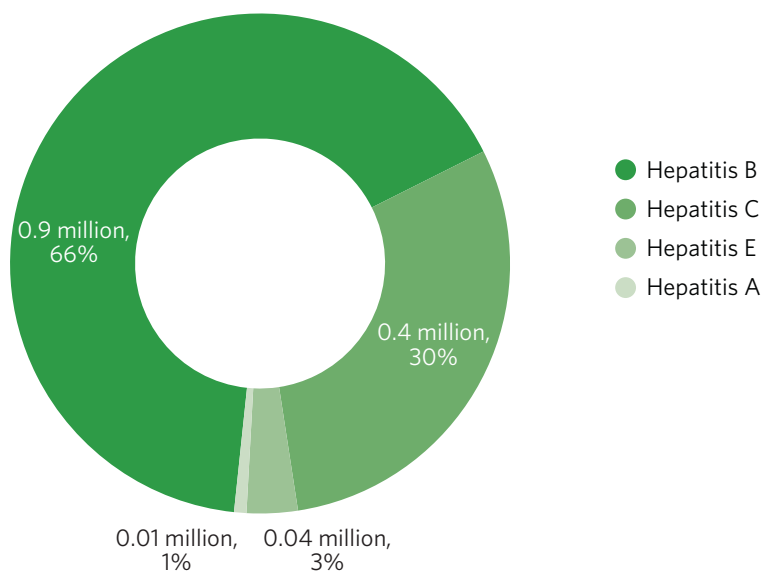

Probability of dying between age 30 and 70 from cardiovascular disease, cancer chronic respiratory disease or diabetes, 2000 and 2015 (percentage)

\section{Oceania*}

Central and Southern Asia

Sub-Saharan Africa

Northern Africa and Western Asia

Eastern and South-Eastern Asia

Europe and Northern America

Latin America and the Caribbean

Australia and New Zealand

World

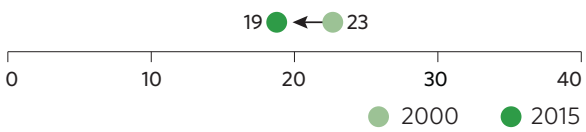

$34 \bigcirc+37$

$23 \bigcirc \leftarrow 26$

$21 \bigcirc 23$

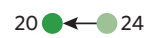

$18 \odot 22$

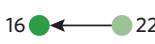

$16 \bigcirc 20$

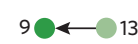

Hepatitis deaths are on the rise, but vaccination of infants for hepatitis $B$ is greatly reducing incidence

Untreated chronic viral hepatitis can lead to life-threatening complications. Since 2000, the total number of deaths from hepatitis has increased by 22 per cent, contributing to an estimated 1.34 million deaths in 2015. About 900,000 of these deaths were attributed to hepatitis B virus infections. Greater access to hepatitis testing and treatment is essential to reversing the trend of increasing mortality. In 2015, only 9 per cent of an estimated 257 million persons infected with the hepatitis $B$ virus were diagnosed, and 8 per cent of those diagnosed were on treatment.

An early win in the global response to viral hepatitis was achieved through expanded vaccination coverage. In 2015, 84 per cent of 1-year-olds received vaccinations for hepatitis $B$, compared to 29 per cent in 2000. As a result, the global prevalence of hepatitis $B$ virus infection among children under age 5 was 1.3 per cent in 2015 , much lower than the 4.7 per cent found during the pre-vaccination period, which ranges from the 1980 s to the early 2000 s.

\section{Premature deaths from cancer, heart disease, diabetes or chronic respiratory disease are declining, but not rapidly enough to meet the 2030 target}

In 2015, an estimated 30 million people worldwide died prematurely (before age 70). More than half of these deaths (56 per cent) were attributed to non-communicable diseases; of these, over three quarters (13 million) were caused by cardiovascular disease, cancer, diabetes or chronic respiratory disease. From 2000 to 2015, the risk of dying between the ages of 30 and 70 from one of these four diseases fell from 23 per cent to 19 per cent. This progress, while significant, falls short of the rate needed to meet the 2030 target of a one-third reduction in premature deaths from these four non-communicable diseases.

People in Oceania excluding Australia and New Zealand are at greatest risk: they had a 34 per cent probability of dying prematurely from one of these four diseases in 2015. Many of these deaths could be prevented through reductions in tobacco use and harmful alcohol consumption, the promotion of healthy diets and physical activity, and universal health coverage.
Suicide mortality rate by sex, 2015 (deaths per 100,000 population)

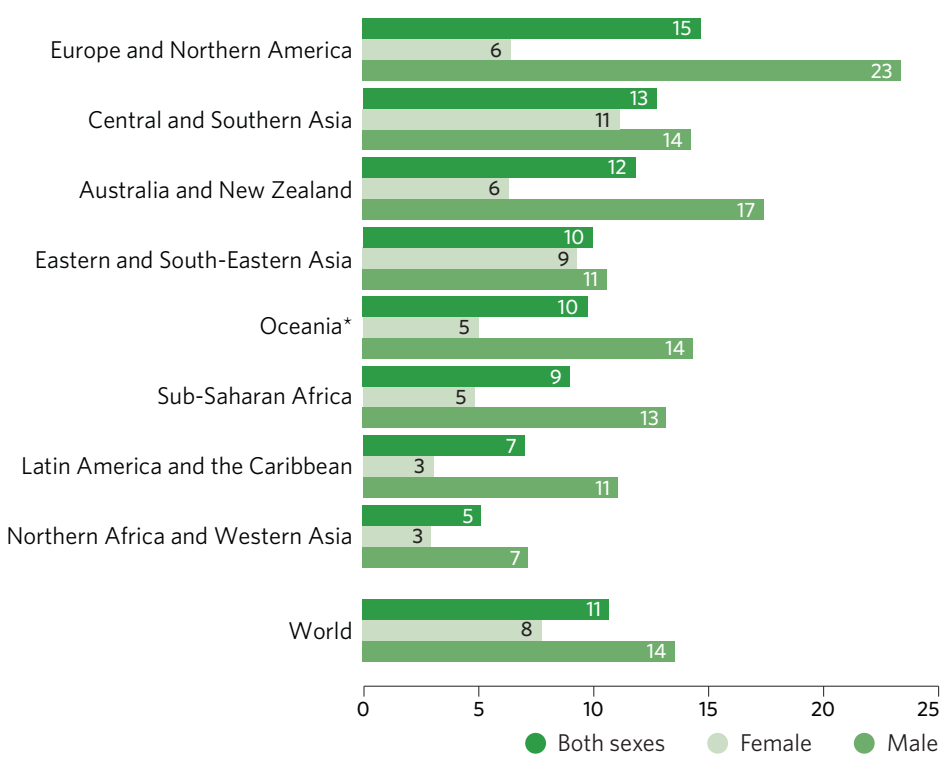

\section{Men are more likely than women to die by suicide}

Mental disorders, including depression, can lead to suicide. Nearly 800,000 suicides occurred in 2015 , representing an annual global rate of 11 per 100,000 people. Men are about two times more likely to die by suicide than women: men had a suicide mortality rate of 14 per 100,000 in 2015 versus 8 per 100,000 for women.

Gender disparities in suicide extend across all regions, with the largest relative gap observed in Europe and Northern America as well as in Latin America and the Caribbean. In these regions, men are almost four times as likely to die by suicide as women. In contrast, the gender gap in Central and Southern Asia as well as in Eastern and South-Eastern Asia is much smaller, owing to the significantly higher suicide rates among women in those two regions. Worldwide, suicide is one of the leading causes of death for both men and women between the ages of 15 and 29. 


\section{Household and ambient air pollution are major environmental health risks}

Air pollution, whether indoor (household) or outdoor (ambient), increases the risk of cardiovascular disease, stroke, chronic obstructive pulmonary disease, lung cancer and acute respiratory infections. In 2012, household air pollution due to cooking with inefficient fuels and technologies led to an estimated 4.3 million deaths worldwide. Most parts of Asia and sub-Saharan Africa have the highest mortality rate owing to household pollution, at between 68 and 87 deaths per 100,000 people, compared to 60 globally. Exposure to household pollution is particularly high among women and young children, who tend to spend more time indoors and near the stove. In 2012, ambient air pollution from traffic, industry, power generation, waste burning and residential fuel combustion resulted in an estimated 3 million deaths.
Mortality rate attributable to household and ambient air pollution, 2012 (deaths per 100,000 population)

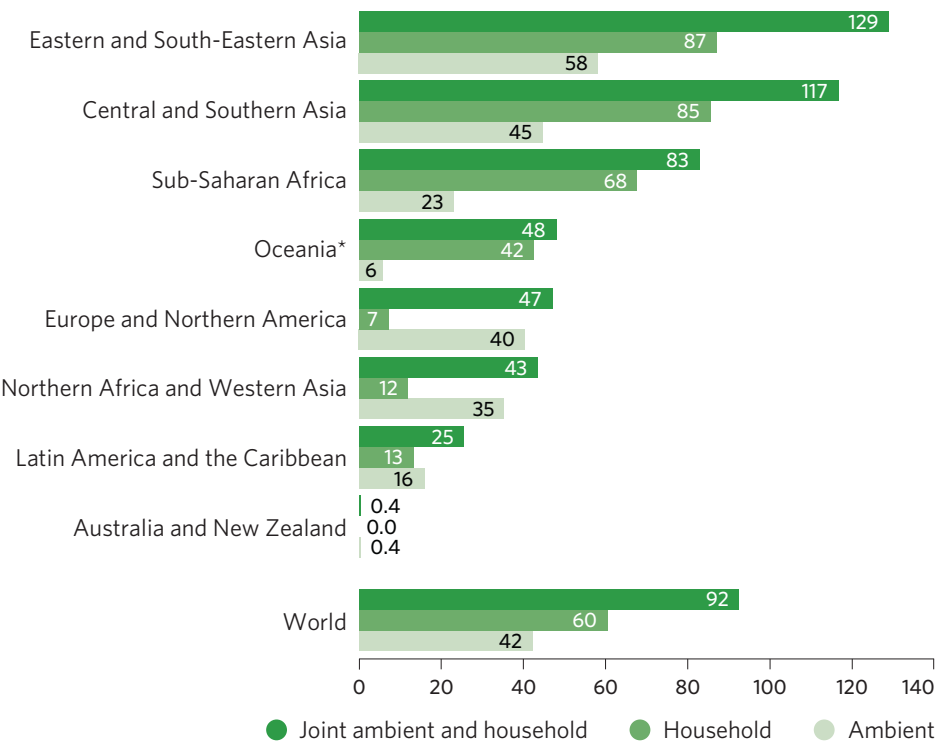

\section{Road traffic deaths have increased since 2000, although at a slower pace than the increase in the number of vehicles}

Halving the number of deaths and injuries from road traffic accidents by 2020 is an ambitious goal given the dramatic increase ( 90 per cent) in the number of vehicles registered between 2000 and 2013 worldwide. In 2013, 1.25 million people died as a result of road traffic injuries, an increase of 13 per cent since 2000 . This rise, which is small relative to the increase in the number of vehicles on the road, points to the effectiveness of interventions to improve global road safety.

From 2000 to 2013, the rate of road traffic deaths decreased in Australia and New Zealand, Europe and Northern America as well as sub-Saharan Africa, and increased in Latin America and the Caribbean. Sub-Saharan Africa had the highest rate, at 27 deaths per 100,000 people in 2013, compared to 17 deaths per 100,000 people globally. The road traffic mortality rate is lowest in Australia and New Zealand ( 5 deaths per 100,000 people), followed by Europe and Northern America, at 9 deaths per 100,000 people.
Mortality rate due to road traffic injuries, 2000 and 2013 (deaths per 100,000 population)

$$
\text { Sub-Saharan Africa }
$$

Latin America and the Caribbean

Northern Africa and Western Asia

Eastern and South-Eastern Asia Central and Southern Asia Oceania*

Europe and Northern America Australia and New Zealand World

\begin{tabular}{|c|c|c|c|c|c|c|}
\hline & & & & & & \\
\hline 0 & 5 & 10 & 15 & 20 & $\begin{array}{l}1 \\
25\end{array}$ & 30 \\
\hline
\end{tabular}

\section{Averting a shortfall of 18 million health workers by 2030 is critical to universal health coverage}

Achieving Goal 3 places high demands on the global health workforce and requires substantive and strategic investments. Available data from 2005-2015 reveal that over 40 per cent of all countries have less than one physician per 1,000 people, and around half have fewer than three nurses or midwives per 1,000 people.

An estimated 18 million additional health workers will be needed by 2030 to attain high and effective coverage of the broad range of health services necessary to ensure healthy lives for all. Major shortages of these trained professionals represent a serious concern in almost all countries in sub-Saharan Africa and LDCs, where fewer than one physician and three nurses or midwives serve 1,000 people on average. Without targeted interventions, the situation in some of those countries could be further exacerbated by increased labour migration of trained health personnel towards high-income countries with greater demand, thereby undermining already vulnerable health systems.
Proportion of countries with insufficient health care professionals, 2005-2015 (latest available) (percentage)

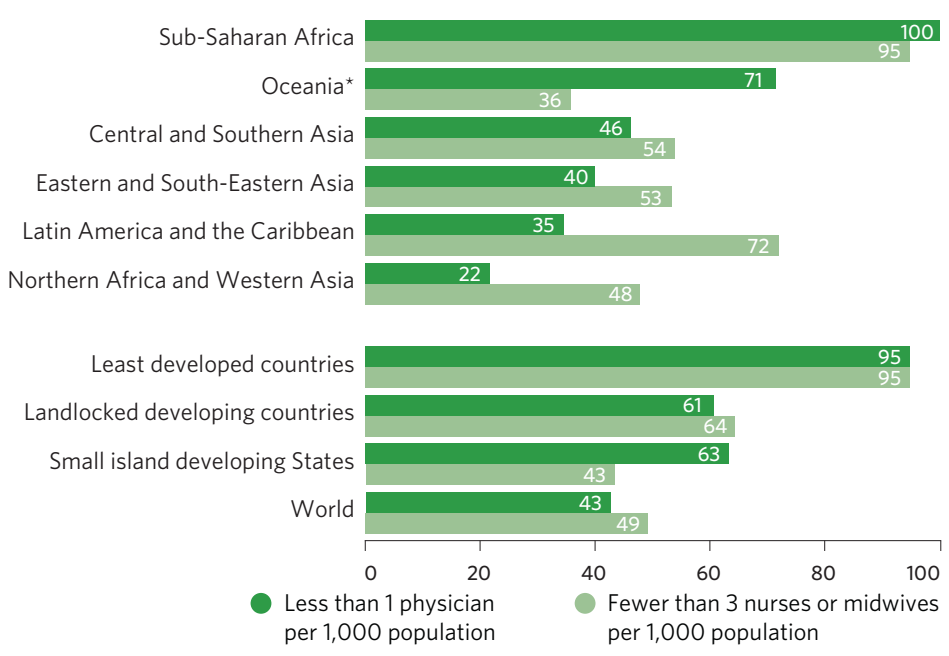

Note: A country with less than 1 physician and fewer than 3 nurses or midwives per 1,000 people is considered to have an insufficient number of health care professionals. All countries with data in the Europe and Northern America and Australia and New Zealand regions have at least 1 physician and at least 3 nurses or midwives per 1,000 people. 


\section{Goal 4: Ensure inclusive and equitable quality education and promote lifelong learning opportunities for all}

Quality education and lifelong learning opportunities for all are central to ensuring a full and productive life to all individuals and to the realization of sustainable development. Despite considerable progress in school enrolment, millions of children remain out of school, especially where educational systems struggle to keep up with population growth. Even when more children are enrolled, many do not acquire basic skills. Quality education is hampered by the lack of trained teachers and adequate school facilities. Achieving this Goal will require intensified efforts-particularly in sub-Saharan Africa and Southern Asiatargeted to vulnerable populations, specifically persons with disabilities, indigenous people, refugees and the rural poor.

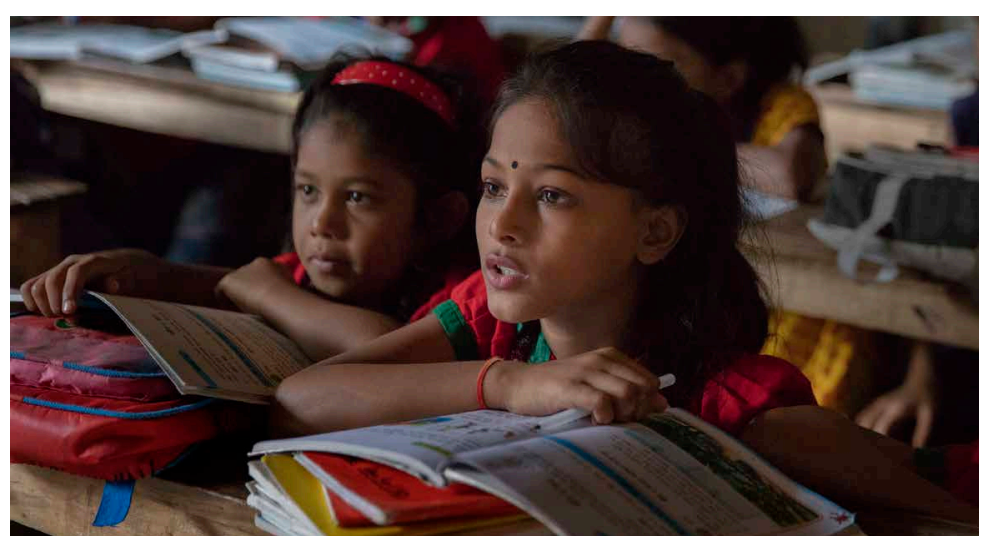

In the poorest countries, only $\mathbf{4 0}$ per cent of children participate in education one year before the start of primary school

Early childhood is a critical period for a child's cognitive development. Organized learning before the official start of primary school has been shown to boost a child's social, emotional and intellectual development and support readiness for primary education and future learning. Pre-primary education is, in fact, considered an important part of a holistic and robust educational system. In 2014, two thirds of children worldwide participated in pre-primary or primary education in the year prior to the official entrance age to primary school. However, in sub-Saharan Africa, the least developed countries and landlocked developing countries, the rate was only 4 in 10 children, versus 9 in 10 children in Europe and Northern America, and Latin America and the Caribbean.
Proportion of school-aged children out of school worldwide, by level of education and sex, 2000-2014 (percentage)

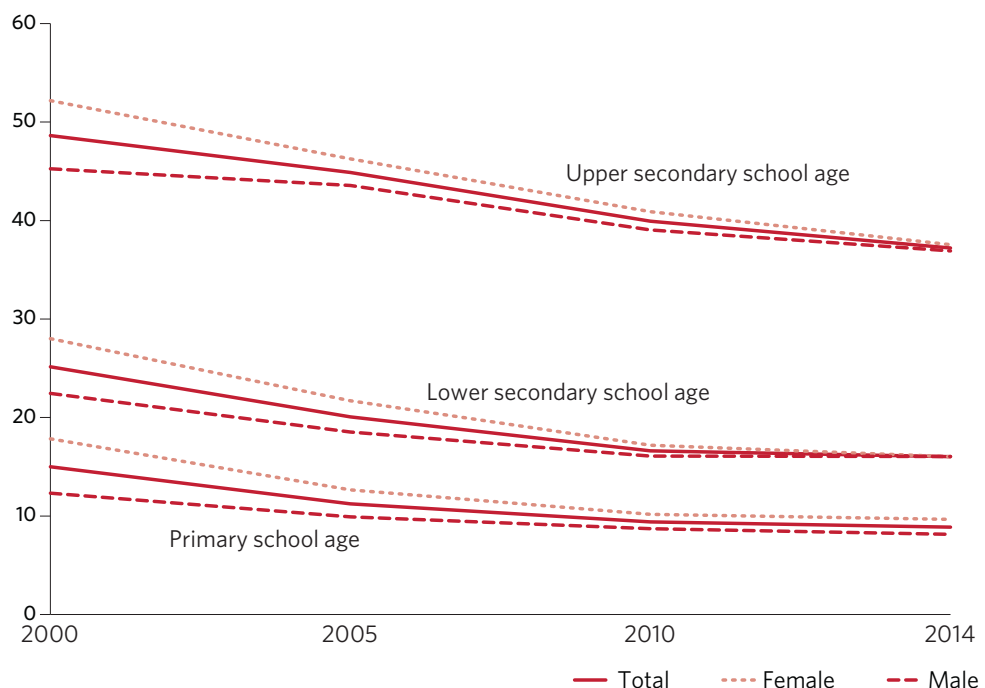

Despite progress in enrolment, more than a quarter of a billion school-aged children, adolescents and youth are not in school

Despite considerable progress in primary school enrolment between 2000 and 2014, 9 per cent of primary-school-aged children worldwide were still out of school in 2014. The rate has stagnated since 2008, reflecting pockets of exclusion and hard-to-reach populations. The outof-school rates for lower and upper secondary-school-aged adolescents and youth decreased, but remain higher than for primary-school-aged children, reflecting the difficulty in keeping pupils in school and the fact that youth have fewer opportunities to enter school in the first place.

As a result, about 263 million children, adolescents and youth were out of school in 2014. Of these, 61 million were children of primary school age, 60 million were adolescents of lower secondary school age, and 142 million were youth of upper secondary school age.

They largely resided in sub-Saharan Africa and Southern Asia, where educational systems struggle to keep up with population growth. In fact, these two regions accounted for over 70 per cent of the global out-of-school population at every level. 


\section{Poverty, gender and location of residence all influence reading proficiency}

Even though more children than ever are going to school, many do not acquire basic skills. For example, only about half of students at the end of primary education have attained minimum proficiency levels in reading or mathematics in many countries in sub-Saharan Africa and Latin America and the Caribbean.

Results of recent reading assessments show that inequity constitutes a major challenge. Parity indices from the assessments revealed that children and adolescents from the richest 20 per cent of households achieved greater proficiency in reading than those from the poorest 20 per cent of households, and urban children scored higher than rural children. The indices also showed that while out-of-school rates are higher for school-aged girls than boys, girl students had better reading proficiency at the end of primary and lower secondary school than their male counterparts.
Gender, location and wealth parity indices for children and adolescents achieving at least a minimum proficiency level in reading, 2007-2015 (latest available)

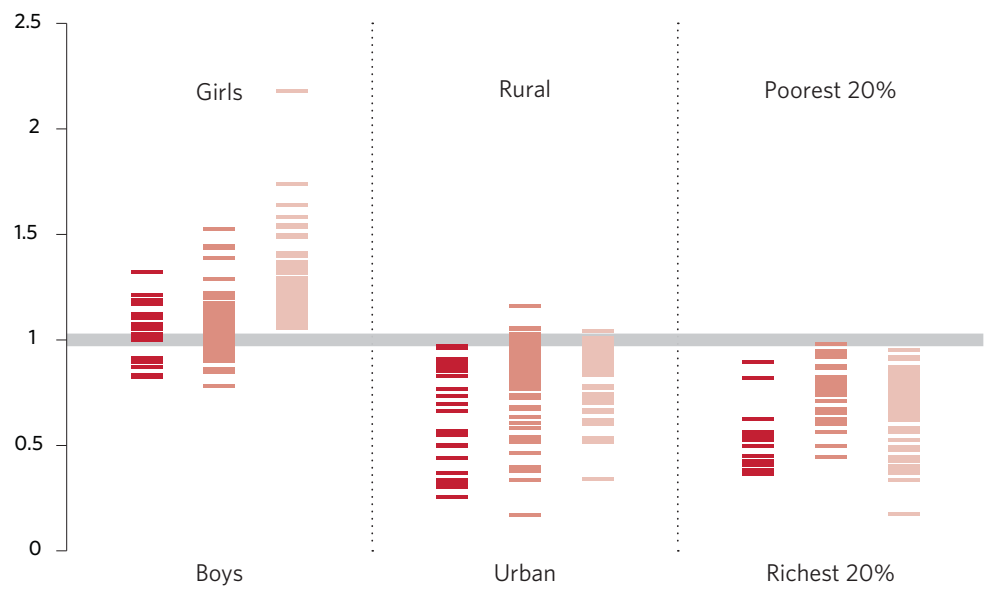

- Grade 2/3 in primary education - End of lower secondary education - End of primary education

- Parity index between 0.97 and 1.03

Note: Parity indices below 1 indicate a comparative advantage for the sub-population shown in the lower segment of each graph (i.e., boys, urban and richest 20 per cent). Parity is assumed to occur in the range 0.97-1.03.

\section{Lack of trained teachers and adequate facilities threatens quality education for all, especially in sub-Saharan Africa}

In some regions, most notably sub-Saharan Africa, the lack of trained teachers and the poor condition of schools are jeopardizing the goal of quality education for all. Sub-Saharan Africa has the lowest percentage of trained teachers in all three levels of schooling: 44 per cent in pre-primary, 74 per cent in primary and 55 per cent in secondary education. Central Asia, in contrast, has the highest percentages (above 90 per cent) in all three levels of education.
Proportion of trained teachers at each education level, 2011 or latest available data (percentage)

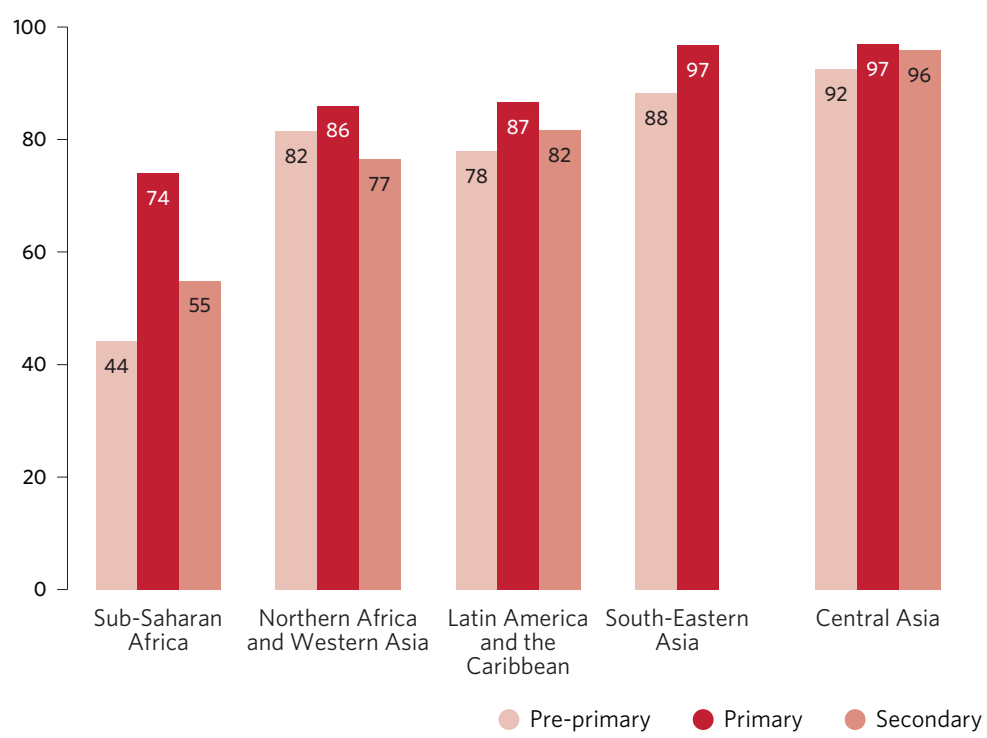

In sub-Saharan Africa, schools often lack basic amenities long taken for granted in other parts of the world. Only around one quarter of schools in the region have electricity and less than half have access to basic drinking water. Although 69 per cent have toilets, many still lack separate sanitation facilities for girls and boys. Based on data from 65 developing countries, the median value of the percentage of schools with access to computers and the Internet for pedagogical purposes is above 70 per cent in both primary and secondary education. However, the proportion drops below 40 per cent for many countries in sub-Saharan Africa.

Proportion of schools with access to computers for pedagogical purposes, 2014 or latest available year (percentage)

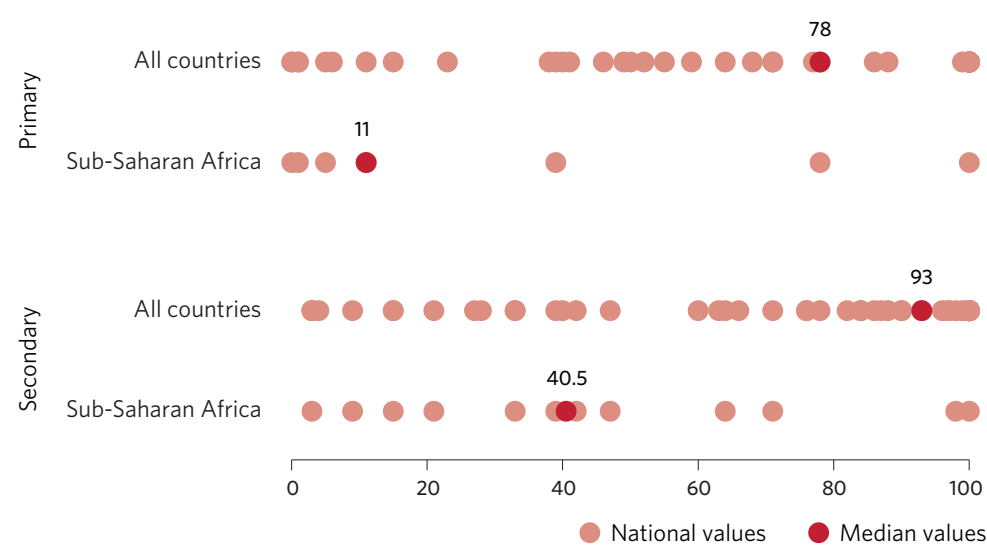

Note: Data for secondary education in South-Eastern Asia are not available. 


\section{Goal 5: Achieve gender equality and empower all women and girls}

Gender equality and women's empowerment have advanced in recent decades. Progress in enrolment at all education levels has been observed, yet wide gender disparities exist in some regions and countries at higher education levels. Maternal mortality has declined and skilled care during delivery has increased. Progress has been made in the area of sexual and reproductive health and reproductive rights. Childbearing among adolescents has decreased. However, gender inequality persists worldwide, depriving women and girls of their basic rights and opportunities. Achieving gender equality and the empowerment of women and girls will require more vigorous efforts, including legal frameworks, to counter deeply rooted gender-based discrimination that often results from patriarchal attitudes and related social norms.

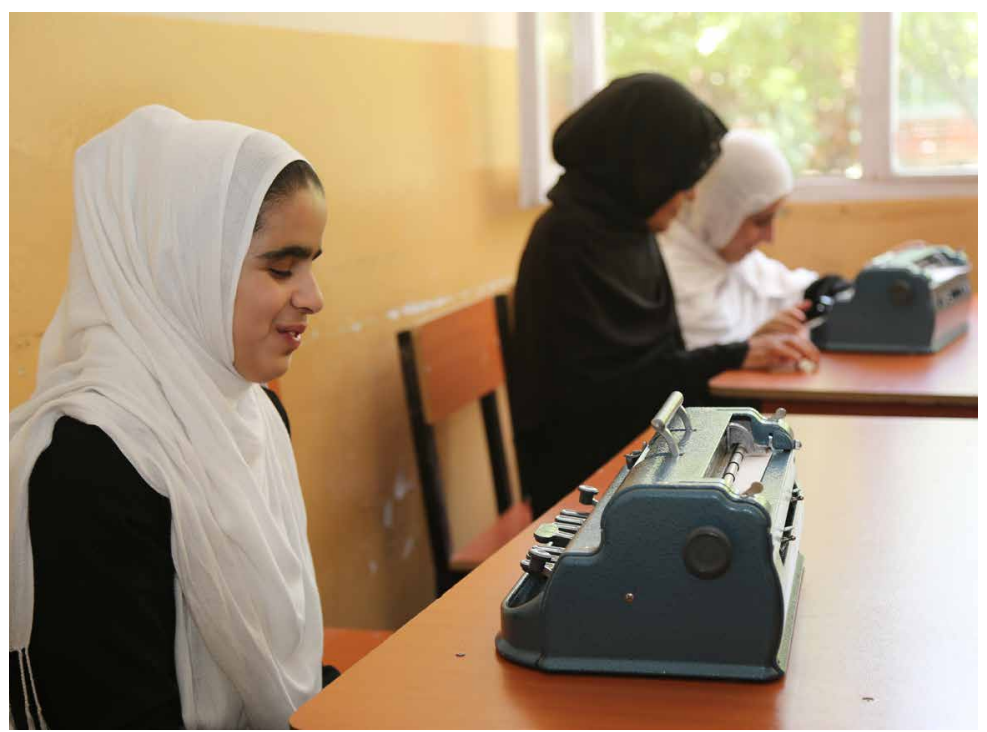

Proportion of ever-partnered women and girls aged 15 to 49 years subjected to physical or sexual violence by a current or former intimate partner in the previous 12 months, 2005-2016 (latest available) (percentage)

Oceania* (6)

Sub-Saharan Africa (27)

Central and Southern Asia (7)

Latin America and the Caribbean (10)

Northern Africa and Western Asia (5) South-Eastern Asia (3)

Europe (29)
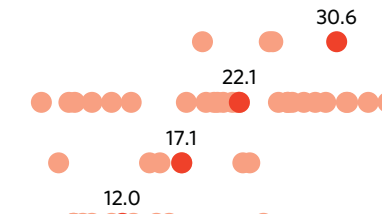
12.0 12.0 11.0 10.9

10.9

\section{0}

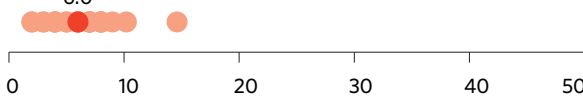

National values Median values

Note: The figure reflects available data from 87 countries (covering 43 per cent of the world's population) over the period 2005-2016. The number of countries represented in each region is in parentheses.

\section{Intimate partner violence against women and girls is found in every region}

Physical and sexual violence against women and girls is common in all regions, and much of it is at the hands of intimate partners. When perpetrated by an intimate partner, violence can be especially traumatic and debilitating. According to surveys undertaken between 2005 and 2016 in 87 countries (including 30 from developed regions), 19 per cent of girls and women aged 15 to 49 said they experienced physical and/or sexual violence by an intimate partner in the 12 months prior to the survey.

The prevalence of violence against women varies within and among regions. Levels of intimate partner violence are highest in Oceania excluding Australia and New Zealand, ranging from 19 to 44 per cent in countries with data. Prevalence is lower overall in Europe, with levels of less than 10 per cent in most of the 29 countries with available data.

In the most extreme cases, violence against women and girls can result in death. In 2012, almost half of all women who were victims of intentional homicide worldwide were killed by an intimate partner or family member, compared to 6 per cent of male victims.

Social acceptability and widespread impunity for perpetrators are among the main challenges contributing to violence against women. In 37 countries, for example, perpetrators of rape are exempted from prosecution if they are married to or subsequently marry the victim. 


\section{Child marriage is slowly declining, but remains commonplace in Southern Asia and sub-Saharan Africa}

Child marriage violates the rights of children in a way that often leads to a lifetime of disadvantage and deprivation, especially for girls. Typically, child brides have limited opportunities for education and employment, are at increased risk of domestic violence and other assaults to their physical and mental health, and have little decision-making power within the household, especially when married to older men.

The practice of child marriage has been slowly declining. Around 2015, just over one in four women between the ages of 20 and 24 were married before the age of 18 ; around 2000 , the ratio was one in three. Faster progress has been made in delaying the marriage of girls under age 15, which declined from 11 per cent around 2000 to 8 per cent around 2015. That said, progress has been uneven across regions and countries.
In Southern Asia, the proportion of women married before age 18 dropped by about 27 per cent; the proportion married before age 15 declined by about 44 per cent. In sub-Saharan Africa, the proportions dropped by 13 per cent and 24 per cent, respectively. Nevertheless, early marriage in these regions remains commonplace, with more than one in three women reportedly married before age 18 . Indeed, the 10 countries with the highest rates of child marriage are found in these two regions.

Proportion of women aged 20 to 24 years who were married or in union before ages 15 and 18, around 2000 and around 2015 (percentage)
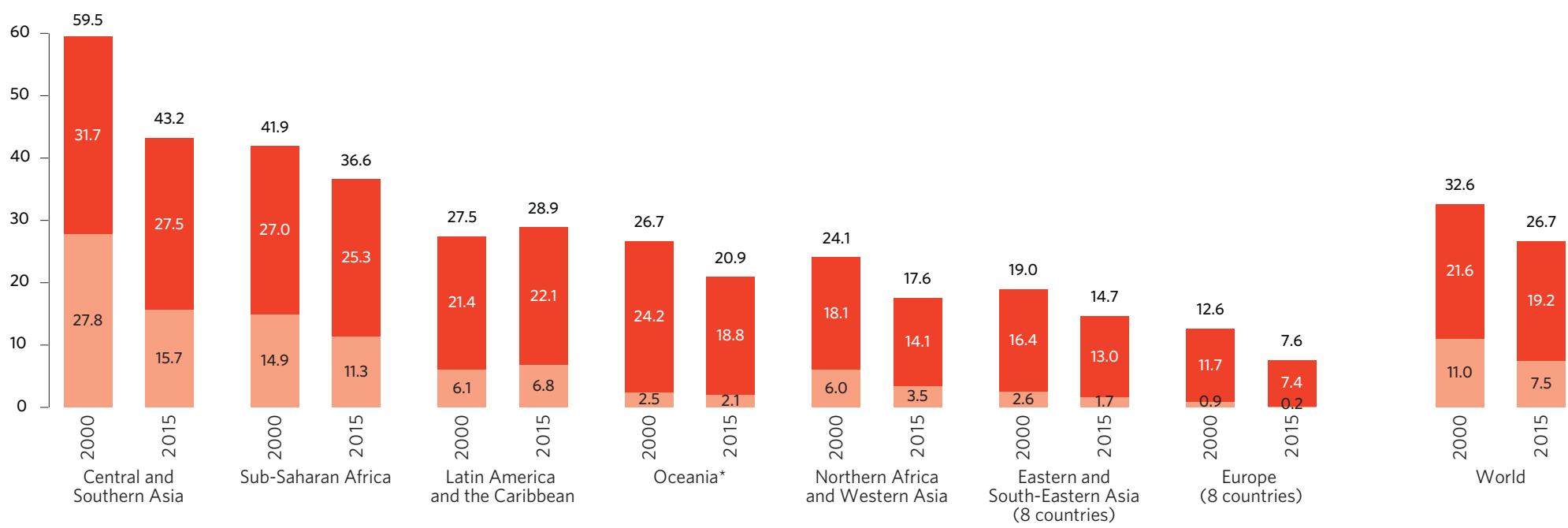

Married/in union before age 15

Married/in union after age 15 but before age 18

Note: The values for 2015 refer to the latest available data for 120 countries (covering 64 per cent of the world's population of women aged 20 to 24 years) over the period $2010-2016$. For regions where the population coverage is below 50 per cent, the number of countries with available data is in parentheses.

\section{Despite progress, childbearing among adolescents in sub-Saharan Africa remains high}

Child marriage is closely linked to childbirth among adolescents and a concomitant loss of opportunities. Target 3.7 calls for universal access to sexual and reproductive health care services (including family planning), information and education, which would help to prevent adolescent childbearing and unintended pregnancies.

Reducing the adolescent birth rate is integral to the health and wellbeing of adolescent girls and to their social and economic prospects. Globally, childbearing among adolescents declined by 21 per cent between 2000 and 2015. Central and Southern Asia made the greatest progress: the region reduced the adolescent birth rate by more than 50 per cent, largely due to advances in Southern Asia. Rates remain highest in sub-Saharan Africa and Latin America and the Caribbean, despite progress in both regions.
Adolescent birth rate, 2000 and 2015 (number of live births per 1,000 adolescent women aged 15 to 19 years)

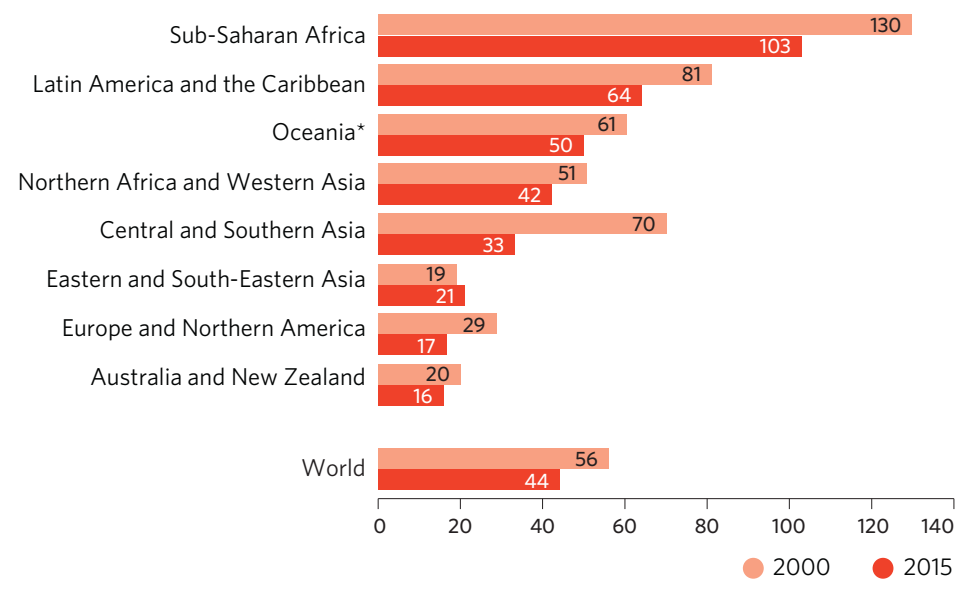


Proportion of girls aged 15 to 19 years who have undergone female genital mutilation in 30 countries with representative prevalence data, around 2000 to around 2015 (percentage)

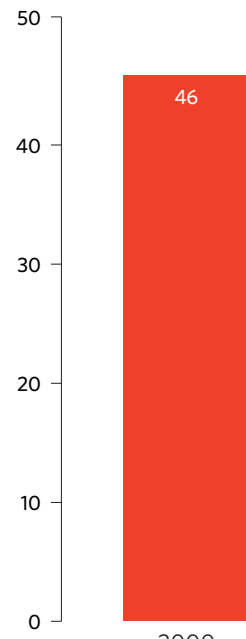

2000

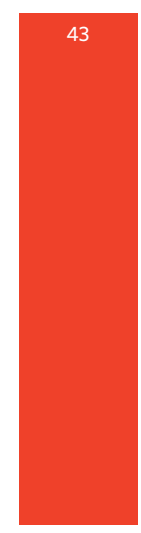

2005

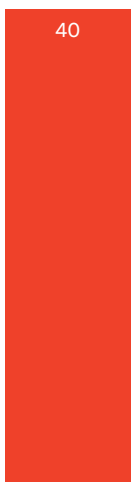

2010

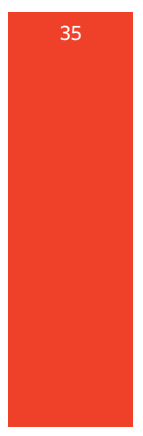

2015
Note: The figures are population-weighted averages based on comparable data from 30 countries where the practice is concentrated and with representative prevalence data. The values for 2015 refer to the latest available data collected between 2010 and 2016 .
The prevalence of FGM remains high in some countries, despite overall progress

Female genital mutilation (FGM) is a human rights violation affecting girls and women worldwide, but especially in communities where it persists as a social norm. The practice can cause severe pain, excessive bleeding, infections (including HIV), infertility, complications during childbirth and sometimes death. The exact number of girls and women affected globally is unknown, but at least 200 million have been subjected to FGM in the 30 countries (half of them in Western Africa) where the practice is concentrated and that have nationally representative prevalence data.

Prevalence rates for this harmful practice have declined by 24 per cent since around 2000, with some countries making rapid progress. FGM remains widespread in other countries with data. On average, more than one in three girls aged 15 to 19 have been subjected to FGM in the 30 countries where the practice is concentrated, compared to nearly one in two around 2000.
Proportion of time spent on unpaid domestic and care work, women and men, 2000-2016 (latest available) (percentage of time spent per day)
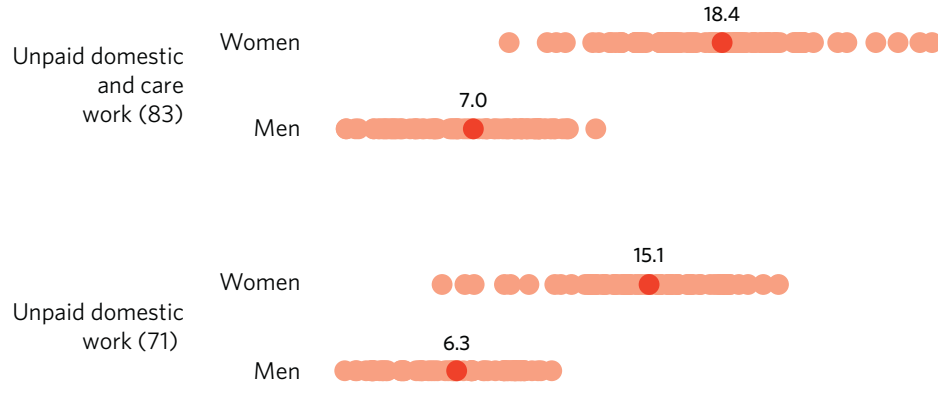

Unpaid domestic work (71)

Men

Unpaid care work (71)

Women

2.7

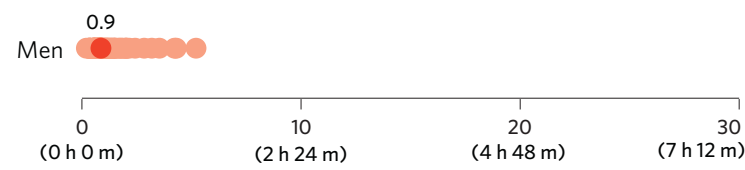

National values

Median values

Note: The figure reflects available data for 83 countries and areas over the period 2000-2016. Data disaggregated by unpaid domestic work and unpaid care work are only available for 71 countries. The number of countries and areas represented in each type of unpaid work is indicated in parentheses.

\section{Women spent almost three times as many hours on unpaid domestic and care work as men}

The time spent on unpaid housework and caregiving undermines women's ability to engage in other activities, such as education and paid labour. The amount of time women spend on unpaid domestic work and caregiving at home is almost triple that of men, according to survey data from 83 countries and areas.

Data for a subset of countries (mainly from Latin American and European countries) suggest this disparity widens during periods when women are most likely to have young children at home. Women dedicate more time than men caring for family members, especially children. This activity often overlaps with domestic duties, making it difficult to capture it accurately in time-use surveys. 


\section{The corridors of political and economic power continue to be dominated by men}

Effective policymaking to achieve gender equality demands broad political participation. Yet women's representation in single or lower houses of parliament in countries around the world was only 23.4 per cent in 2017, just 10 percentage points higher than in 2000.

Even in the two regions most advanced in terms of women's representation-Australia and New Zealand and Latin America and the Caribbean-women occupy fewer than one out of three seats in parliament. Northern Africa and Western Asia has made impressive advances: the proportion of seats held by women rose nearly fourfold between 2000 and 2017. Nevertheless, women still hold fewer than one in five parliamentary seats in the region.

Slow progress suggests that stronger political will and more ambitious measures are needed. Quotas to boost women's political participation and empowerment have been helpful: 75 out of 190 countries (39 per cent) have used some form of quota system to increase women's representation, and election results in 2016 show that the strategy is working. However, quotas may also impose a false ceiling on women's representation; they therefore need to be periodically reviewed and updated to ensure continued progress.

Women are also underrepresented in managerial positions, especially in senior and middle management. In most of the 67 countries with data from 2009 to 2015, less than a third of senior- and middlemanagement positions were held by women. Modest improvements can be observed in some countries.
Over the past decade, the share of women in senior and middle management increased in about half of the countries with available data. However, the proportion of women in these positions remains significantly lower than the share of women in total employment for all of the countries studied. The data also suggest that more women are in junior- rather than middle- or senior-management positions and need to break through the glass ceiling in order to reach top-echelon positions.

Proportion of seats held by women in single or lower houses of national parliament, 2000 and 2017 (percentage)

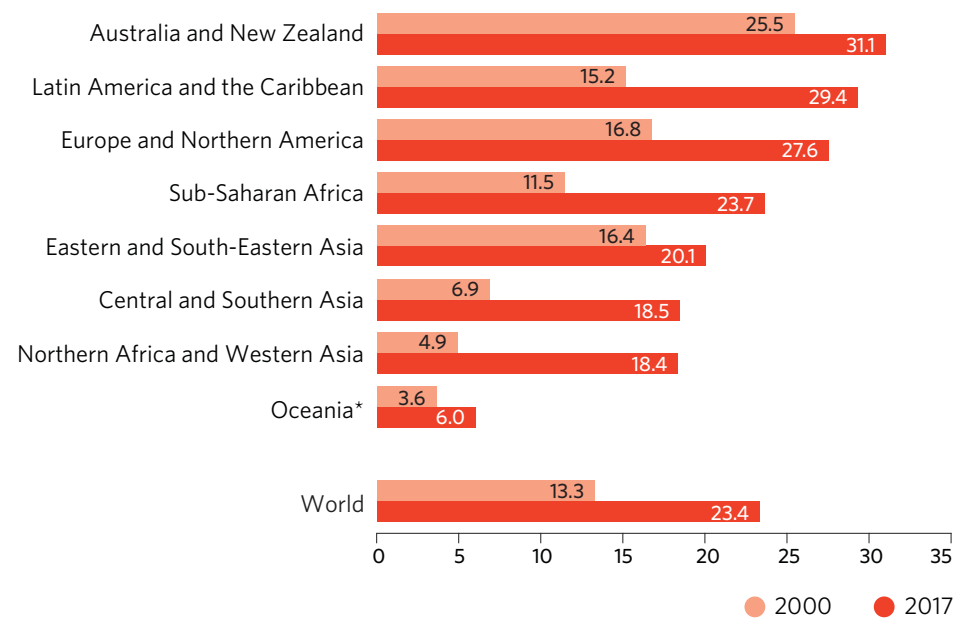

\section{Only half of women in selected countries make their own decisions regarding sexual relations, contraceptive use and health care}

Women's and girls' autonomy in decision-making over sexual relations, contraceptive use and access to sexual and reproductive health services is key to their empowerment and to fully exercising their reproductive rights. In 45 countries with available data, 43 of which are in developing regions, just over half (52 per cent) of women aged 15 to 49 years who are married or in union make their own informed decisions about sexual relations and the use of contraceptives and health services.
Proportion of women aged 15 to 49 years (married or in union) who make their own informed decisions regarding sexual relations, contraceptive use and health care, 2007-2015 (latest available) (percentage)

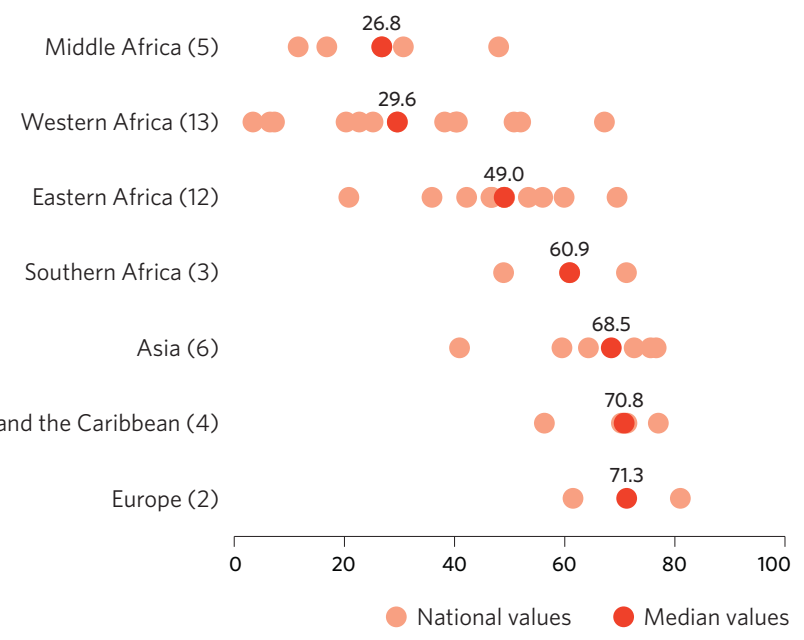

Note: The figure reflects available data from 45 countries (covering 7 per cent of the world's

population) over the period 2007-2015. The number of countries represented in each region is in parentheses. 


\section{Goal 6: Ensure availability and sustainable management of water and sanitation for all}

Sustainable water resources are essential to human health, environmental sustainability and economic prosperity. This vital resource is under threat, making it crucial to address the challenges related to water, sanitation and hygiene for populations and water-related ecosystems. Currently, more than 2 billion people are affected by water stress, which will only increase with population growth and the effects of climate change. Achieving universal access to drinking water, sanitation and hygiene and ensuring that services are safely managed remain major challenges, and meeting them is crucial to further progress in health, education and poverty eradication.

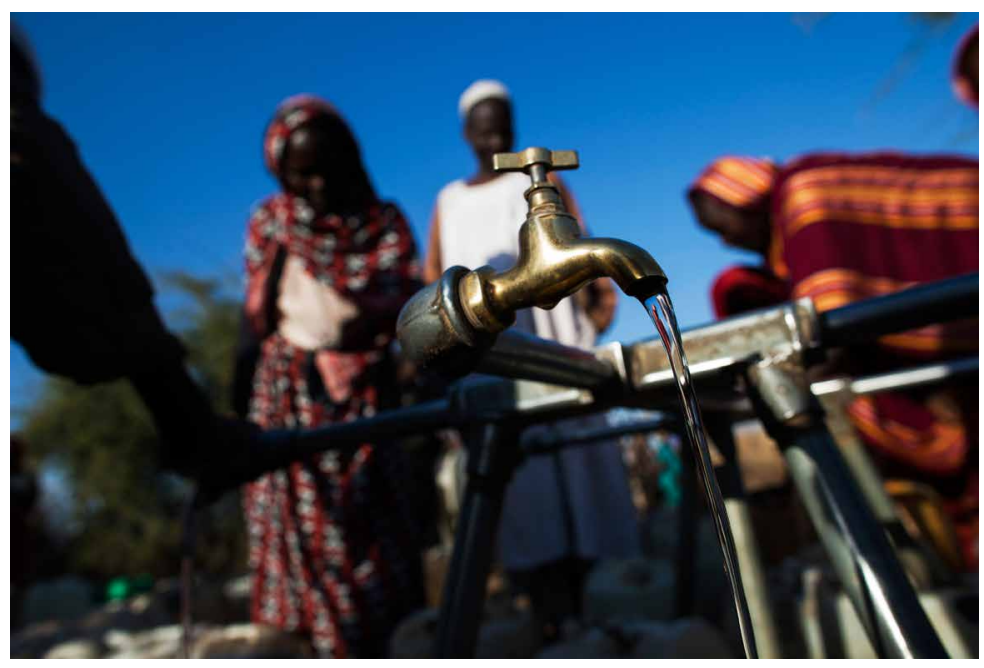

Proportion of population using different types of drinking water services, 2015 (percentage)

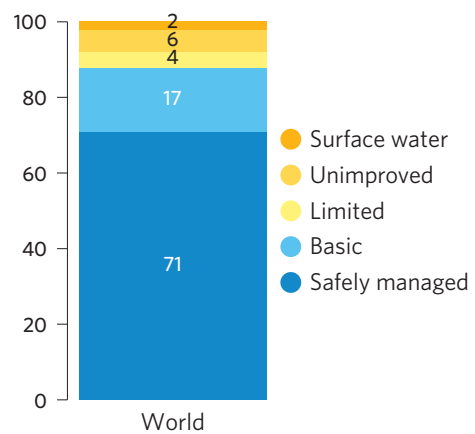

Proportion of the population with basic handwashing facilities, 2015 (percentage)

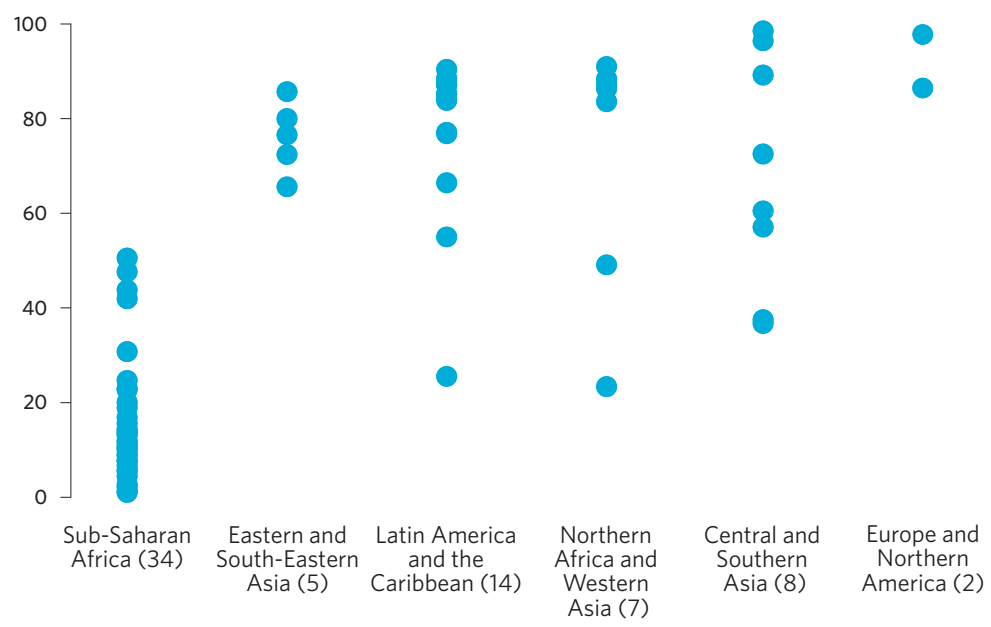

\section{A new approach for measuring progress in drinking water, sanitation and hygiene highlights remaining challenges in greater depth}

"Safely managed" drinking water services-an improved water source located on premises, available when needed and free from contamination-represents an ambitious new rung on the ladder used to track progress on drinking water during the SDG period. This new approach reveals that, in 2015, 5.2 billion people used a "safely managed" drinking water service, while 1.3 billion others used a "basic" service, defined as an improved water source not more than 30 minutes away (round-trip collection time). Another 263 million people spent over 30 minutes collecting water from an improved source and were therefore classified as having "limited" service. In most countries, the burden of collecting water falls mainly on women and girls.

The new ladder for global monitoring of sanitation also incorporates a higher level of service that takes into account the disposal and treatment of human waste. In 2015, 2.9 billion people used a "safely managed" sanitation service, defined as a basic facility that safely disposes of human waste. Another 2.1 billion people used a "basic" service-an improved facility that is not shared. And 600 million people used a "limited" service-an improved facility shared with other households.

Based on comparable data from 70 countries in 2015, hygiene coverage, defined as the availability of a handwashing facility with soap and water on premises, varied widely across regions. In the 34 sub-Saharan Africa countries with data, less than 20 per cent of the population on average had a facility with soap and water at home in 2015. In the 14 countries with data in Latin America and the Caribbean, hygiene coverage was greater than 75 per cent on average. 


\section{Accelerated progress is needed to end open defecation, especially in rural areas of Southern Asia and sub-Saharan Africa}

Open defecation, practised by 892 million people (12 per cent of the global population) in 2015 , continues to pose a serious health risk. It contributes to the incidence of diarrhoea and to the spread of intestinal parasites, which makes children more vulnerable to malnutrition. Open defecation can lead to water pollution. Moreover, it exposes girls and women to the danger of physical attacks. Ending open defecation and achieving universal access to basic sanitation services by 2030 will require a substantial acceleration of progress, particularly in Southern Asia and sub-Saharan Africa. Nine out of 10 people who practised open defecation in 2015 lived in rural areas.
Population practising open defecation, 2000-2015, and reduction required to end open defecation by 2030 (millions)

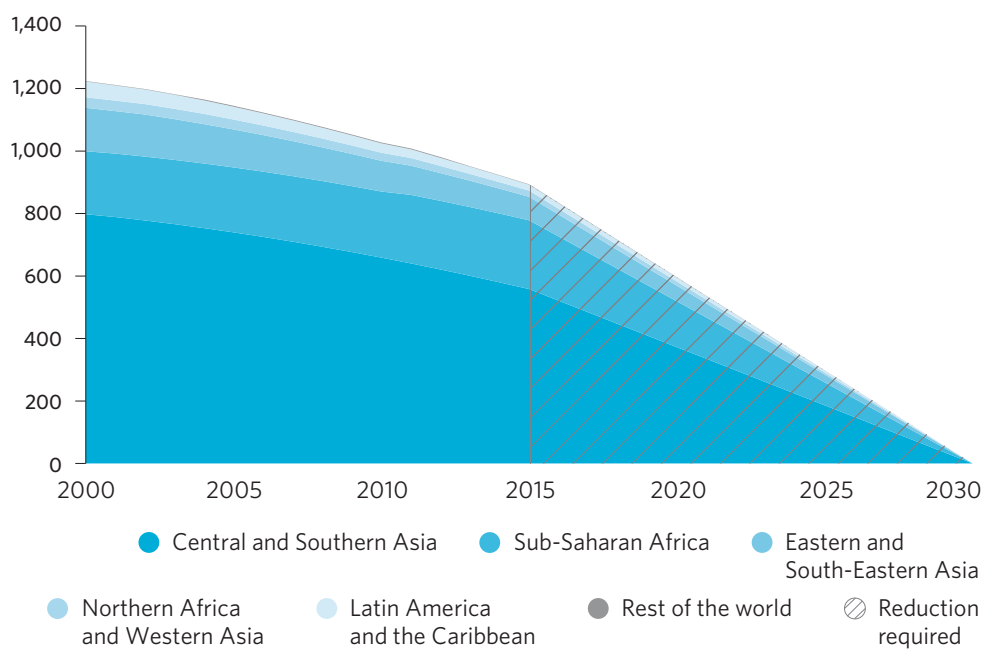

Note: Rest of the world includes Australia and New Zealand, Europe and Northern America and Oceania*.

\section{Water stress intensifies the need for more efficient ways of using water and producing food}

More than 2 billion people globally are affected by water stress, which occurs when the ratio of fresh water withdrawn to total renewable freshwater resources is above a 25 per cent threshold. The situation will likely worsen as populations grow and the effects of climate change intensify. Northern Africa and Western Asia, as well as Central and Southern Asia, experience water stress levels above 60 per cent, indicating the strong probability of future water scarcity, particularly in specific subregions or seasons of the year. Primary sectors for water use in a country include agriculture, industry and municipalities. Agriculture accounts for almost 70 per cent of global water withdrawals, a figure that rises to 95 per cent in some developing countries. This poses a significant challenge for sustainable development, especially since agricultural production is projected to increase significantly to meet global food needs. Protecting water and using it more efficiently will therefore be critical for producing food as well as in all sectors.
Level of water stress: freshwater withdrawal as a proportion of available freshwater sources, around 2014 (percentage)

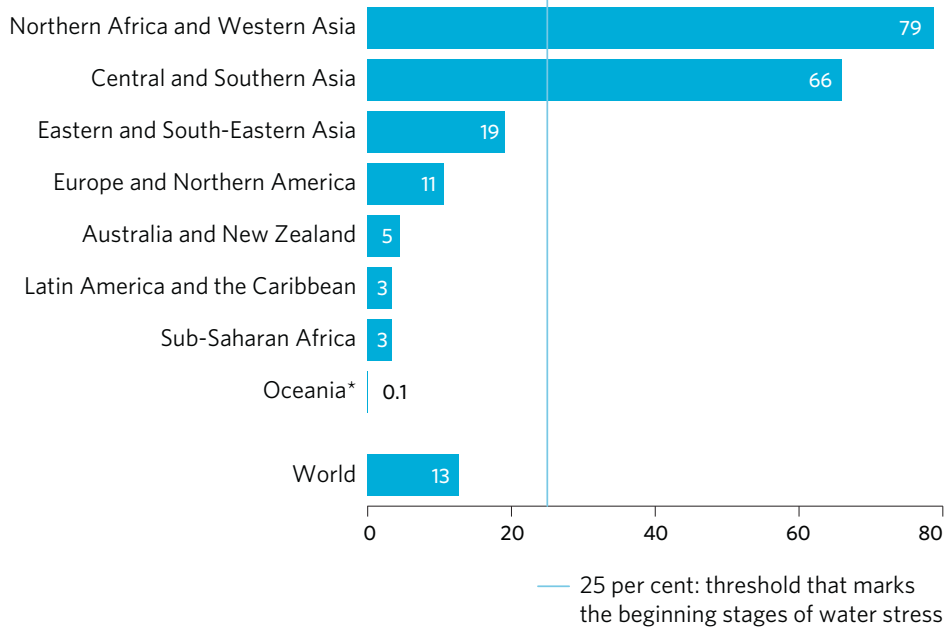

\section{Obtaining adequate financial resources will be critical to achieving progress in the water sector}

Official development assistance (ODA) to the water sector includes aid for drinking water supplies, sanitation and hygiene as well as aid in other areas, such as agricultural water resources, flood protection and hydroelectric power. ODA disbursements to the water sector reached 8.6 billion US dollars in 2015, an increase of 64 per cent in real terms since 2005. Sub-Saharan Africa accounted for 31 per cent of global water- and sanitation-related ODA disbursements in 2015, more than doubling in the past 10 years. However, since 2005, ODA to the water sector has remained relatively constant as a proportion of total ODA disbursements, at about 5 per cent. Countries are making steady progress in achieving increased access to drinking water, sanitation and hygiene services. However, critical to achieving Goal 6 by 2030 will be obtaining adequate financial resources-whether by attracting new sources or better utilizing existing resources.
Annual water sector ODA disbursements, 2000-2015 (billions of constant 2015 US dollars) and water sector ODA as a percentage of total ODA disbursements, 2000-2015 (percentage)

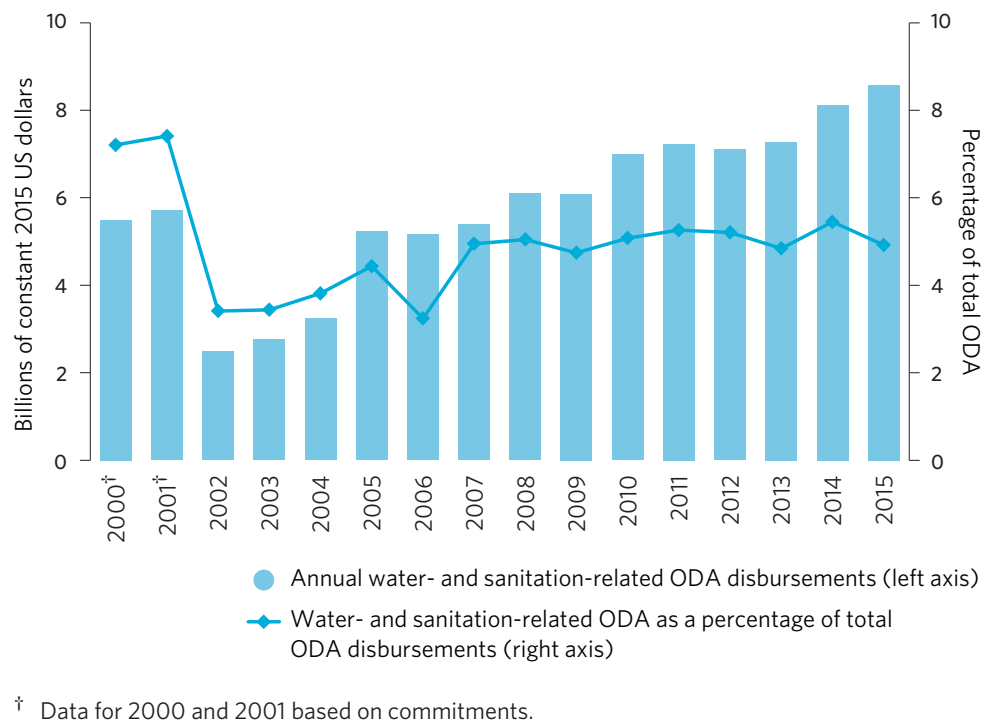




\section{Goal 7: Ensure access to affordable, reliable, sustainable and modern energy for all}

Universal access to affordable, reliable and sustainable energy services requires expanding access to electricity and clean cooking fuels and technologies, as well as improving energy efficiency and increasing the share of renewable energy. However, progress in all these areas falls short of what is needed to achieve the Goal by 2030. Increased financing and bolder policies are required, along with the willingness of countries to embrace new technologies on a much more ambitious scale.

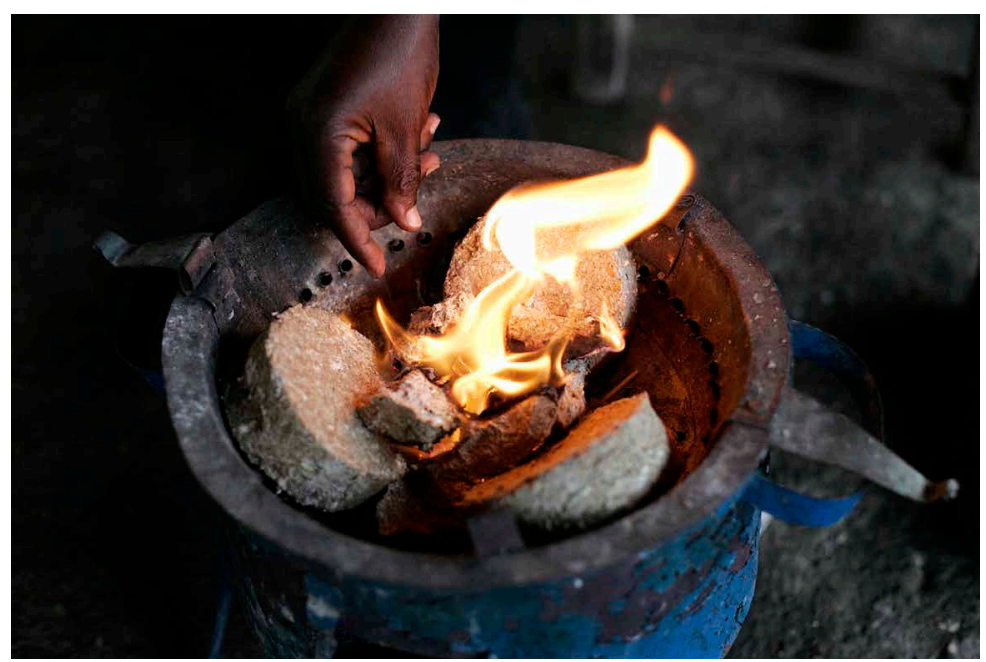

\section{More than a billion people, mostly in rural areas, live without the benefits of electricity}

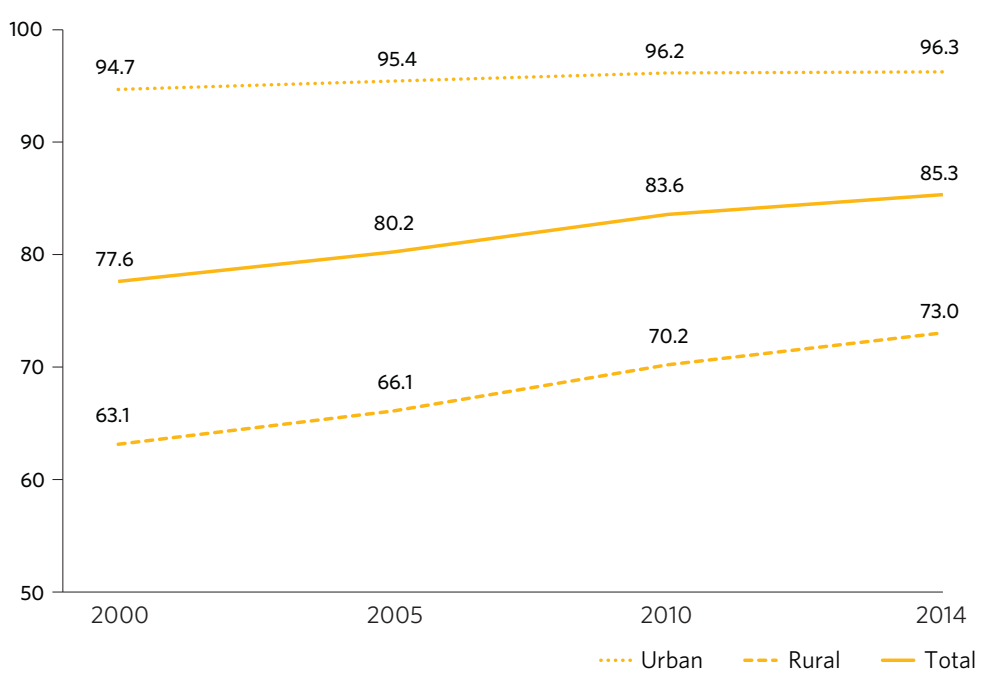

Reliable and affordable access to electricity saves and improves lives. Among its many benefits, electricity powers computers in schools, charges phones, keeps food cold and businesses and essential infrastructure functioning. In 2014, 85.3 per cent of the global population had access to electricity, up from 77.6 per cent in 2000 , with progress slowing in the last few years. While 96 per cent of urban residents had access to electricity in 2014, the share was only 73 per cent for those in rural areas.

Globally, 1.06 billion people still lived without this essential service, with 80 per cent of them concentrated in just 20 countries. More than half the people without electricity lived in sub-Saharan Africa. The region had the lowest electrification rate overall at 37 per cent, but the figure dropped to just 17 per cent in rural areas. A major challenge is providing electrification rapidly enough to outpace growing populations. While some 86 million people a year are able to access electricity for the first time, this progress has been offset in some areas by population growth. 


\section{About three billion people still lack access to clean and safe cooking fuels and technologies}

Lack of access to clean cooking fuels and technologies presents many health hazards and results in millions of deaths each year due to household air pollution. From 2000 to 2014, the proportion of the global population with access to such fuels and technologies (for instance, gas and electricity) increased from 50 per cent to 57 per cent, progressing much more slowly than electrification. About 3 billion people, the majority in Asia and sub-Saharan Africa, are still cooking without the benefit of clean fuels and technologies. Rural areas lagged behind urban areas, with 22 per cent access versus 78 per cent, a gap much larger than in the case of access to electricity. Although 80 million people globally gained access to clean cooking fuels and technologies during 2012-2014, population growth offset this gain. Current progress-a 0.46 percentage point increase annually-is far lower than the annual 2.66 percentage point increase required for universal access by 2030 .
Proportion of the population with primary reliance on clean cooking fuels and technologies, 2000 and 2014 (percentage)

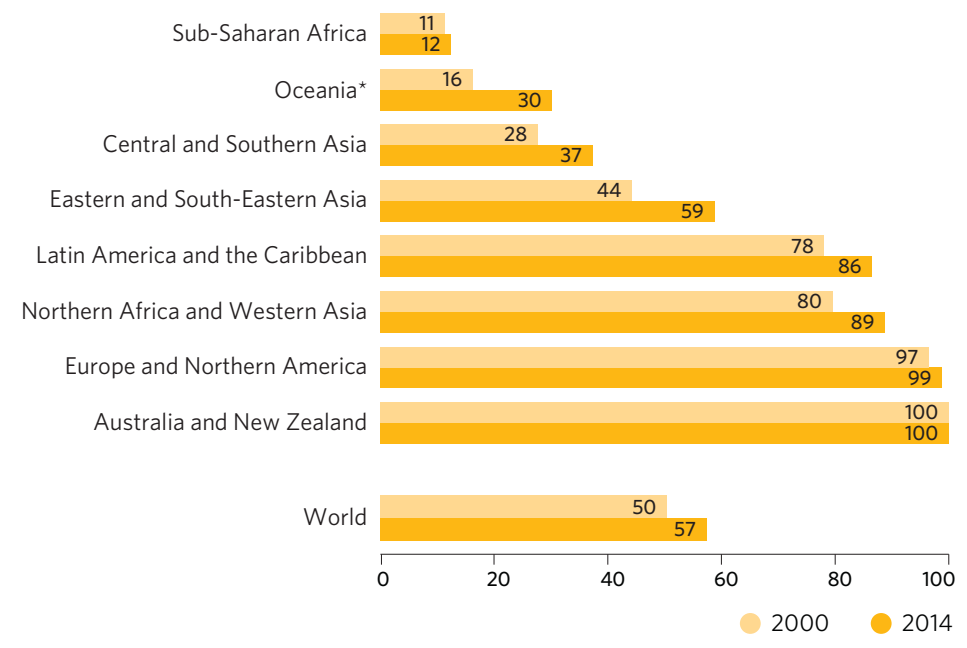

\section{While renewable power generation is rising rapidly, comparable progress has not occurred in the heat or transport sectors}

The share of renewable energy in final energy consumption globally has increased only modestly, from 17.5 per cent in 2010 to 18.3 per cent in 2014 . However, driven by advances in technology and falling costs, wind and solar generation more than doubled over the same period. Most growth in renewable energy has been concentrated in the electricity sector. As a result, the share of renewable energy in power generation rose from 19.6 per cent in 2010 to 22.3 per cent in 2014 . However, electricity makes up only 20 per cent of total final energy consumption. The key to expanding renewable energy will be to increase its share in heat and transport, which together account for the remaining 80 per cent of energy consumption. However, the share of renewable energy in the heat sector barely increased, from 25.7 per cent to 26.3 per cent from 2010 to 2014, while the share of renewables in the transport sector remained very low-at 2.8 per cent-in 2014.
Global share of renewable energy in heat, electricity and transport sectors, 2010-2014 (percentage)

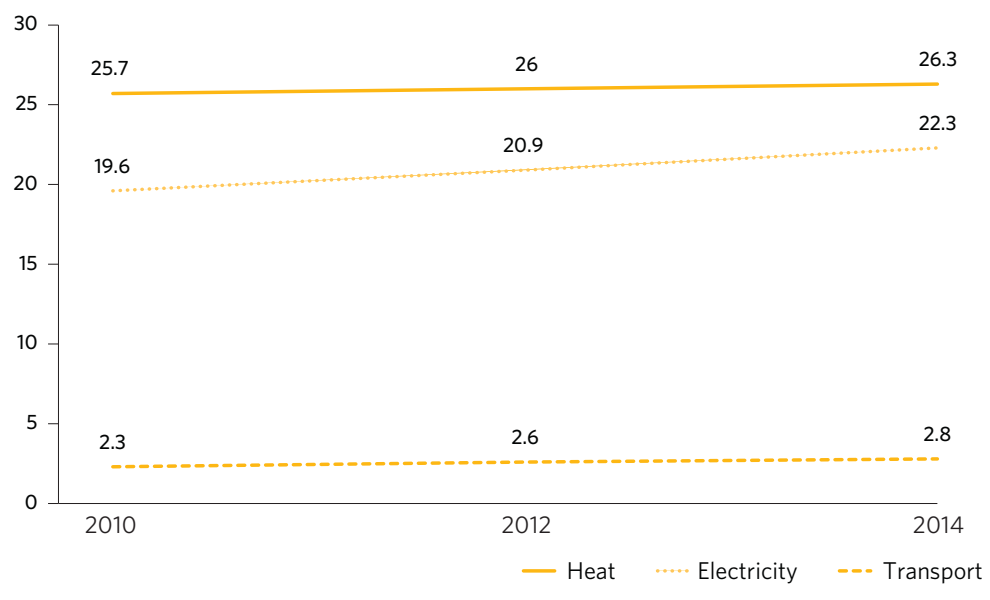

\section{Despite gains in reducing energy intensity, progress is not yet sufficient to meet the target}

Reducing energy intensity (the ratio of energy used per unit of GDP) can lower demand for energy, lighten the environmental footprint of energy production, and make energy more affordable. Globally, primary energy intensity declined by 2.1 per cent a year from 2012 to 2014. Over that period, three quarters of the world's 20 largest energy-consuming countries reduced their energy intensity. The associated savings were equivalent to the total energy consumed by Brazil and Pakistan combined in 2014. However, progress is insufficient to double the global rate of improvements in energy efficiency as called for by the target.

Industry and passenger transport sectors contributed to declining global energy intensity through greater efficiencies, with annual reductions of 2.2 per cent and 2.8 per cent, respectively, between 2012 and 2014. In transport, widespread diffusion of fuel-efficiency standards helped accelerate reductions in energy intensity, particularly for passenger transport. The residential sector, on the other hand, has become more energy intensive over time.
Compound annual growth rate of final energy intensity in end-use sectors, 2012-2014 (percentage)

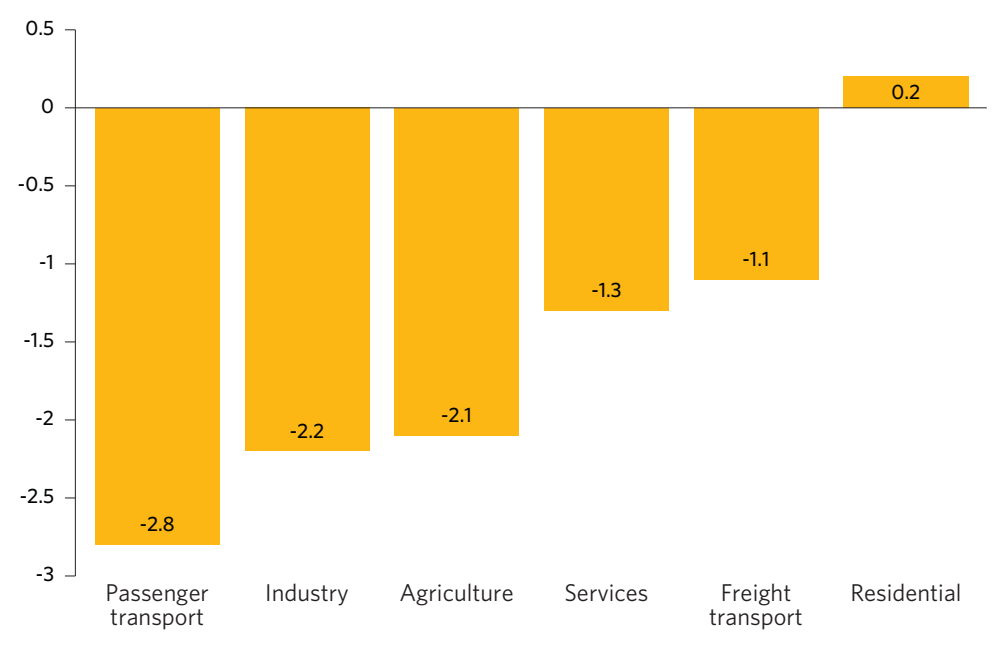




\section{Goal 8: Promote sustained, inclusive and sustainable economic growth, full and productive employment and decent work for all}

Sustained and inclusive economic growth drives development by providing more resources for education, health, personal consumption, and transport, water and energy infrastructure. Economic growth can also lead to new and better employment opportunities. Sustaining high real economic growth is not easy, however, and only a few of the least developed countries have consistently closed in on the 7 per cent average annual growth target for real GDP. Moreover, economic growth is not necessarily sustainable when countries are depleting their natural resources for the sake of economic growth and thus shifting the burden of environmental degradation and damage to future generations.

Average annual growth rate of real GDP per capita, 2005-2009 and 2010-2015 (percentage)

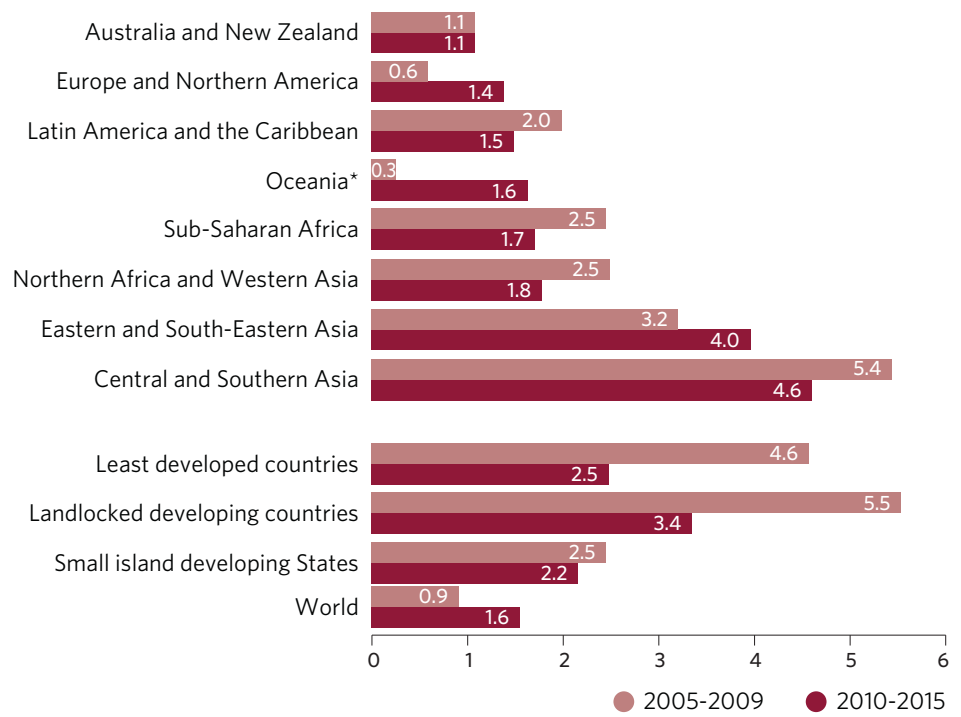

Average annual growth rate of real GDP per worker, 2000-2008 and 2009-2016 (percentage)

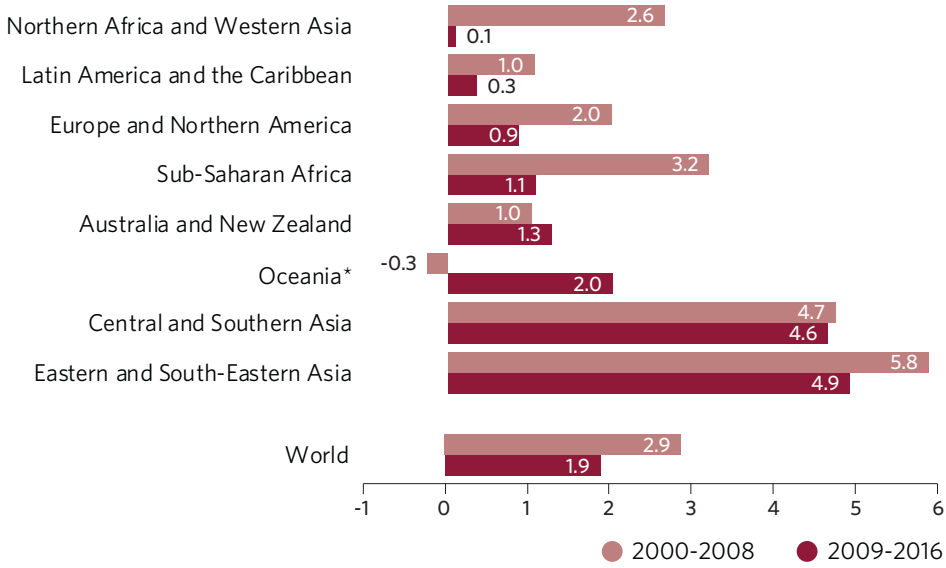

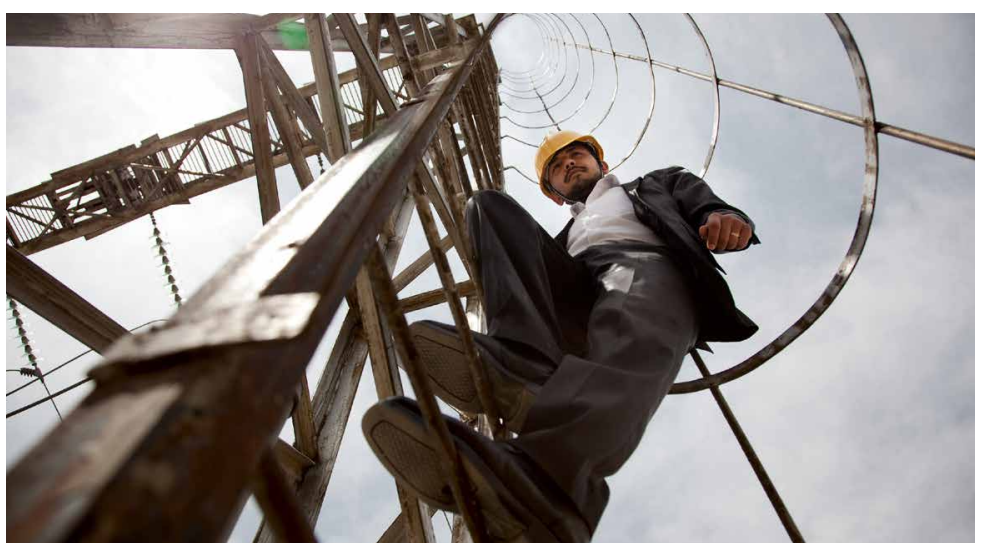

\section{Sustained high real economic growth remains elusive} in least developed countries

Globally, real GDP per capita grew, on average, by 1.6 per cent in 2010-2015. That is almost double the rate of 0.9 per cent in 2005-2009 and slightly below the 1.8 per cent rate achieved in 2000-2004. Real GDP per capita in Central and Southern Asia and Eastern and South-Eastern Asia grew most rapidly from 2010 to 2015 (4.6 per cent and 4.0 per cent, respectively). In contrast, real GDP per capita growth slowed in the least developed countries (LDCs), landlocked developing countries and small island developing States to an average of 2.5, 3.4 and 2.2 per cent, respectively, in 2010-2015. Overall real GDP growth in LDCs averaged 4.9 per cent in 2010-2015, compared to 7.1 per cent in 2005-2009. Accelerated progress is needed if LDCs are to reach the target of at least 7 per cent annual growth in real GDP.

\section{Growth in labour productivity remains below its pre-financial-crisis level in almost all regions}

Growth in labour productivity - measured by GDP per workerslowed sharply after the financial crisis of 2008-2009, expanding at an average annual rate of 1.9 per cent between 2009 and 2016, compared to 2.9 per cent between 2000 and 2008. Nearly every region of the world, with the exception of Oceania excluding Australia and New Zealand, experienced a significant slowdown, most notably Northern Africa and Western Asia, sub-Saharan Africa, and Europe and Northern America. Growth in labour productivity drives sustainable increases in living standards and real wages. The slowdown therefore represents a negative development for the global economy and for many labour markets around the world. 


\section{Youth unemployment is a worldwide problem}

The global unemployment rate in 2016 was 5.7 per cent, a slight improvement from 2010 (at 6.1 per cent). Women are more likely to be unemployed than men across all age groups. In 2016, youth (aged 15 to 24 years) were nearly three times as likely as adults to be unemployed, with unemployment rates of 12.8 per cent and 4.4 per cent, respectively. That year, more than one quarter of youth in Northern Africa and Western Asia and more than 15 per cent of youth in Latin American and the Caribbean and in Europe and Northern America were unemployed. Moreover, in about three quarters of countries with data, more than 1 in 10 youth are neither in the educational system nor employed. Young women are more likely than young men to fall into this category in almost 70 per cent of countries with data.
Unemployment rates, youth and adult, 2016 (percentage)

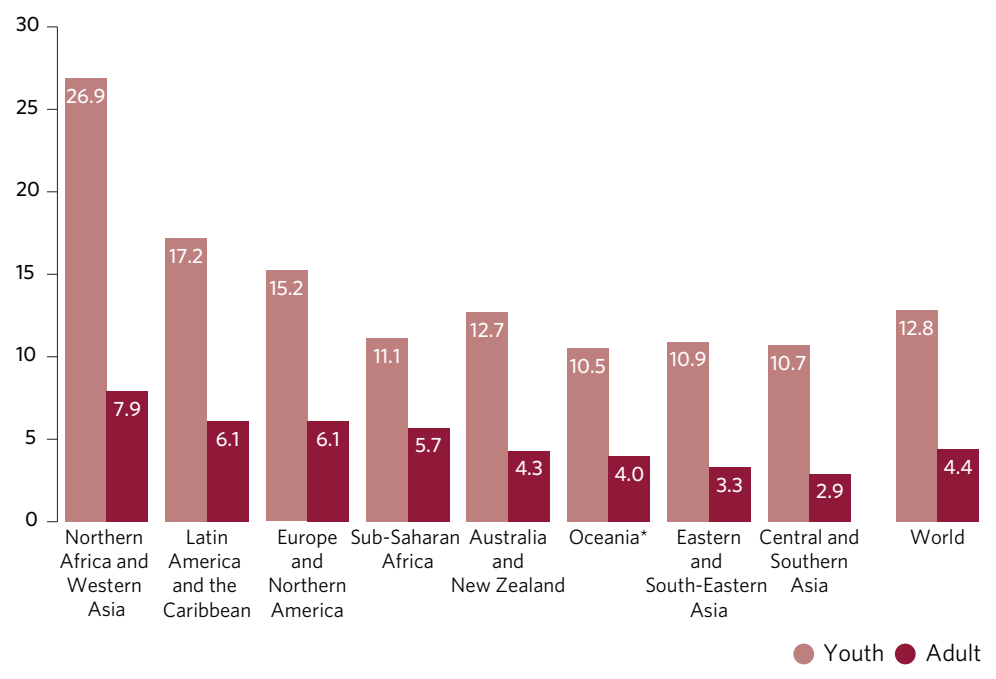

\section{While the situation is improving, 1 in 10 children are still engaged in child labour}

The number of children (aged 5 to 17) in child labour globally declined from 246 million in 2000 to 168 million in 2012. Still, child labour remains a serious concern. Around 1 in 10 children worldwide were engaged in child labour in 2012; more than half of them ( 85 million) were exposed to hazardous forms of work. About 59 per cent of child labourers worked in the agricultural sector. From 2000 to 2012, the number of girls engaged in child labour declined by 40 per cent, versus a decline of 25 per cent for boys. Sub-Saharan Africa had the highest incidence of child labour, involving more than one in five children (21.4 per cent, or 59 million).
Proportion of children aged 5 to 17 years engaged in child labour, by hazardous and non-hazardous work, 2000-2012 (percentage)
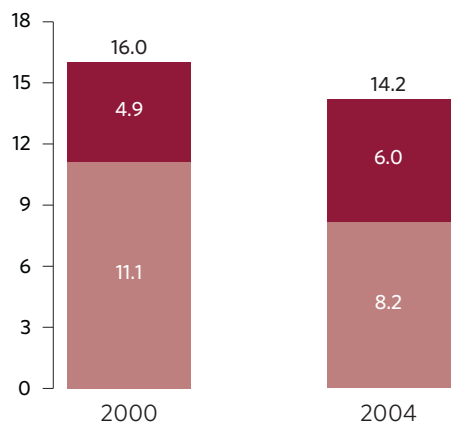

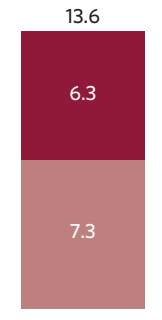

2008

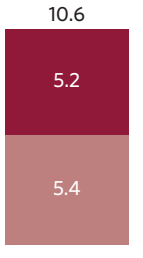

2012
Child labour: hazardous work Child labour: non-hazardous work

\section{The rapid expansion of ATMs provides access to financial services in many underserved regions}

Access to financial services enables individuals and firms to manage changes in income, deal with fluctuating cash flows, accumulate assets and make productive investments. Globally, access to automated teller machines (ATMs) increased by 55 per cent between 2010 and 2015. Commercial bank branches grew by 5 per cent over the same period, with the lower growth explained by increased digital access to financial services. There were 60 ATMs and 17 commercial bank branches per 100,000 adults in 2015. Compared to other regions, the availability and growth of both types of access are relatively low in sub-Saharan Africa and Oceania excluding Australia and New Zealand. Between 2011 and 2014, 700 million adults became new account holders, and the share of adults with an account at a financial institution increased from 51 per cent to 61 per cent. In Australia and New Zealand as well as in Europe and Northern America, access to ATMs has become almost universal while the number of commercial bank branches has declined.
Number of ATMs and branches of commercial banks per 100,000 adults, 2010 and 2015

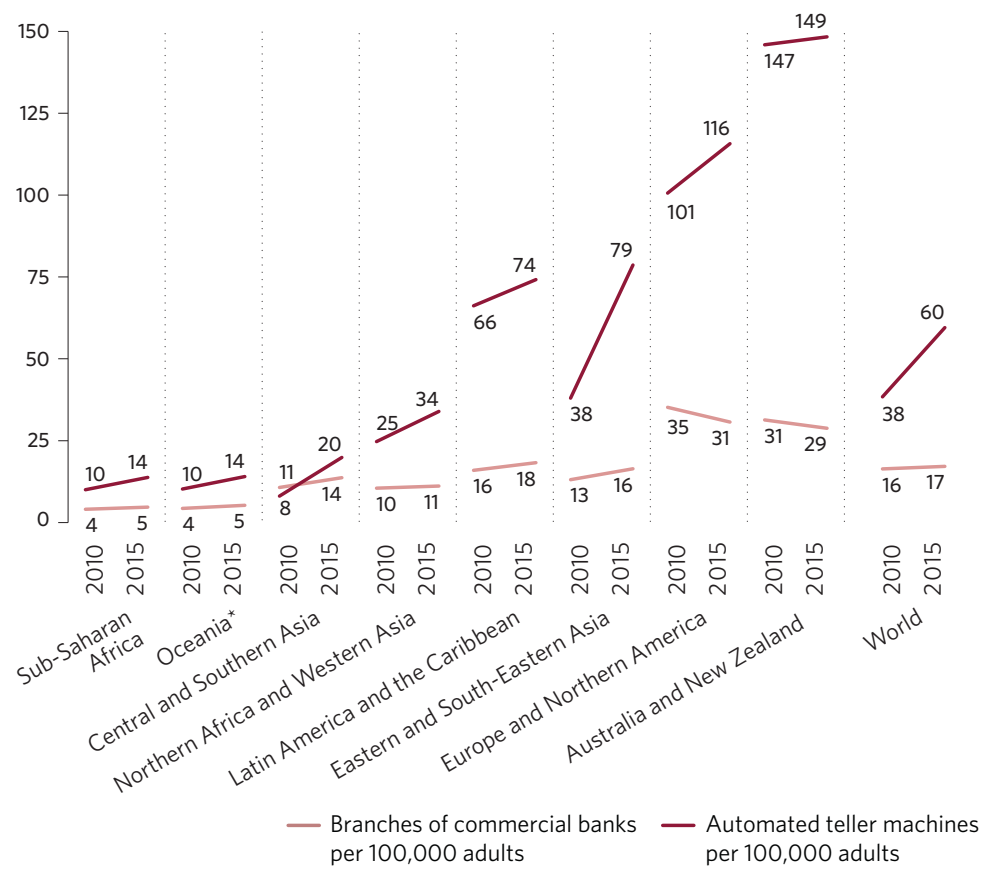




\section{Goal 9: Build resilient infrastructure, promote inclusive and sustainable industrialization and foster innovation}

Investing in infrastructure, promoting inclusive and sustainable industrialization, and supporting technological development, research and innovation are three driving forces for economic growth and sustainable development. These drivers can help countries reduce poverty by creating job opportunities, stimulating growth, and encouraging the building and improvement of physical facilities that are essential to the functioning of business and society. In recent years, steady improvements have been made in all three of these areas of sustainable development. However, renewed investment will be needed in the least developed countries (LDCs) to build infrastructure and ensure the doubling of industry's share of GDP in those countries by 2030 .

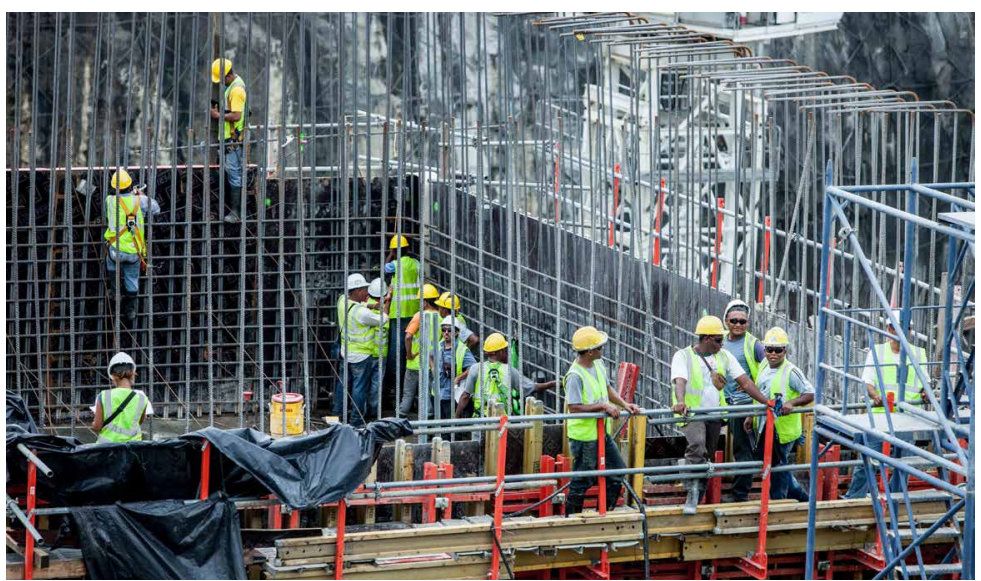

Transportation services provide a vital link to global markets, but are still lacking in some regions

Efficient transportation services drive economic development. In 2015, the global economic impact (both direct and indirect) of air transport was estimated at 2.7 trillion US dollars, or 3.5 per cent of global GDP. Road transport continues to be the predominant form of freight transport globally, accounting for 61 per cent of the total. Europe and Northern America, and Eastern and South-Eastern Asia account for most freight transport (all modes), with Oceania excluding Australia and New Zealand, and sub-Saharan Africa accounting for only a small fraction of the global total. Passenger transport follows a similar pattern. The LDCs, landlocked developing countries and small island developing States represent far less air travel and freight volumes, with each country group accounting for only 1 per cent to 2.7 per cent of the global total.
Manufacturing value added per capita, 2005 and 2016 (constant 2010 US dollars)

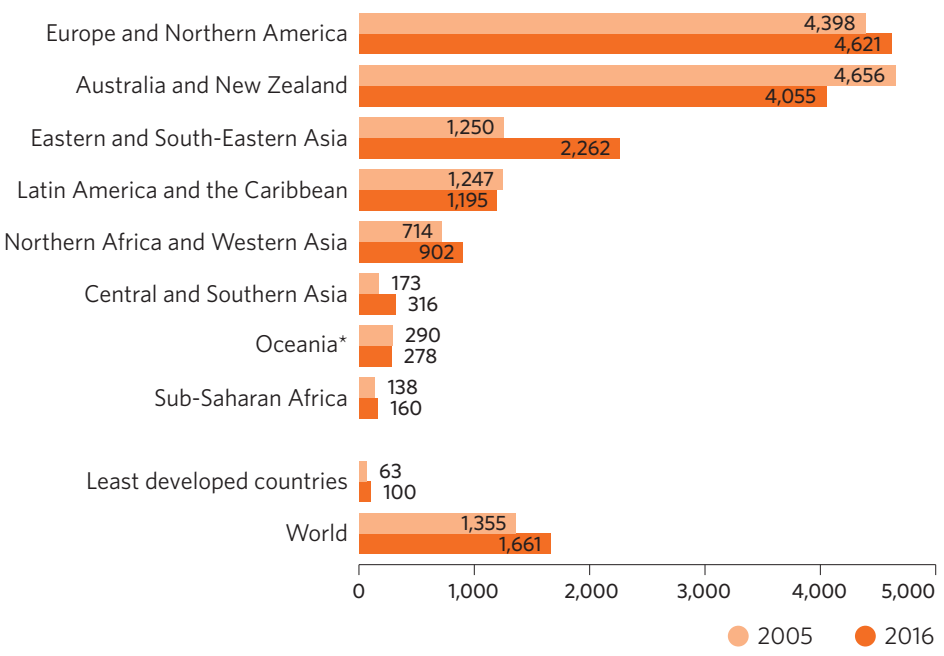

Despite progress, the least developed countries are still far behind in manufacturing growth

Manufacturing is the principal engine of economic growth that satisfies the growing demand for goods worldwide. Manufacturing output has increased in most regions of the world, and manufacturing value added (MVA) per capita increased globally by 22.6 per cent in real terms between 2005 and 2016. But while MVA per capita has increased globally, broader industrialization has been hampered by intense concentrations of production in some countries and regions. This has resulted in marked inequalities, with industrial productivity varying widely between richer and poorer regions. In 2016, MVA per capita was 100 US dollars a year in LDCs (although it had increased 59 per cent in real terms since 2005), compared to 4,621 US dollars in Europe and Northern America. As manufacturing production shifts from higher-income regions in search of lower costs, countries that currently have low levels of MVA per capita stand to benefit. 


\section{A general decrease is observed in emissions intensity of manufacturing across regions}

Manufacturing is consistently improving its emissions performance as countries move to less energy-intensive industries, cleaner fuels and technologies, and stronger energy efficiency policies. Emissions levels have also been reduced through structural changes and product diversification in manufacturing. Between 2000 and 2014, almost all regions showed a reduction in carbon dioxide $\left(\mathrm{CO}_{2}\right)$ emissions from manufacturing per unit of MVA. Europe and Northern America reduced their emissions intensity by 36 per cent over this period, and all of the 10 largest manufacturing countries saw decreases. These promising trends are not reflected in the global emissions intensity level, however, since a significant share of global MVA has moved to countries with poorer emissions performance.
$\mathrm{CO}_{2}$ emissions from manufacturing per unit of MVA, 2000 and 2014 (kilograms per constant 2010 US dollars)

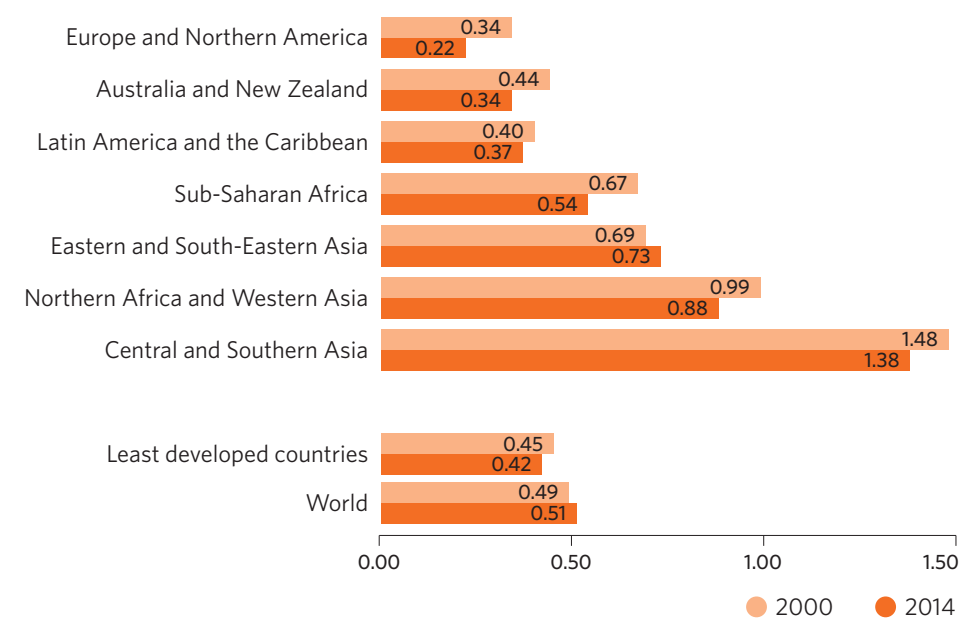

\section{Global investments in research and development continue their brisk growth, though large disparities persist among regions}

In 2014, global investments in research and development (R\&D) stood at 1.8 trillion US dollars (purchasing power parity), up from 733 billion US dollars in 2000. This represented an average annual growth rate of 4.5 per cent. In relative terms, 1.7 per cent of global GDP was devoted to $R \& D$. However, this figure masks wide differences among regions. In Europe and Northern America, the average stood at 2.2 per cent of GDP, while in sub-Saharan Africa, the share was only 0.4 per cent. A large proportion of $R \& D$ expenditures go towards the wages and salaries of researchers, technicians and support staff, which is why the figures for researchers follow a similar pattern. Globally, there were almost 1,098 researchers per million inhabitants in 2014, ranging from a low of 63 in LDCs to a high of 3,500 in Europe and Northern America.
Research and development expenditure as a proportion of GDP, 2000 and 2014 (percentage)

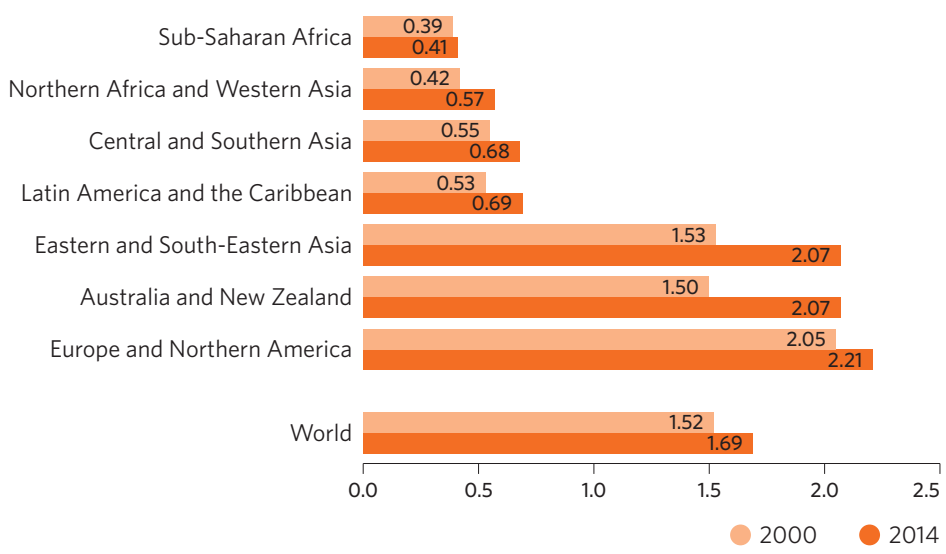

Note: There is insufficient data coverage for Oceania* to calculate a regional aggregate.

\section{Coverage by a mobile cellular signal has become almost universal}

Mobile cellular services have spread much faster than anticipated, enabling people living in previously unconnected areas to join the global information society. By 2016, second-generation (2G) mobile telephony was almost universal, with 95 per cent of the world's population covered. Third-generation (3G) mobile coverage, which delivers higher speed access to the Internet and information and communication technology services and applications, stood at 84 per cent globally. In LDCs, about 85 per cent of people lived in areas covered by a mobile cellular signal and 52 per cent lived in areas covered by a $3 G$ signal.
Number of people covered by a mobile network, by technology, 2007-2016 (billions)

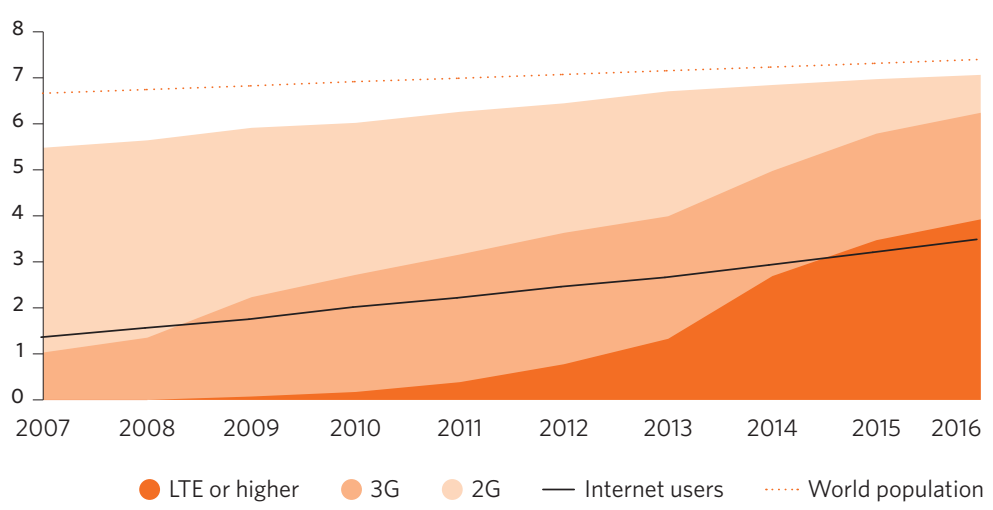

Note: LTE (Long-Term Evolution) is a standard for high-speed wireless communication that allows for faster speeds than $3 \mathrm{G}$ technologies but does not meet the technical criteria of a $4 \mathrm{G}$ wireless service. 


\section{Goal 10: Reduce inequality within and among countries}

Progress in reducing inequality within and among countries has been mixed. Income inequality has declined in many of the countries that experienced sustained economic growth, while increasing in countries with negative growth. Meanwhile, the voices of developing countries in international economic and financial decision-making still need to be strengthened. And, while remittances can be a lifeline for families and communities in the home countries of international migrant workers, the high cost of transferring money continues to diminish the benefits.

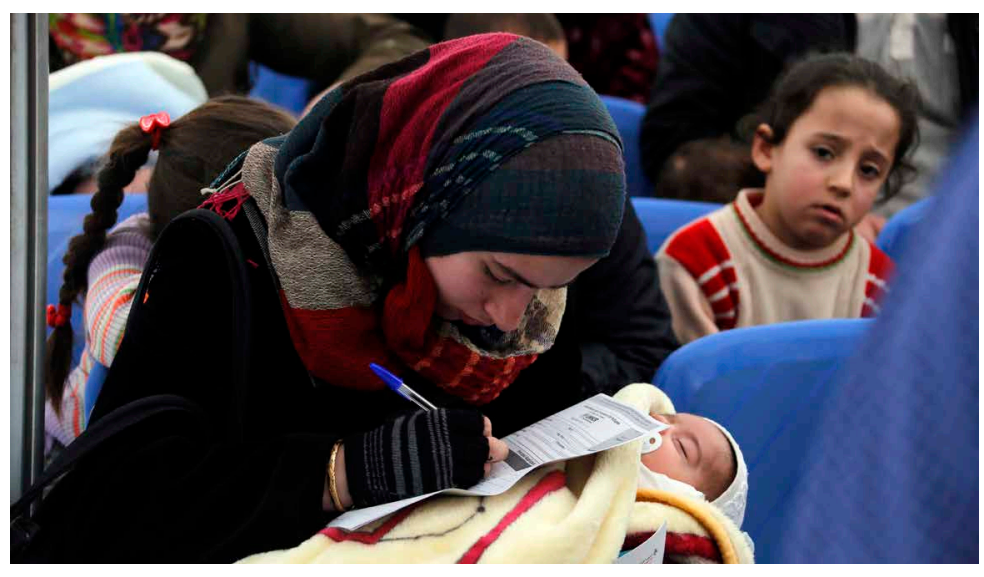

\section{Sustained economic growth has helped reduce income} inequality in many countries

40 per cent of the population and total population, 2011-2015 (latest available) (percentage)

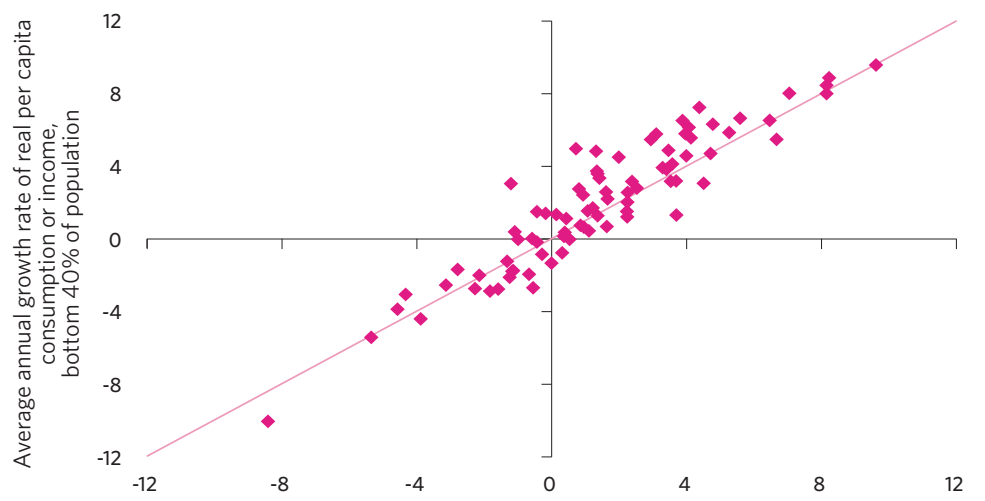

Between 2011 and 2015, the income and/or consumption of the bottom 40 per cent of the population grew faster than the national average in 49 of the 83 countries with data (accounting for three quarters of the world's population). In most countries whose per capita income/consumption grew during this period, growth was faster for the bottom 40 per cent of the population. In contrast, in most countries with contractions in per capita income/consumption, the bottom 40 per cent fared worse than the overall population. This suggests that those in the bottom 40 per cent are particularly vulnerable to economic changes, and that sustained income growth overall is necessary to reduce inequality and ensure shared prosperity.

Note: The line included on the graph is a reference line indicating whether a country's growth of the bottom 40 per cent was greater or less than the total population. It is not a trend line

The proportion of developing countries' voting share and membership share in select international organizations, 2000 and 2016 (percentage)
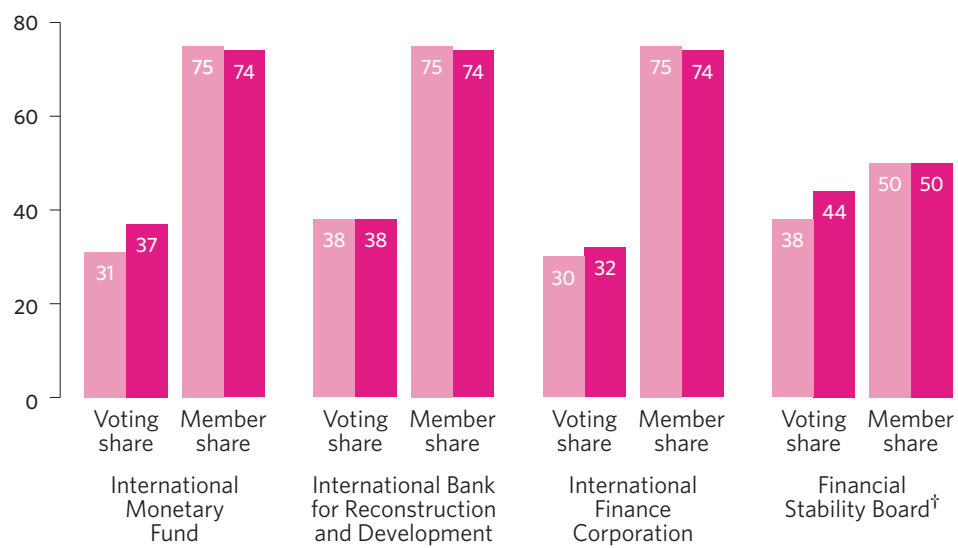

2000

i Data for the Financial Stability Board are for 2010 and 2016. For this analysis only, developing countries are defined as countries in developing regions according to the M49 classification.

\section{Voting rights of developing countries have increased in some international organizations, but still fall far below their membership share}

Many international organizations and bodies, including the United Nations General Assembly and the World Trade Organization, operate under a one member/one vote system. Others have a more complex decision-making mechanism in place. For example, in both the International Bank for Reconstruction and Development and the International Finance Corporation (both part of the World Bank Group), the voting shares of developing countries remain far below their membership levels and have not increased much over the past 16 years. Other organizations, such as the International Monetary Fund (through its recent quota reform) and the Financial Stability Board, have increased the voting shares of developing countries during this period. However, more work needs to be done to ensure that the voices and participation of developing countries in international economic decision-making, norm-setting and global economic governance are broadened and strengthened. 
The international trade community continues to grant more favourable access conditions to lower-income countries

Duty-free treatment and favourable access conditions for exports from least developed and developing countries have expanded. From 2005 to 2015, the proportion of tariff lines globally with duty-free treatment for products originating in developing countries increased from 41 per cent to 50 per cent; for products originating in the least developed countries, the proportion rose from 49 per cent to 65 per cent. These increases indicate that the international community is continuing its efforts to grant preferential treatment to countries with lower income levels.
Proportion of tariff lines applied to exports from least developed and developing countries with zero tariffs, 2005, 2010 and 2015 (percentage)

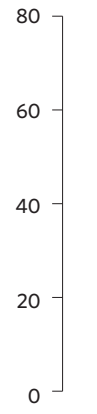

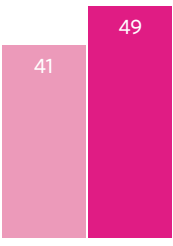

2005

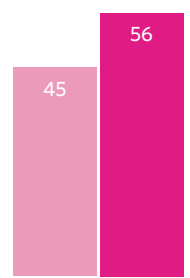

2010

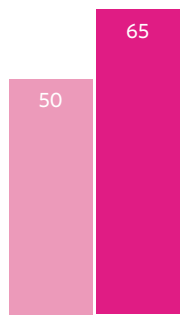

2015
All developing countries

\section{Total resource flows for developing countries fluctuate widely from year to year}

Total resource flows for development include official development assistance, other official flows, private flows and net grants by non-governmental organizations. In 2015, global total resource flows for development to developing countries totalled just over 319 billion current US dollars. The contraction in 2015 was largely due to a steep decline in private resource flows. Least developed and landlocked developing countries received more than 10 per cent of all total resource flows for development in 2015, a continuation of consistent increases over the last 15 years. The region that received the largest share of total resource flows was Latin America and the Caribbean (a little over 100 billion US dollars), while flows to Eastern and South-Eastern Asia fell from about 80 billion US dollars in 2010 to about 50 billion US dollars in 2015.
Total resource flows (net disbursements) for development, 2000, 2005, 2010 and 2015 (billions of current US dollars)

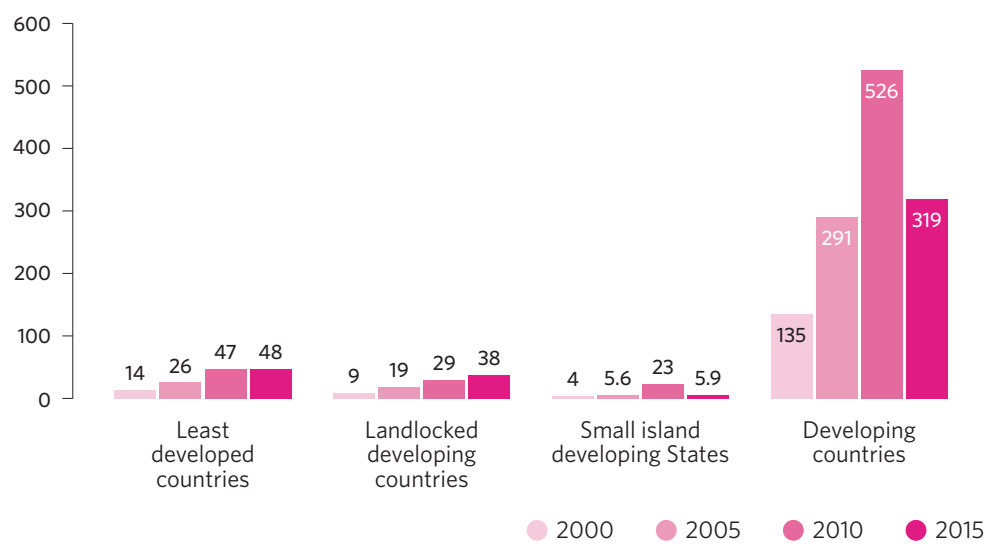

\section{While technology is spurring lower costs, sending remittances is still relatively expensive}

Although the benefits of remittances from international migrant workers are substantial, they are diminished somewhat by the generally high cost of transfer. On average, post offices and money transfer operators charge over 6 per cent of the amount remitted; commercial banks charge 11 per cent; and the global average cost of transferring money is just over 7 per cent, according to World Bank Remittance Prices Worldwide. While the cost of sending money has declined gradually since 2008 , all three of these remittance services providers charge significantly more than the 3 per cent target. New and improved technologies, such as prepaid cards and mobile operators, charge lower fees for sending money home (between 2 per cent and 4 per cent), but are not yet widely available or used in many remittance corridors. These new technologies may help reduce the cost of sending remittances to some of the poorest countries, where costs tend to be highest. This is particularly true in sub-Saharan Africa, where average costs absorb about 10 per cent of the amount sent.
Total average cost of sending remittances by remittance service provider, first quarter 2017 (percentage of total amount sent)

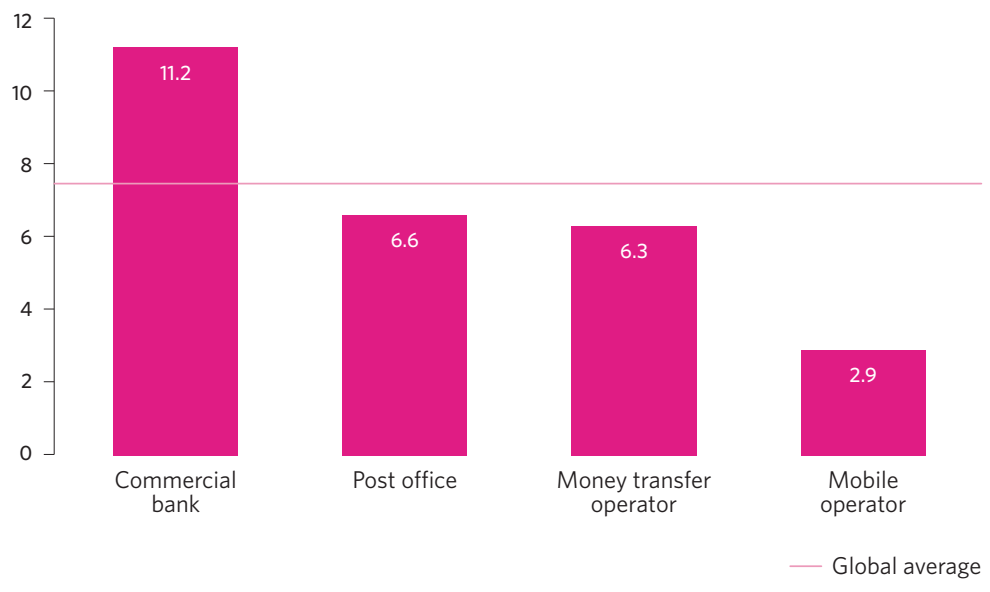




\section{Goal 11: Make cities and human settlements inclusive, safe, resilient and sustainable}

The pace of urban growth has been unprecedented. Around the turn of the century, for the first time in history, urban dwellers outnumbered their rural counterparts, and by 2015, nearly 4 billion people- 54 per cent of the world's population-lived in cities. That number is projected to reach 5 billion by 2030. Rapid urbanization brings enormous challenges, including growing numbers of slum dwellers, increased air pollution, inadequate basic services and infrastructure, and unplanned urban sprawlwhich also make cities more vulnerable to disasters. With sound urban planning and management, however, the world's urban spaces can become inclusive, safe, resilient and sustainable, as well as dynamic hubs of innovation and enterprise.

Proportion of urban population living in slums, 2000 and 2014 (percentage)

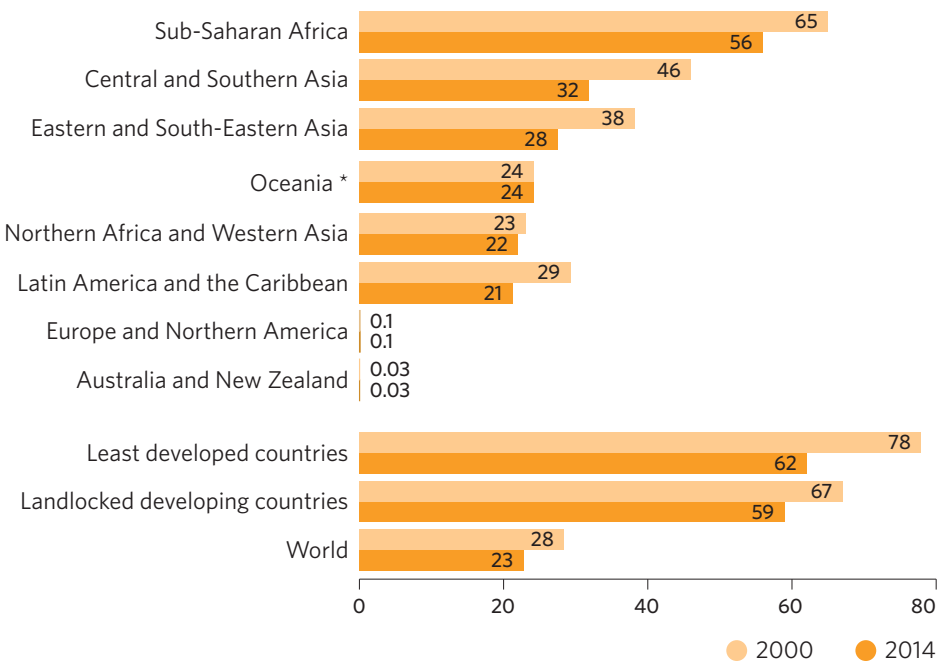

Average ratio of land consumption rate to population growth rate, 1990-2000 and 2000-2015

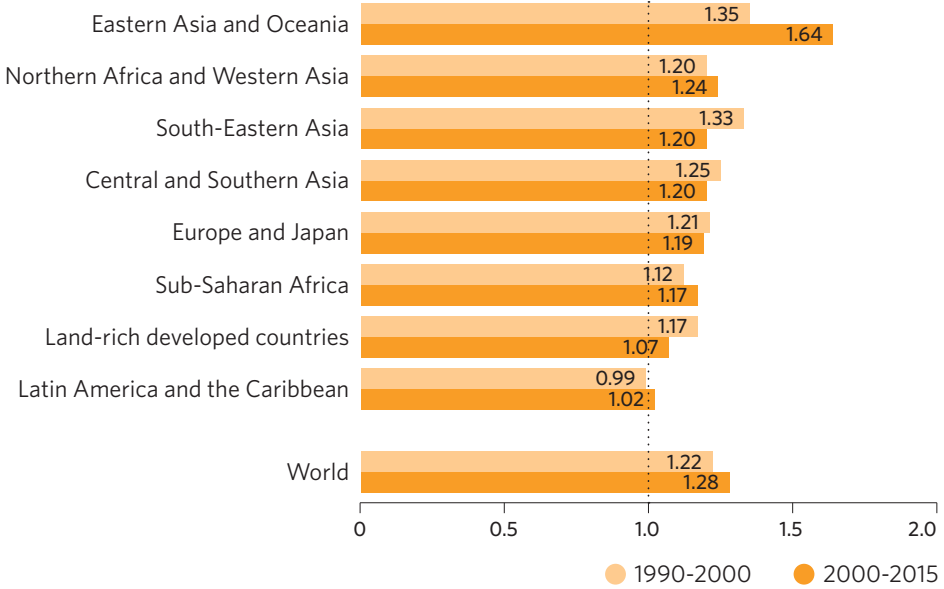

Note: This chart includes a combination of SDG regional groupings and regional groupings from UN-Habitat "Europe and Japan" includes European countries and Japan. "Land-rich developed countries" includes Australia, Canada, New Zealand and the United States of America; and "Eastern Asia and Oceania" excludes Japan, Australia and New Zealand.

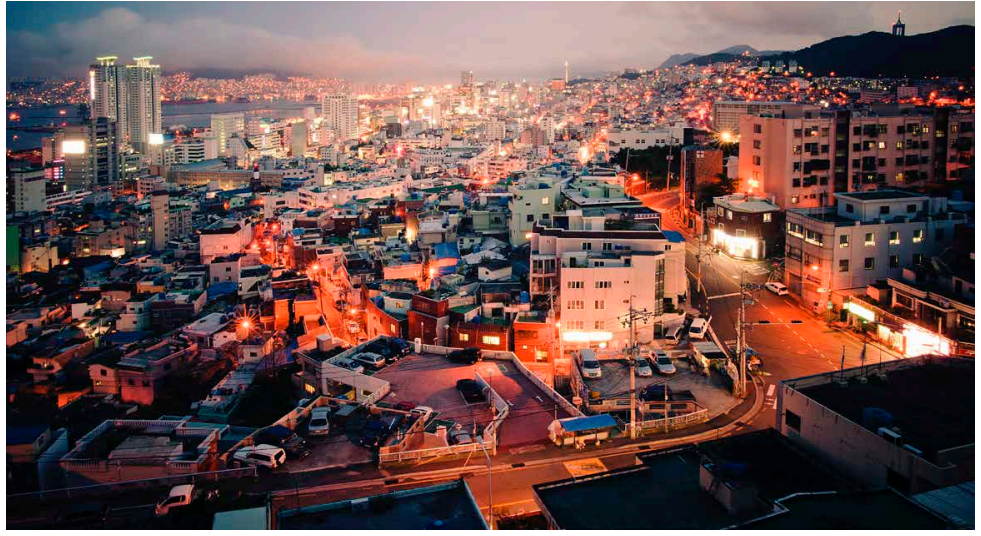

The proportion of urban populations living in slums has declined by 20 per cent since 2000, but their numbers continue to grow

People living in slums, informal settlements or inadequate housing are triply disadvantaged: they tend to be excluded-spatially, socially and economically - from the opportunities that other city dwellers enjoy. Over the years, policy and programmatic responses by national and municipal governments, international development partners, and nongovernmental and community-based organizations have resulted in improved slum conditions. The proportion of the urban population living in slums worldwide fell from 28 per cent in 2000 to 23 per cent in 2014.

Despite these gains, the absolute number of slum dwellers has continued to grow owing to accelerating urbanization, population growth and lack of appropriate land and housing policies. In 2014, an estimated 880 million urban residents lived in slums, compared to 792 million in 2000. Substandard living conditions and the lack of basic services hit children and youth the hardest, diminishing their prospects for good health and education, with potentially lifelong consequences for their cognitive and social development. Slums are most pervasive in sub-Saharan Africa, where more than half (56 per cent) of urban dwellers live in slum conditions.

\section{The expansion of urban land is outpacing urban population growth}

As larger numbers of people move to urban areas, city boundaries typically expand to accommodate new inhabitants. Understanding the relationship between population shifts and urban land can help policymakers and planners ensure that cities remain economically productive and environmentally sustainable. From 2000 to 2015, in all regions of the world, the expansion of urban land outpaced the growth of urban populations - that is, the average ratio of the land consumption rate to the population growth rate was greater than one. The ratio increased from 1.22 between 1990 and 2000 to 1.28 between 2000 and 2015. This means that cities are becoming less dense as they grow, with unplanned urban sprawl negatively affecting the sustainability of urban development. 


\section{Municipal waste collection reaches only 65 per cent of urban dwellers worldwide}

Proper management of solid waste-through waste reduction, reuse, recycling and composting, incineration or disposal in landfillsis a basic component of sustainable cities. When left uncollected or improperly managed, solid waste can end up blocking drains or festering in open dump sites, resulting in a host of unsanitary conditions. As cities and their populations expand, so does their urban waste, though quantitative estimates remain challenging. According to data from cities in 101 countries from 2009 to 2013, approximately 65 per cent of the population is served by municipal waste collection. The lowest coverage was found in sub-Saharan Africa and Central and Southern Asia, at around 40 per cent. In many cities in these regions, open dumping remains a common practice.
Proportion of the population served by municipal waste collection, 2009-2013 (percentage)

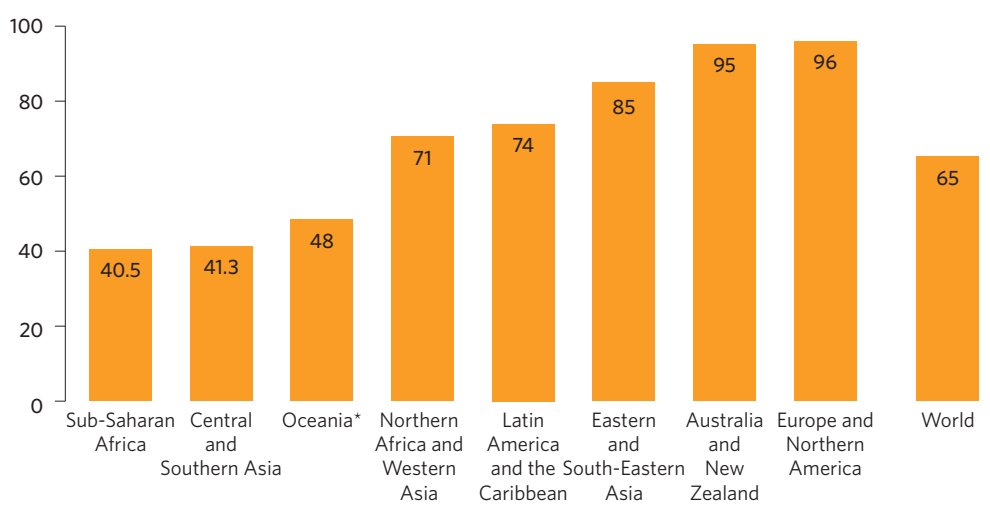

Note: Information in chart is based on data from cities in 101 countries.

\section{In most cities around the world, polluted air is an unavoidable and major health hazard}

Polluted air threatens the health of most city dwellers around the world. In 2014, nine out of 10 people living in urban areas did not breathe clean air, according to modelled data derived from satellite estimates and ground-level measurements in 3,000 cities in 103 countries. Clean air, in this case, refers to air that meets the annual World Health Organization (WHO) air quality guidelines value for particulate matter (PM2.5) of 10 micrograms per cubic metre. Striking differences are found among regions: in Australia and New Zealand, for example, 100 per cent of city dwellers breathed clean air versus 50 per cent and 40 per cent, respectively, of urban populations in Oceania excluding Australia and New Zealand, and in Europe and Northern America. In contrast, none of the urban areas in subSaharan African countries or in Asian countries met the world air quality guidelines in 2014.
Proportion of the urban population living in areas that meet the annual WHO air quality guideline value for particulate matter of a diameter less than 2.5 micrometres (PM2.5), 2014 (percentage)

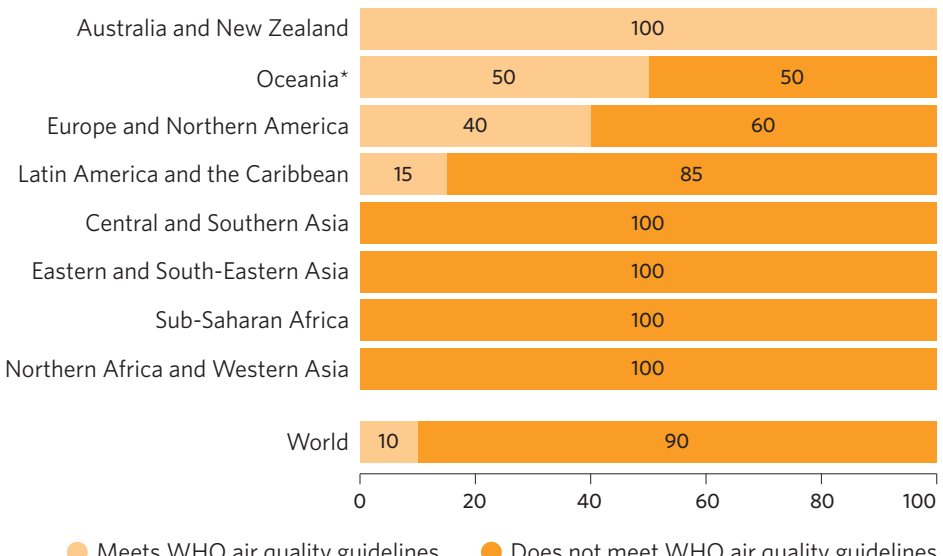

Proportion of countries in various stages of implementing a national urban policy, 2017 (percentage)

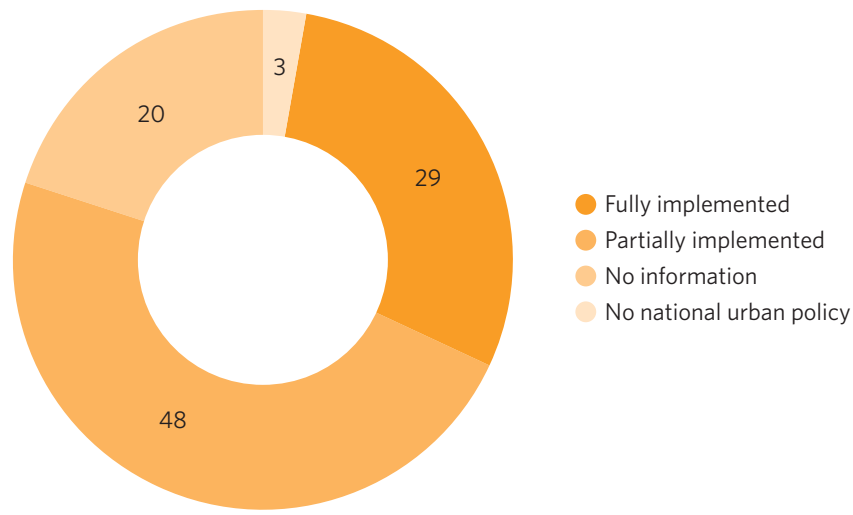

Note: Information in chart is based on data from 193 countries.

\section{More than $\mathbf{7 5}$ per cent of countries are engaged in coordinated urban planning}

National urban policies provide structure and organization to the often-haphazard process of urbanization. As such, these policies have been identified as key to the implementation of the SDGs. With input from regional and local levels, a national urban policy or regional development plan can ensure coordinated efforts among all levels of government and provide the best opportunity for sustainable urbanization. At the same time, these policies and plans promote stronger connections between urban, peri-urban and rural areas by linking sectorial policies that affect national, regional and local governments. As of May 2017, 149 countries (or 77 per cent) had fully or partially implemented national-level urban policies, most of which are aligned with priority areas identified in the SDGs. 


\section{Goal 12: Ensure sustainable consumption and production patterns}

Consumption and production patterns shape resource use management and related social and environmental impacts, thereby affecting sustainability. Sustainable production uses fewer resources for the same value of economic output, and sustainable consumption reduces the need for excessive resource extraction. Over the first decade of this century, however, the material footprint, which measures the amount of raw material extracted to meet consumption demand, increased globally, as did the amount of material used in production processes. Achieving this Goal requires strong national frameworks for sustainable consumption and production that are integrated into national and sectoral plans, along with sustainable business practices and consumer behaviour. Finally, it requires adherence to international norms related to hazardous chemicals and wastes.

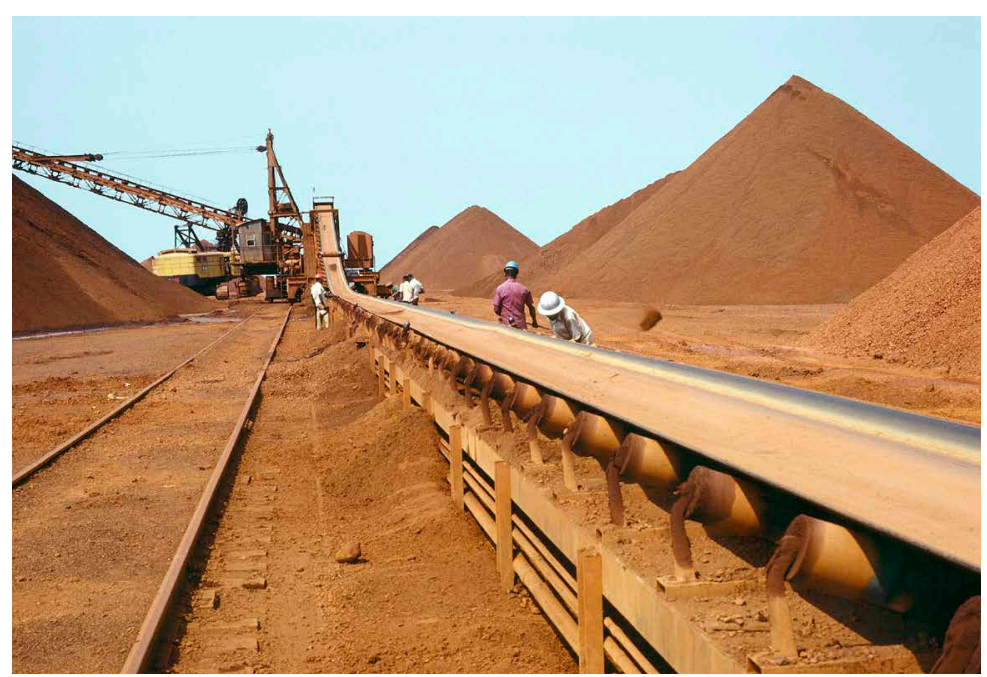

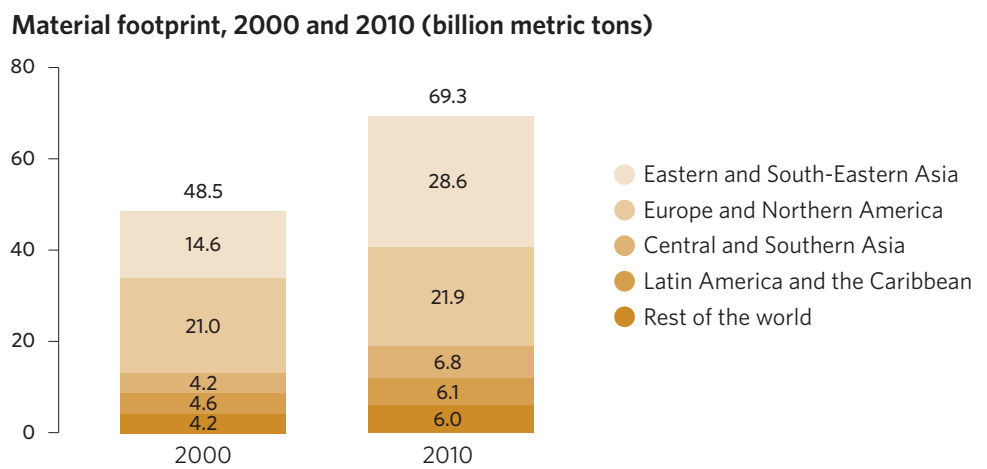

Note: Rest of the world includes regions whose material footprint is less than 4 billion metric tons each. These regions include Northern Africa and Western Asia, sub-Saharan Africa, Australia and New Zealand, and Oceania*. Because of rounding, numbers in chart may not add up to totals.

Material footprint per capita, 2000 and 2010 (metric tons per capita)

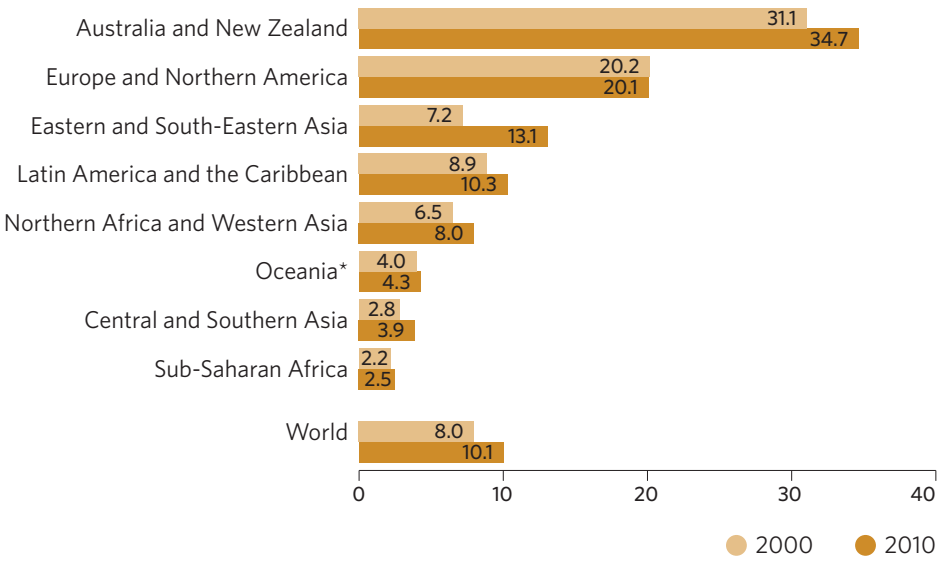

\section{The material footprint of a person in developed regions is considerably higher than that of a person in developing regions}

The term "material footprint" refers to the amount of raw materials extracted globally that are used to meet the domestic final consumption demand of a country. It highlights the volume of primary materials required across the entire supply chain-domestic and foreign-to meet consumption needs. Globally, the material footprint rose from 48.5 billion metric tons in 2000 to 69.3 billion metric tons in 2010. Two regions accounted for the largest share of this footprint: Eastern and South-Eastern Asia (28.6 billion metric tons) and Europe and Northern America (21.9 billion metric tons).

In per capita terms, the global material footprint increased as wellfrom 8 metric tons per capita in 2000 to 10.1 metric tons per capita in 2010. The material footprint per capita increased in almost all regions, meaning that the world now needs more raw materials to satisfy the consumption needs of an individual.

In 2010, Australia and New Zealand had the highest material footprint per capita (34.7 metric tons per person), while sub-Saharan Africa had the lowest ( 2.5 metric tons per person). The material footprint per capita of developed regions far exceeds that of the developing regions. In other words, much of the raw material extracted globally goes to serve the consumption needs and habits of individuals in developed regions. 


\section{Most regions have managed to use fewer resources per unit of production}

Domestic material consumption (DMC) refers to the amount of material used in production processes within an economy. DMC per unit of GDP is the amount of resources required to produce a unit of output. From 2000 to 2010, DMC per GDP decreased in all regions except Eastern and South-Eastern Asia, and Northern Africa and Western Asia. In Eastern and South-Eastern Asia, DMC per unit of GDP increased from 2.0 to 2.7 kilograms over that period. This is mainly due to the global shift in manufacturing to this region and the rapid industrialization that followed. As a result, DMC per unit of GDP increased globally from 1.2 kilograms to 1.3 kilograms. Total DMC also rose over this period, from 48.7 billion metric tons to 71 billion metric tons; Eastern and South-Eastern Asia accounted for 42 per cent of all materials consumed in 2010.
Domestic material consumption per unit of GDP, 2000 and 2010 (kilogram per unit of GDP)

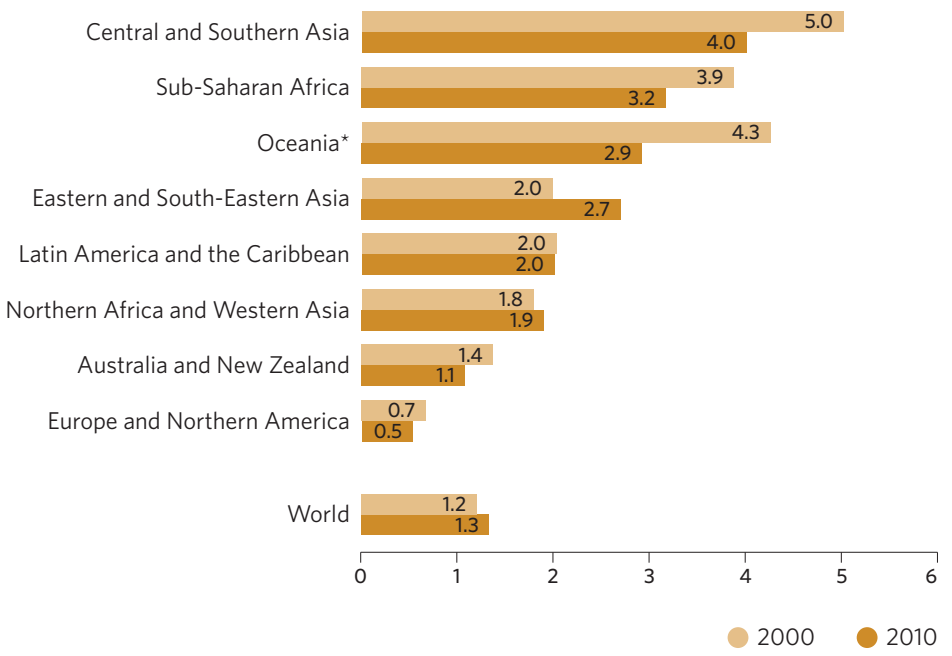

\section{Many countries still fail to fully meet their reporting commitments under key global environmental agreements on chemical and hazardous waste}

Countries continue to address air, soil and water pollution, and exposure to toxic chemicals, under the auspices of various multilateral agreements. These include the Montreal Protocol on Substances that Deplete the Ozone Layer, the Basel Convention on the Control of Transboundary Movements of Hazardous Wastes and their Disposal, the Rotterdam Convention on the Prior Informed Consent Procedure for Certain Hazardous Chemicals and Pesticides in International Trade, and the Stockholm Convention on Persistent Organic Pollutants. Furthermore, the new Minamata Convention on Mercury will enter into force on 16 August 2017. Almost all United Nations Member States are party to at least one of these conventions and 157 of them are party to three. Under the current conventions' obligations, countries are requested to regularly report data and information related to hazardous wastes, persistent organic pollutants and ozonedepleting substances. However, between 2010 and 2014, only 51 per cent of Parties to the Stockholm Convention, 57 per cent of Parties to the Basel Convention, and 71 per cent of Parties to the Rotterdam Convention provided the requested data and information. All Parties reported to the Montreal Protocol.
Global transmission rate ${ }^{\dagger}$ for the Montreal Protocol, Rotterdam, Base and Stockholm Conventions, 2010-2014 (percentage)
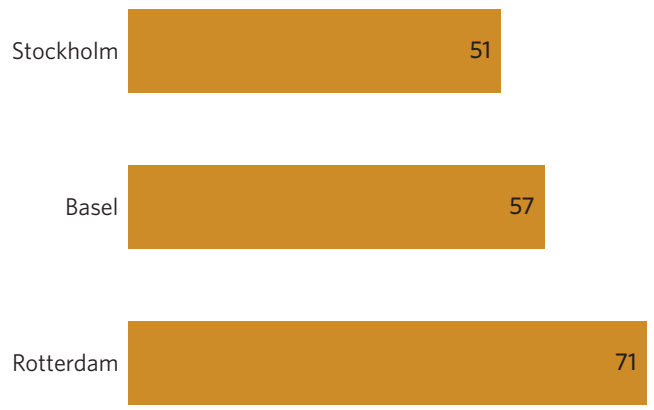

Montreal Protoco

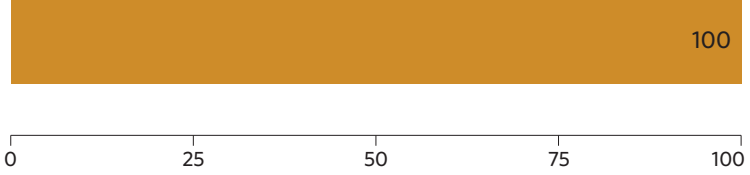

$\dagger$ Transmission rate is defined as the percentage of all commitments fulfilled in transmitting data and information by a Party as required by each agreement. Under the Stockholm Convention, national reports are to be submitted every four years. Under the Basel Convention, national reports are to be submitted annually. Under the Rotterdam Convention, there is no such national report requirement. However, Parties are obliged to submit decisions concerning the future importation of the chemicals listed under the convention. 


\section{Goal 13: Take urgent action to combat climate change and its impacts}

Climate change is already having a profound and alarming impact worldwide. Global temperatures continued to increase in 2016, setting a new record of about 1.1 degrees Celsius above the pre-industrial period. The extent of global sea ice fell to 4.14 million square kilometres in 2016, the second lowest on record. Atmospheric $\mathrm{CO}_{2}$ levels reached 400 parts per million. Drought conditions predominated across much of the globe, influenced by the El Niño phenomenon. In addition to rising sea levels and global temperatures, extreme weather events are becoming more common and natural habitats such as coral reefs are declining. These changes affect people everywhere, but disproportionately harm the poorest and the most vulnerable. Concerted action is urgently needed to stem climate change and strengthen resilience to pervasive and ever-increasing climate-related hazards.

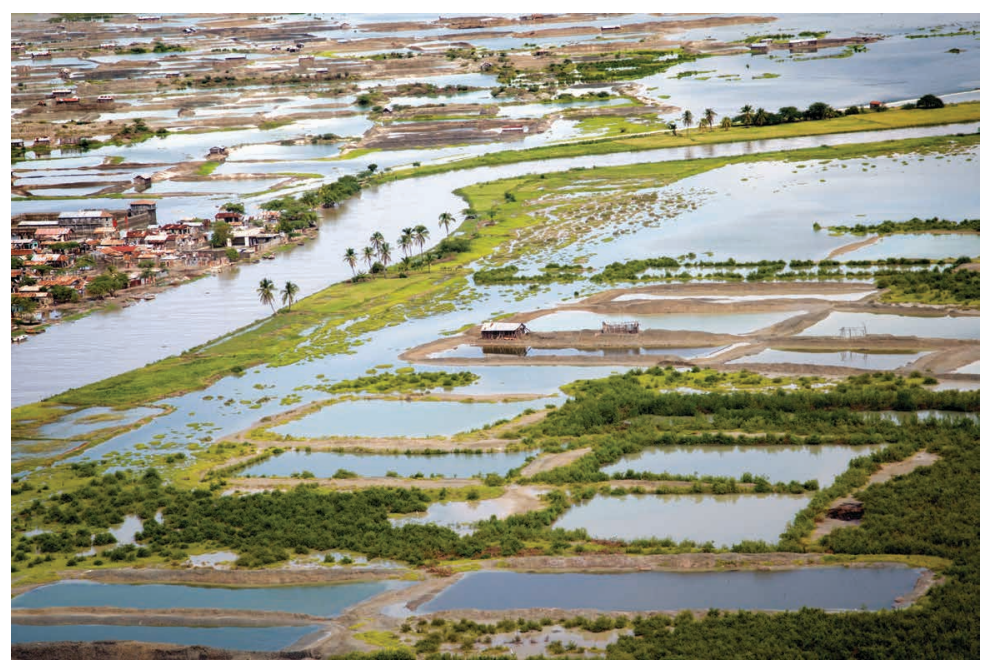

\section{Countries' commitment to taking climate action is gaining momentum, as indicated by the early entry into force of the Paris Agreement}

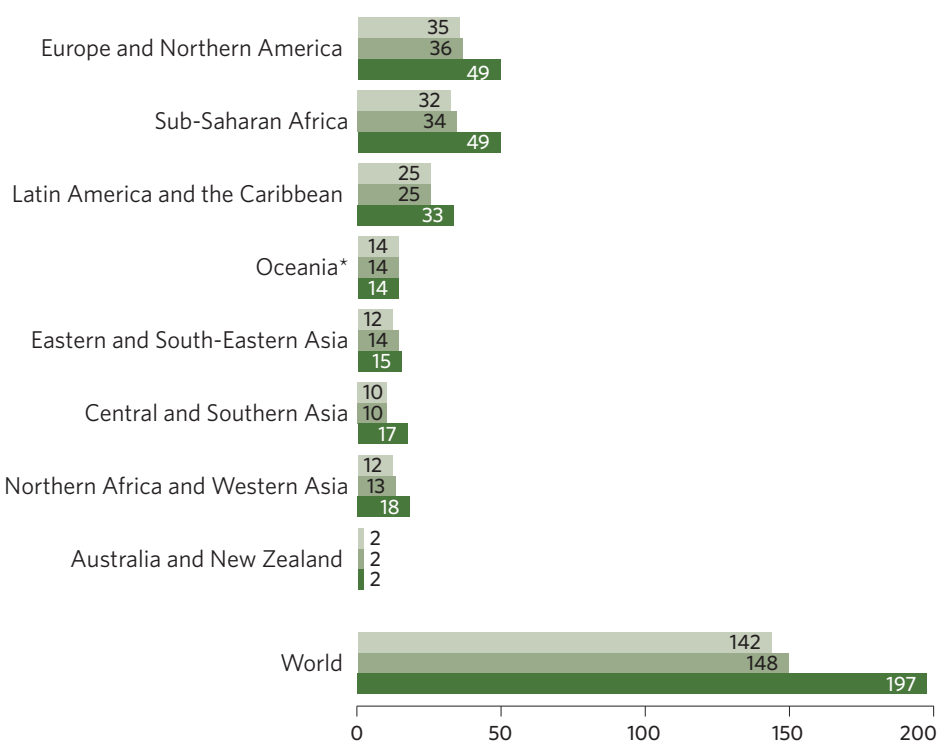

NDC submitted Paris Agreement ratified Total number of Parties to the UNFCCC
The landmark Paris Agreement brings nations together to strengthen the response to climate change. It aims to keep the global temperature rise this century to well below 2 degrees Celsius above pre-industrial levels and as close as possible to 1.5 degrees, while building countries' resilience to the adverse effects of climate change. The Agreement entered into force on 4 November 2016, marking a shift in focus towards implementation. It also signals the commitment of nations to take action for the climate and sustainable development, translating the goals of the Paris Agreement into actionable strategies and shifting global financial flows onto lowcarbon, climate-resilient pathways. As of 7 June 2017, 148 parties had ratified the Paris Agreement. In parallel with the Agreement, a push to develop and implement initiatives to enhance financial flows, technologies and capacity-building efforts to support developing and most vulnerable countries is underway.

Parties to the Paris Agreement are expected to prepare, communicate and maintain successive nationally determined contributions (NDCs). NDCs highlight climate-related targets, policies and actions planned in response to climate change. Countries' NDCs relayed so far reveal linkages across all SDGs. They outline development approaches and actions aimed at lowering greenhouse gas emissions and building climate resilience. The NDCs show that governments are integrating climate action into socio-economic development strategies, since both are integral to sustainable development. As of 7 June 2017, 142 Parties ( 141 countries plus the European Commission) had communicated their first NDCs to the United Nations Framework Convention on Climate Change Secretariat (UNFCCC). 


\section{Countries are preparing and implementing national plans to adapt to climate change and enhance resilience}

The national adaptation plan (NAP) process is designed to help developing countries identify their medium- and long-term needs for adaptation to the effects of climate change, and to formulate and implement strategies and programmes to address those needs. It is a continuous, progressive and iterative process with a country-driven, gender-sensitive, participatory and fully transparent approach. Implementation helps countries reduce their vulnerability to the impacts of climate change by building adaptive capacity and resilience, and by integrating climate change adaptation into development planning processes and strategies. As of 7 June 2017, seven countries had completed and submitted the first iteration of their NAP; the process in many other countries is under way. Progress is expected to accelerate with support from the Green Climate Fund, which is mandated to provide expedited support to LDCs and other developing countries in the formulation and implementation of NAPs.
Number of developing countries that have undertaken specific measures to lay the groundwork for and address gaps in formulating and implementing NAPs, 2017

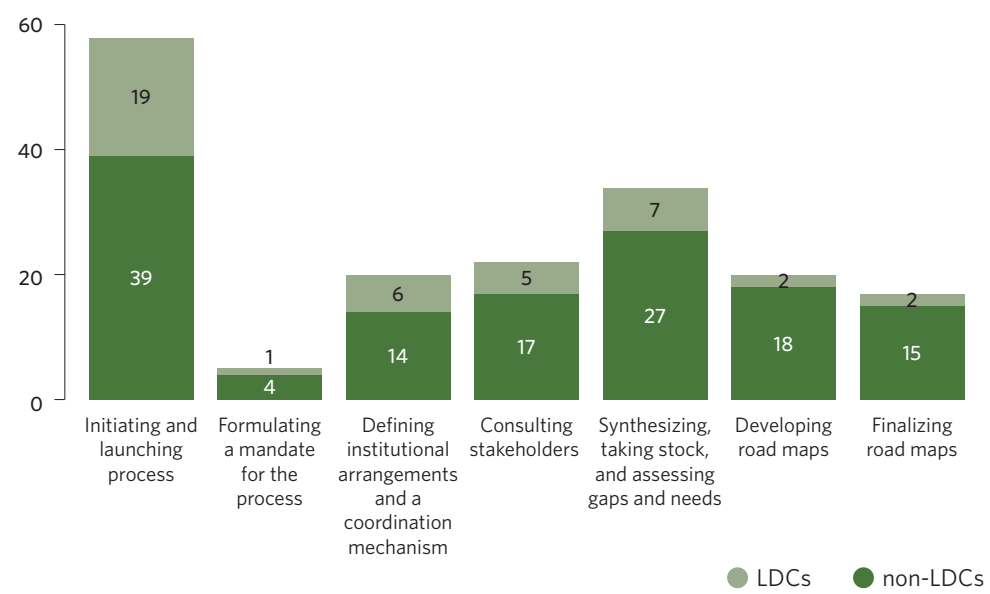

Note: The seven measures listed in the chart correspond to the first measures included in Element A of the process to formulate and implement NAPs. Subsequent elements include preparatory elements (Element $B$ ), implementation strategies (Element $C$ ), and reporting, monitoring and review (Element D). "Non-LDCs" refers to developing country Parties that are not least developed countries.

\section{Disaster risk reduction has the potential to reduce the rising toll of human lives from smaller-scale events}

Between 1990 and 2015, more than 1.6 million people died in internationally reported natural hazards, and the trend is moving upward. Since mortality is often concentrated in very intensive disasters, it is difficult to perceive trends over relatively short periods of time. However, data on smaller-scale disasters show a statistically significant trend towards increasing mortality in events with fewer than 100 deaths. A similar study taking into consideration population growth also showed an upward trend. Disaster mortality reflects not only exposure to hazards, but also a confluence of other vulnerability factors, such as poor urban management, environmental degradation, lack of disaster preparedness, and poverty and inequality. Moreover, these underlying risk factors are responsible for most morbidity resulting from natural hazards, and tend to affect low-income households and communities and small businesses disproportionally. The data suggest that an increased focus on disaster risk reduction is a prudent investment for saving lives.
Total number of deaths from natural hazards (geological and hydrometeorological events) resulting in fewer than 100 deaths, 1990-2013

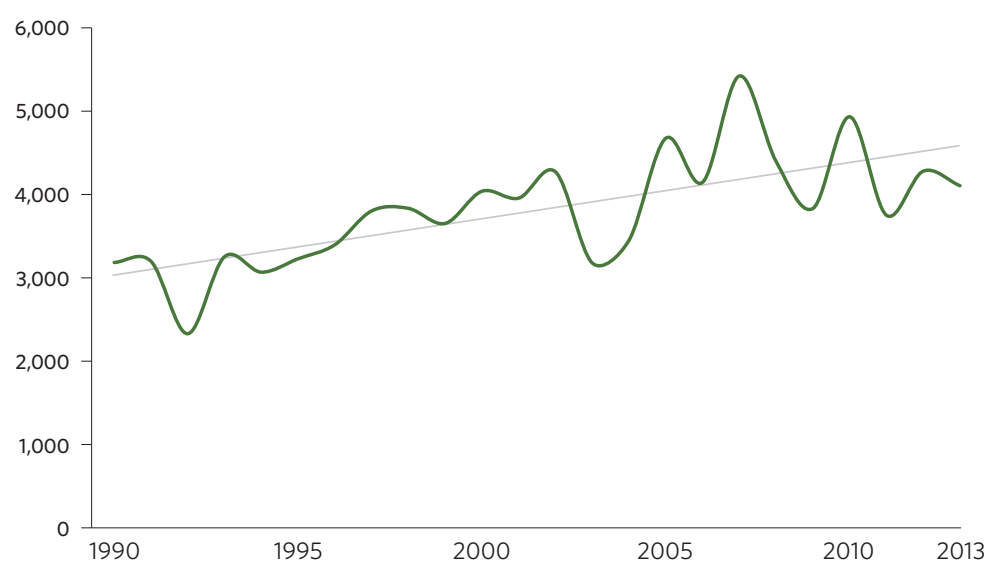

Note: Geological events include earthquakes, mass movement (dry) and volcanic activity. Hydrometeorological events include floods, storms, landslides, extreme temperatures, drought and wildfires.

\section{Disaster risks are magnified by poverty, inequality, environmental degradation and poor urban planning}

Reducing risks associated with natural hazards requires a comprehensive approach that prevents new risk, minimizes existing risk, and strengthens economic, social, health and environmental resilience. Over the last decade, countries have made progress in managing the worst impacts of disasters, mainly by developing institutions and policies for disaster risk reduction and strengthening capacity for disaster preparedness, response and early warning. That said, progress has been limited in tackling the underlying drivers of disaster risk-poverty, poor urban planning and land use, weak environmental and resource management, and climate change. Countries have thus begun implementing national and local disaster risk reduction strategies that also address these risk factors. Of 96 countries that reported data, all used environmental impact assessments as a mechanism to address such factors.

However, only 51 countries used payment for ecosystem services as a mechanism, which is known to promote better land management and the protection of ecological services.
Number of countries with mechanisms for reducing underlying disaster risk factors, 2014-2015

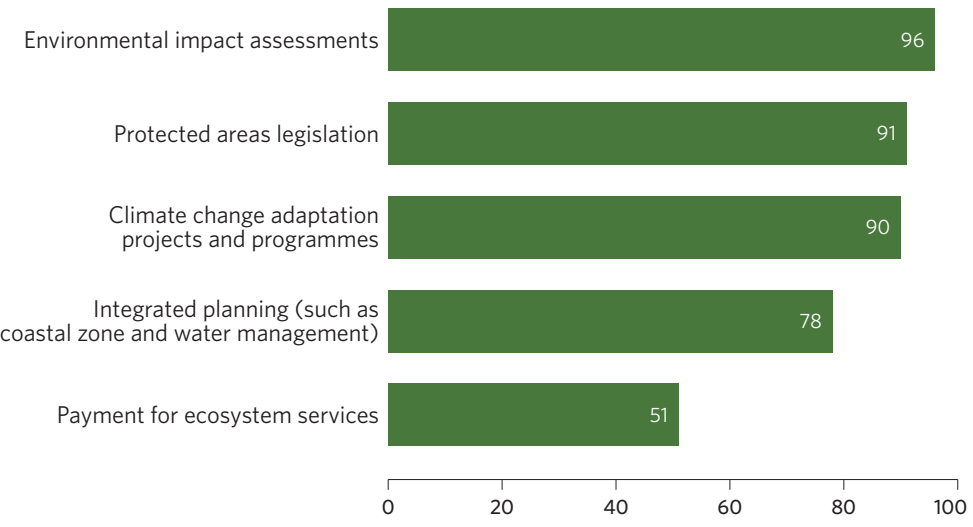

Note: Based on data reported by 96 countries. 


\section{Goal 14: Conserve and sustainably use the oceans, seas and marine resources for sustainable development}

Oceans cover almost three quarters of the planet, comprising the largest ecosystem on Earth. Large coastal populations in every region depend on them for their livelihoods and prosperity. Oceans also provide priceless environmental services: they generate half the oxygen we breathe, support a wealth of marine resources and act as a climate regulator. Yet despite their critical importance, the mounting impacts of climate change (including ocean acidification), overfishing and marine pollution are jeopardizing progress in protecting the world's oceans. Small island developing States are the most threatened. Due to the transboundary nature of oceans, marine resource management requires interventions at all levels (national, regional and global) to mitigate threats.

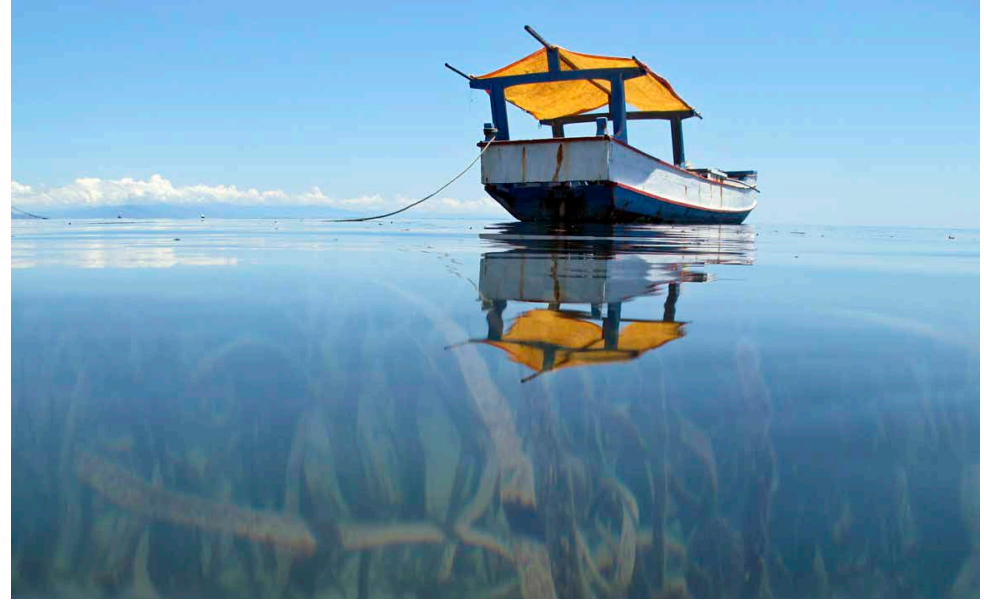

Proportion of marine areas within national jurisdiction (0-200 nautical miles) covered by protected areas, 2017 (percentage)

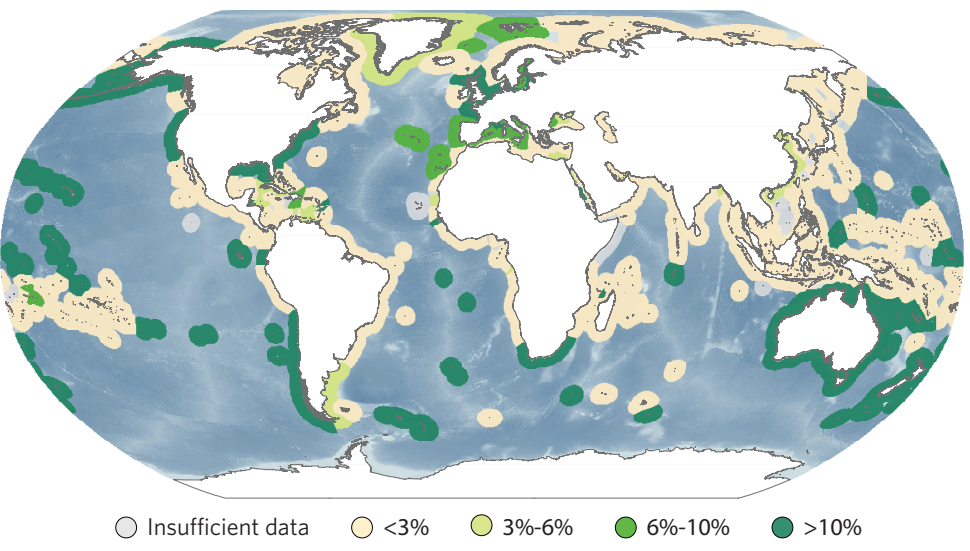

Note: The global map is for illustrative purposes only and does not imply the expression of any opinion whatsoever concerning the legal status of any country or territory, or concerning the delimitation of its frontiers or boundaries.

Average proportion of each important site (KBA) for marine biodiversity that is covered by protected areas, 2000 and 2017 (percentage)

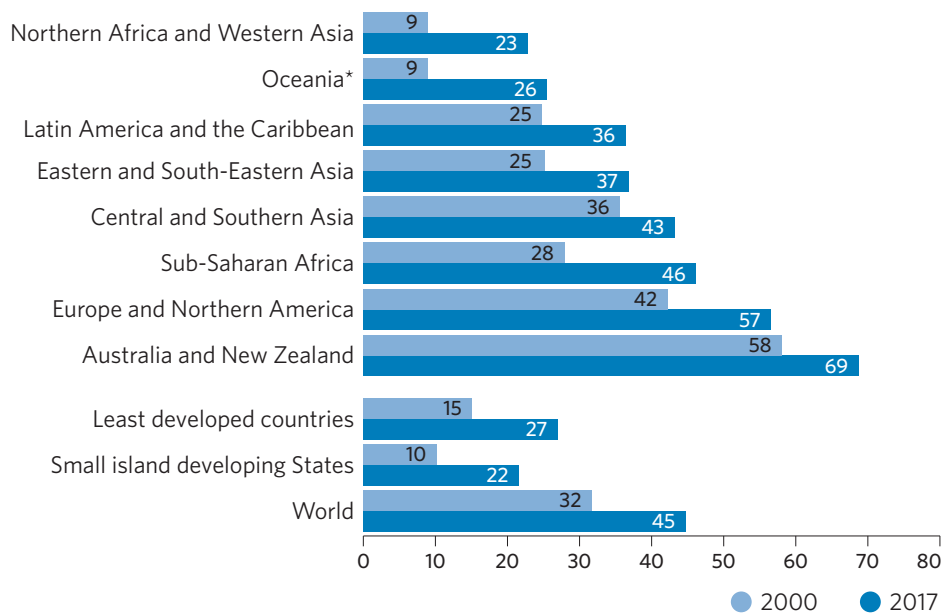

Note: Figures for each region are calculated as the proportion of each KBA covered by protected areas, averaged across all KBAs within the region.

\section{Efforts in some countries continue to yield significant progress in the extent of marine protected areas}

When effectively managed and well-resourced, marine protected areas are important mechanisms for safeguarding ocean life. In 2017, protected areas cover 13.2 per cent of the marine environment under national jurisdiction (up to 200 nautical miles from shore), 0.25 per cent of the marine environment beyond national jurisdiction, and 5.3 per cent of the total global ocean area. Globally, marine protected areas have expanded substantially since 2000 , when only 1.7 per cent of global marine areas were protected. This growth is due to the creation of new sites, expansion of existing sites and contributions of several large-scale additions. Much of the increase over the last few years was due to these large additional sites, particularly off the coasts of Australia, Chile, New Zealand, Palau and the United States, among others.

To achieve the desired long-term benefits of protecting nature, these protected areas must safeguard important sites for biodiversity. An example of such areas is key biodiversity areas (KBAs). Globally, the average coverage of marine KBAs by protected areas has risen from 32 per cent in 2000 to 45 per cent in 2017, an increase of more than 40 per cent. Coverage of marine KBAs by protected areas is highest in Australia and New Zealand (69 per cent) and Europe and Northern America (57 per cent). It is lowest in the small island developing States (22 per cent) and Northern Africa and Western Asia (23 per cent). 


\section{Overfishing threatens about one third of the world's fish stocks}

Fisheries are a source of food and livelihoods for billions of people around the globe. However, they are also extremely vulnerable to environmental degradation, climate change and overfishing. If fisheries are not managed sustainably and are overfished, food production declines, the functioning of ecosystems is impaired, and biodiversity is compromised. The proportion of world marine fish stocks that have been overfished-that is, are at biologically unsustainable levels-increased from 10 per cent in 1974 to 31 per cent in 2013. However, the trend has slowed and appears to have stabilized between 2008 and 2013. Of the 10 most productive species in marine capture fisheries production in 2013, most were fully fished, while some stocks were considered overfished. For example, Atlantic cod is considered overfished in the Northwest Atlantic; 41 per cent of principal tuna species have been placed in the same category. Overfished stocks require strict management plans to rebuild stock abundance to their full and biologically sustainable levels of productivity.
Proportion of fish stocks within biologically sustainable and biologically unsustainable levels, 1974-2013 (percentage)

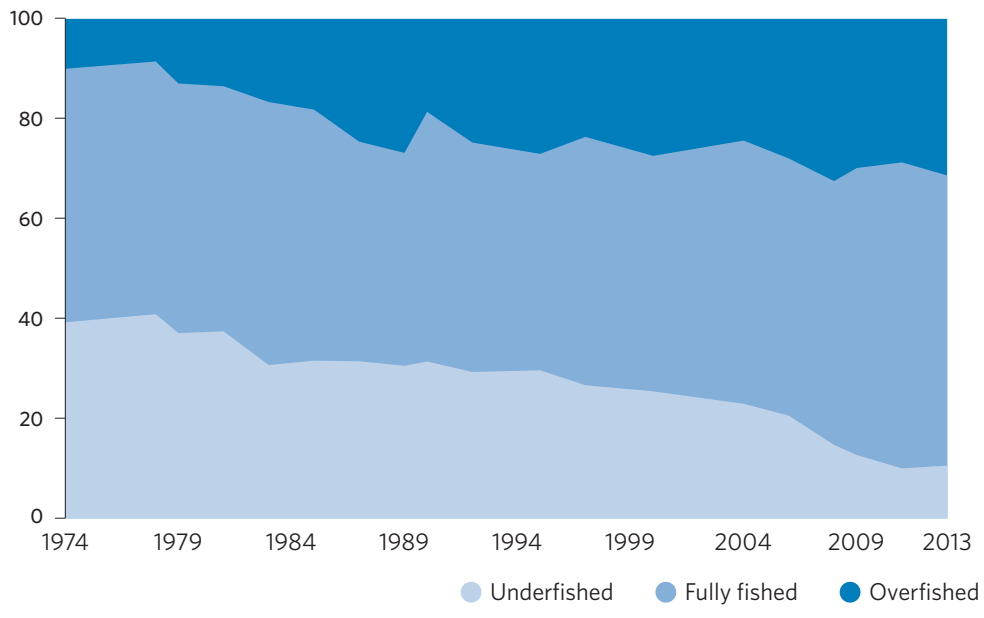

Note: Underfished and fully fished stocks are considered within biologically sustainable levels Overfished stocks are considered at biologically unsustainable levels.

\section{Increasing ocean acidification levels endanger marine ecosystems worldwide}

Oceans absorb up to 30 per cent of the annual emissions of $\mathrm{CO}_{2}$ generated by human activity, helping mitigate the rise in greenhouse gases. However, this benefit comes at a steep ecological cost: the absorbed $\mathrm{CO}_{2}$ alters the carbonate chemistry of the waters, leading to an increase in the acidity of seawater (reduced $\mathrm{pH}$ ) and a decrease of the aragonite saturation state. These changing conditions can lead to significant weakening of the shells and skeletons of many marine species (such as reef-building corals and shelled molluscs, which use aragonite to build their shells). These effects threaten the resilience of marine ecosystems, particularly corals, and could potentially put the marine food web at risk.

Studies at open ocean and coastal sites around that world have revealed that current levels of marine acidity have increased on average by about 26 per cent since the start of the Industrial Revolution ( $\mathrm{pH}$ reduction of 0.1 ) and that marine life is exposed to conditions outside previously experienced natural variability at all study locations around the world. In some regions, the changes are amplified by natural processes such as upwelling (often cold, $\mathrm{CO}_{2}$ and nutrient-rich water from the deep sea rising towards the surface), resulting in conditions outside biologically relevant thresholds.

As atmospheric $\mathrm{CO}_{2}$ levels increase, estimates indicate that oceans could be nearly 150 per cent more acidic by 2100 , resulting in a $\mathrm{pH}$ reduction of up to 0.4 . While the magnitude of carbon input is important, more stressful is the speed at which ocean acidification is occurring-faster than at any time since the last ice age. It could take tens of thousands of years for the ocean $\mathrm{pH}$ to return to conditions established before industrialization. Without sufficient time to buffer the consequences of ocean acidification, the severity and speed of change increase the risks for ocean health.

\section{Without concerted action, coastal eutrophication will increase in one fifth of large marine ecosystems by 2050}

Global trends point to continued deterioration of coastal waters due to pollution and eutrophication (excessive nutrients in water, frequently due to runoff from land, causing dense plant growth and the death of animal life from lack of oxygen). Large urban populations and intensive agricultural production or livestock are often associated with coastal eutrophication. Of the 63 large marine ecosystems evaluated under the Transboundary Water Assessment Programme, 16 per cent are in the "high" or "highest" risk categories for coastal eutrophication, particularly from sewage and agriculture. They are primarily located off the coasts of Western Europe and Southern and Eastern Asia, and in the Gulf of Mexico. Most major marine ecosystems are still considered in the "lowest" or "low" risk category. By 2050, however, it is estimated that coastal eutrophication will increase in 21 per cent of these large ecosystems. To tackle these risks, nutrient inputs need to be reduced through sewage treatment and initiatives addressing agricultural practices.
Merged nutrient risk indicator of large marine ecosystems projected to 2050

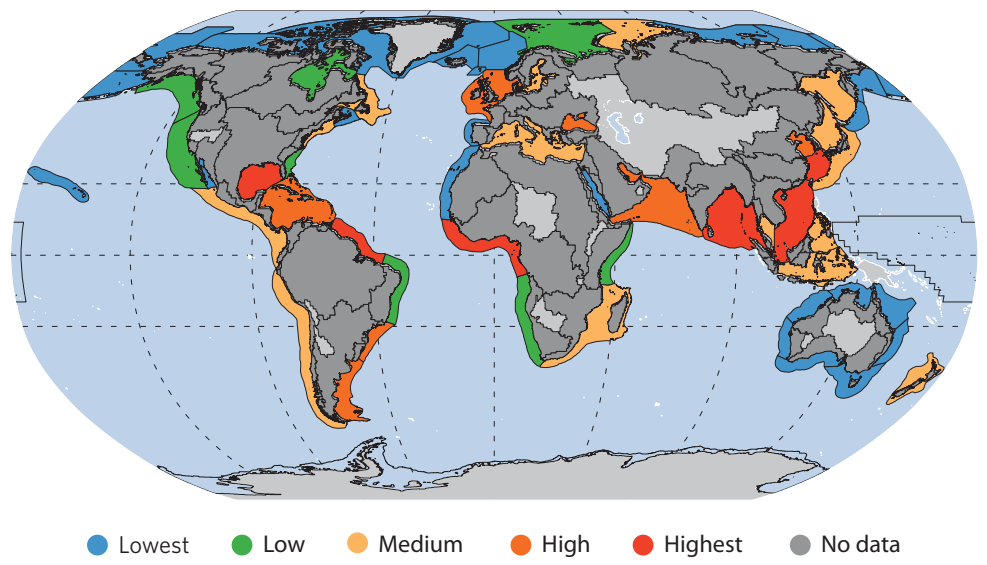

Note: The global map is for illustrative purposes only and does not imply the expression of any opinion whatsoever concerning the legal status of any country or territory, or concerning the delimitation of its frontiers or boundaries. 


\section{Goal 15: Protect, restore and promote sustainable use of terrestrial ecosystems, sustainably manage forests, combat desertification, and halt and reverse land degradation and halt biodiversity loss}

Protected and restored ecosystems and the biodiversity they support can help mitigate climate change and provide increased resilience in the face of increased human pressures and mounting disasters. Healthy ecosystems also produce multiple benefits for all communities: clean air, water, food, raw materials and medicines, to name a few. To date, progress in preserving and sustainably using terrestrial ecosystems and protecting biodiversity has been uneven. The pace of forest loss has slowed, and improvements continue to be made in managing forests sustainably and safeguarding areas important for biodiversity. That said, accelerating biodiversity loss, along with continued poaching and trafficking of wildlife, is alarming. Moreover, from 1998 to 2013, about one fifth of the Earth's land surface covered by vegetation showed persistently declining trends in productivity. Soil and land degradation undermines the security and development of all countries.

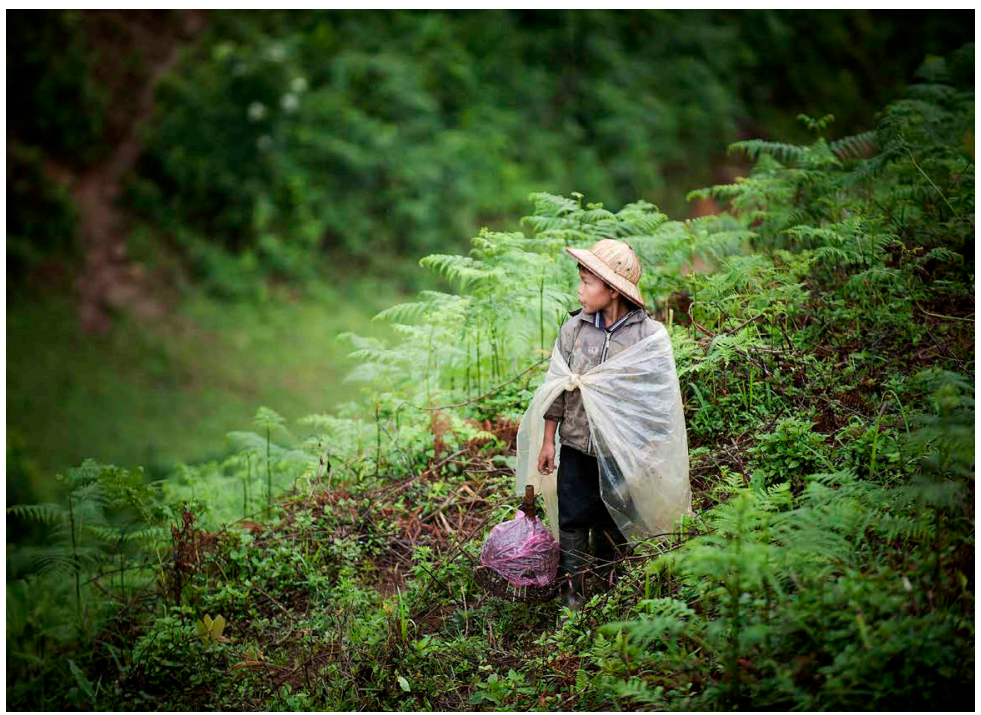

\section{More key biodiversity areas are being protected, although progress has slowed in recent years}

Globally, 15 per cent of terrestrial and freshwater environments are covered by protected areas. These areas can play a critical role in achieving sustainable development if they are effectively managed and strategically located. Protecting key biodiversity areas (KBAs) sites that contribute significantly to global biodiversity-is necessary to strengthen natural resource management and biodiversity conservation. To date, more than 15,000 KBAs have been identified worldwide.
Protecting key sites important for terrestrial, freshwater and mountain biodiversity is vital for ensuring long-term and sustainable use of these various natural resources. Globally, between 2000 and 2017, average coverage of terrestrial, freshwater and mountain KBAs by protected areas increased from 35 to 47 per cent, from 32 to 43 per cent, and from 39 to 49 per cent, respectively. While this upward trend is encouraging, recent growth in KBAs covered by protected areas has been modest, with an increase of only 1 to 2 percentage points since 2010

Average proportion of each terrestrial, inland freshwater and mountain KBA that is covered by protected areas, 2000,2010 and 2017 (percentage)

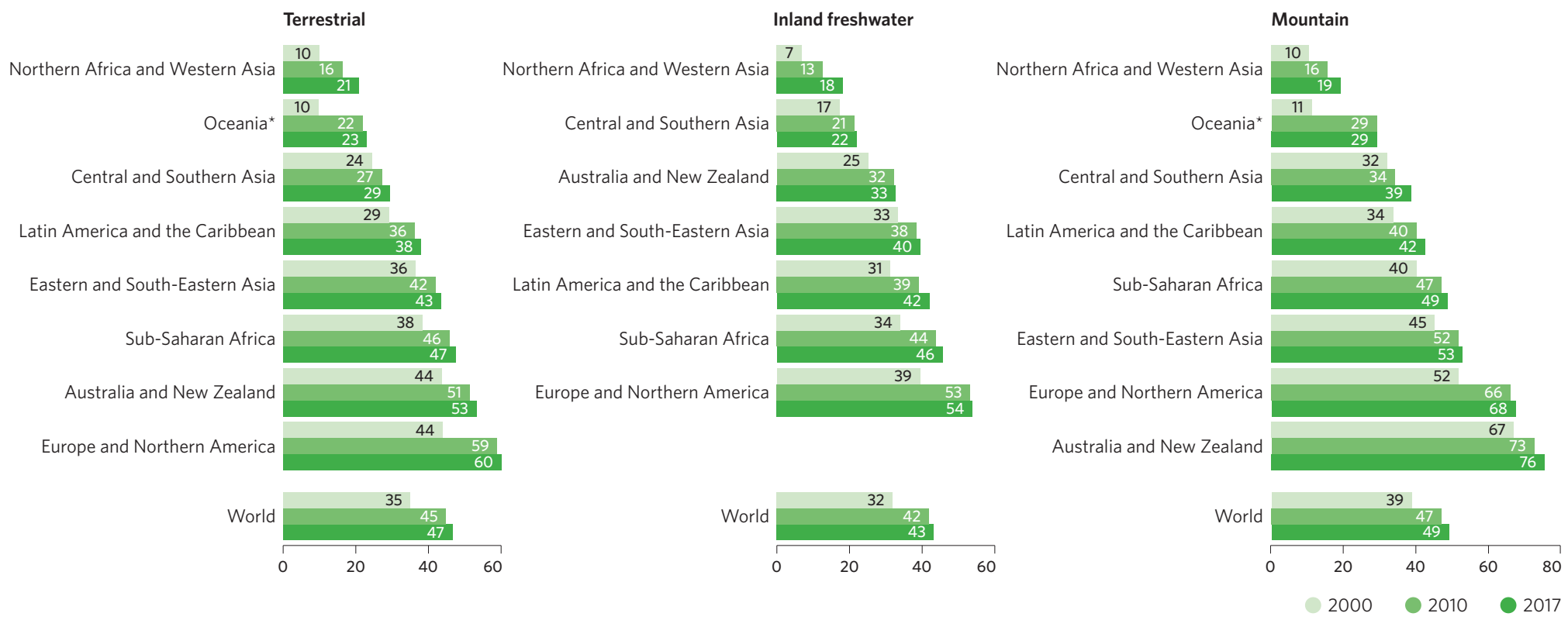




\section{The world's forest area continues to shrink, but the rate of loss is slowing}

Forests protect watersheds, mitigate natural disasters, nurture biodiversity and sequester carbon. While the world's forest area continues to shrink, the pace of forest loss has slowed. From 2010 to 2015 , the annual net loss of forest area worldwide was less than half that of the 1990s. More forests are being protected, and areas under long-term management plans and voluntary certification have increased. The proportion of land area covered by forest decreased from 31.6 per cent in 1990 to 30.8 per cent in 2010 and 30.6 per cent in 2015. Most forest loss can be attributed to deforestation in sub-Saharan Africa and in Latin America and the Caribbean.
Forest area as a proportion of total land area, 1990, 2010 and 2015 (percentage)

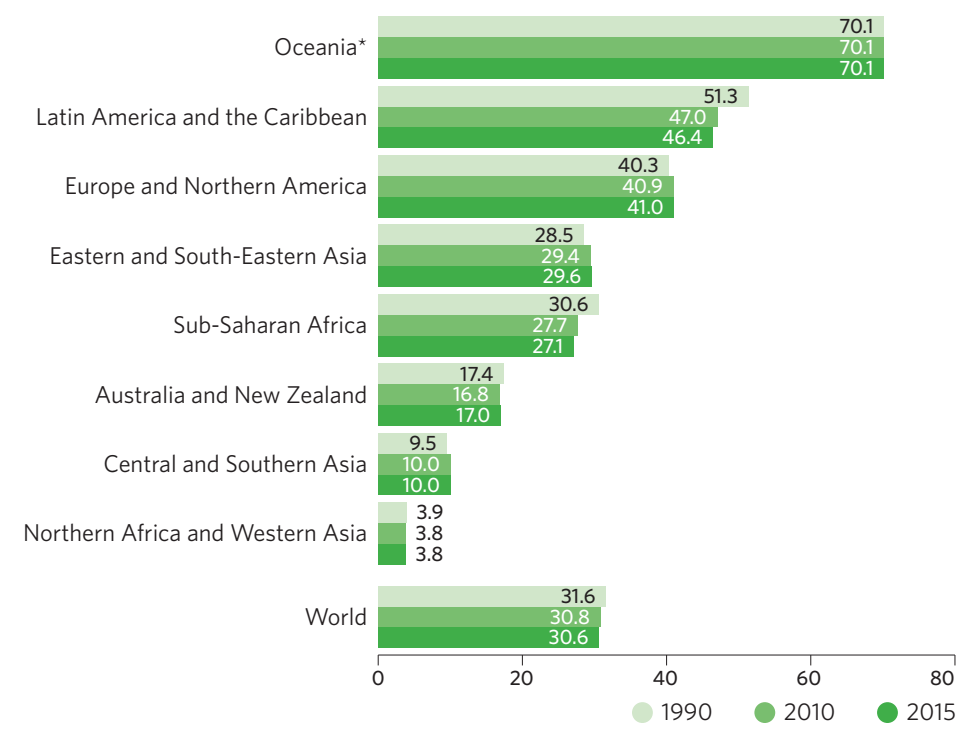

\section{Corals, amphibians and cycads face a growing threat of extinction}

Biodiversity loss is occurring at an alarming rate, according to the Red List Index. The index measures trends in the extinction risk of various species. Available data indicate that three groups-corals, amphibians and cycads-are in serious decline due to distinct and worsening threats. Bleaching, driven by climate change and local impacts, has affected the health of coral reefs worldwide. Reefs support the highest level of marine biodiversity in the world, yet they are in jeopardy of disappearing completely by 2050 . Severe bleaching events are already affecting reefs, as seen in the Great Barrier Reef during 2016 and 2017.

Amphibians also face a high risk of extinction, with 41 per cent already threatened. Many amphibian species are found in a single location, and habitat loss and the spread of disease, such as chytrid fungal disease, present a grave danger. Meanwhile, many cycads, an ancient group of cone-producing plants, are threatened by unsustainable exploitation and habitat destruction.
Red List Index of species survival, 1980-2016

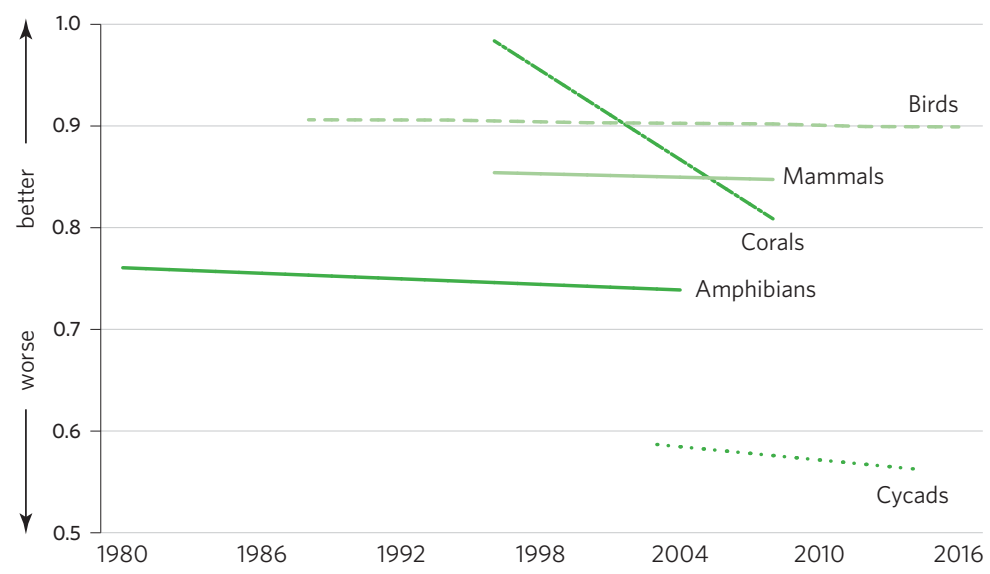

Note: A Red List Index value of 1.0 means that all species are categorized as of "Least concern"; hence, none are expected to become extinct in the near future. A value of zero indicates that all species have gone extinct.

\section{Illicit poaching and trafficking of wildlife poses a threat to the survival of many species}

Illicit poaching and trafficking of wildlife continues to thwart conservation efforts, with nearly 7,000 species of animals and plants reported in illegal trade involving 120 countries. Illicitly trafficked species are normally found far from their original source after having been transported through multiple countries. Iconic species, such as tigers, elephants and rhinos, along with many lesser-known animals, plants and marine life, face intense pressures for survival. Poached and trafficked wildlife are found in many distinct and often-unrelated markets. They are used in a range of industries, from furniture to fashion, each subject to unique dynamics and volatile trafficking patterns. Demand for a given wildlife product can grow quickly, before the international community can effectively respond. In 2013, elephant ivory, rosewood, rhinoceros horn and reptiles comprised 70 per cent of total wildlife seizures. Addressing these dynamics requires a detailed understanding of markets that make use of wild-sourced materials and products, along with greater regulation of these sectors.
Share of wildlife types among total seizures (standard value), 2005-2013 (percentage)

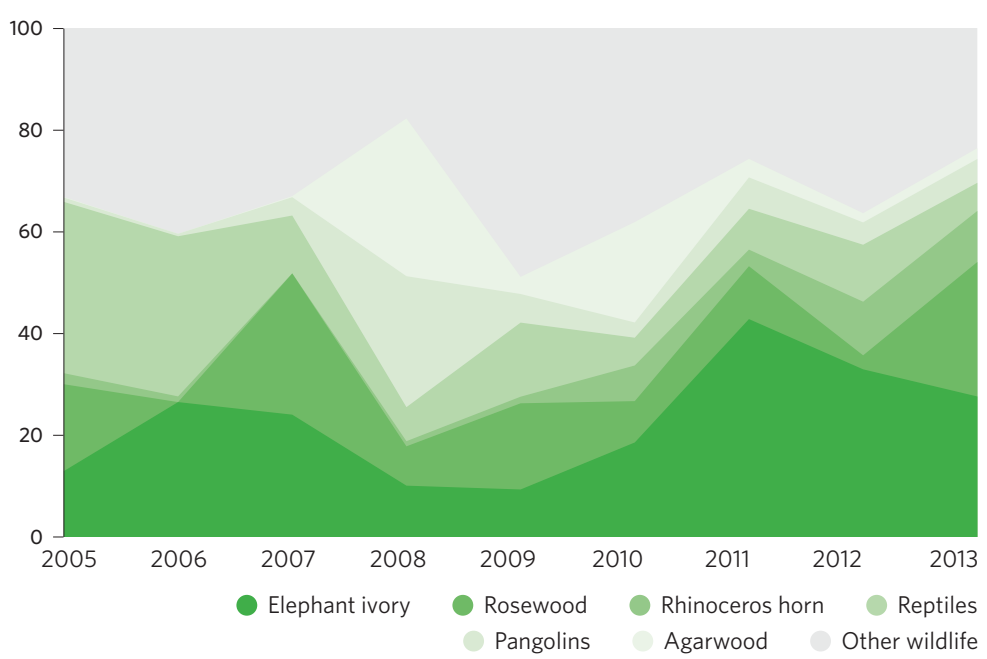

Note: Other wildlife include corals, sturgeons, marine turtles, parrots, big cats, tortoises, raptors and others. To combine seizures of disparate wildlife products, some common unit is required, and measures such as quantity and weight will not suffice. The "standard value" used here is based on declared import values for similar legal products in a reference market and is intended to give a sense of relative value, not an absolute monetary valuation. 


\section{Goal 16: Promote peaceful and inclusive societies for sustainable development, provide access to justice for all and build effective, accountable and inclusive institutions at all levels}

Progress in promoting peace and justice, and in building effective, accountable and inclusive institutions remains uneven across and within regions. Homicides are slowly declining, and more citizens around the world have better access to justice. However, violent conflicts have increased in recent years, and a number of high-intensity armed conflicts are causing large numbers of civilian casualties and driving millions of people from their homes. Disparities abound: data show that countries with higher income inequality suffer from higher levels of violence. Poorer countries and regions tend to be sources of victims for human traffickers and are more prone to corruption. In response, legal frameworks and institutions are being put in placefor example, on access to information and human rights promotion-but implementation does not always follow suit.

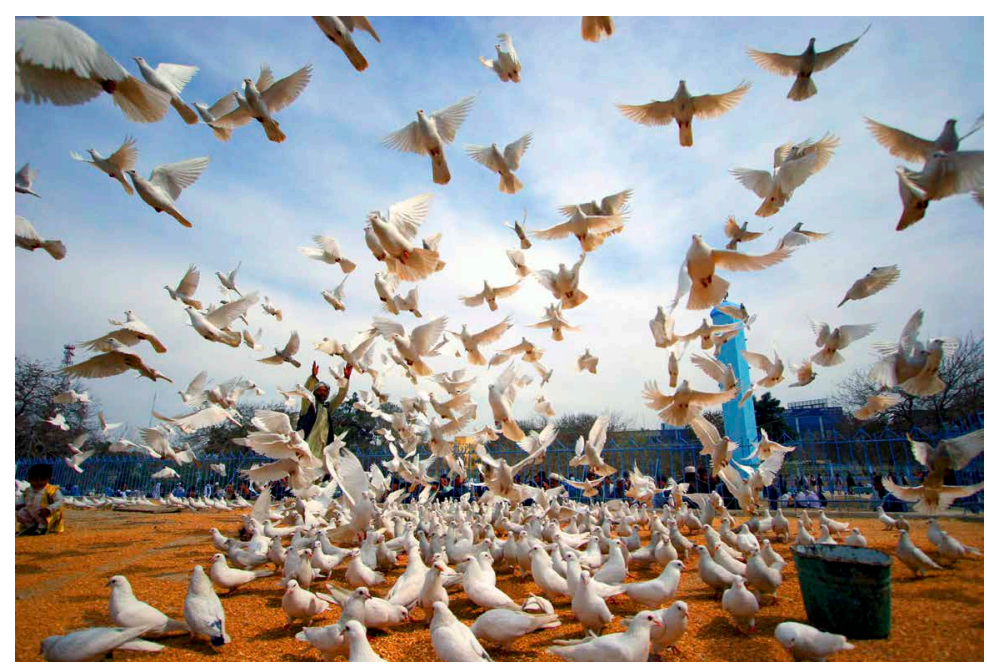

Number of victims of intentional homicide per 100,000 population, 2015 or latest year

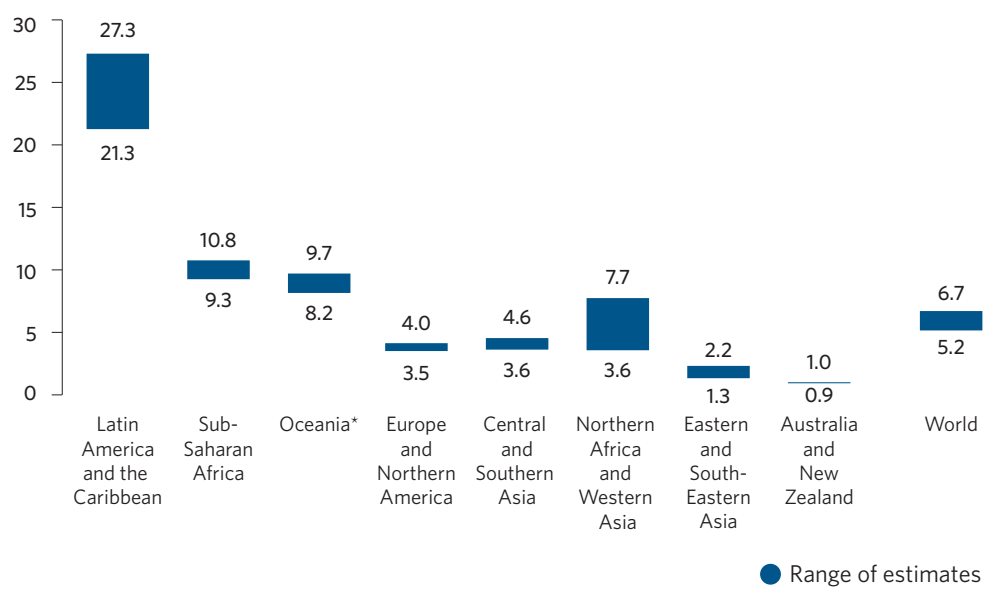

\section{A decline in homicide rates over the past decade hides} wide disparities among countries and regions

In 2015, between 5.2 and 6.7 persons per 100,000 people worldwide were victims of intentional homicide. While intentional homicides saw an overall decline over the past decade, people in some countries in Latin America, sub-Saharan Africa and Asia face a heightened risk of becoming a victim. The incidence of intentional homicide continues to vary markedly across regions. Latin American and the Caribbean had the highest rate by far17 times that of Eastern and South-Eastern Asia and 20 times the rate in Australia and New Zealand. The majority of homicide victims are male. In recent years, four to five times as many males as females were murdered annually.
Number of victims of intentional homicide per 100,000 population, by income inequality (as measured by a country's Gini index), 2005 and 2015
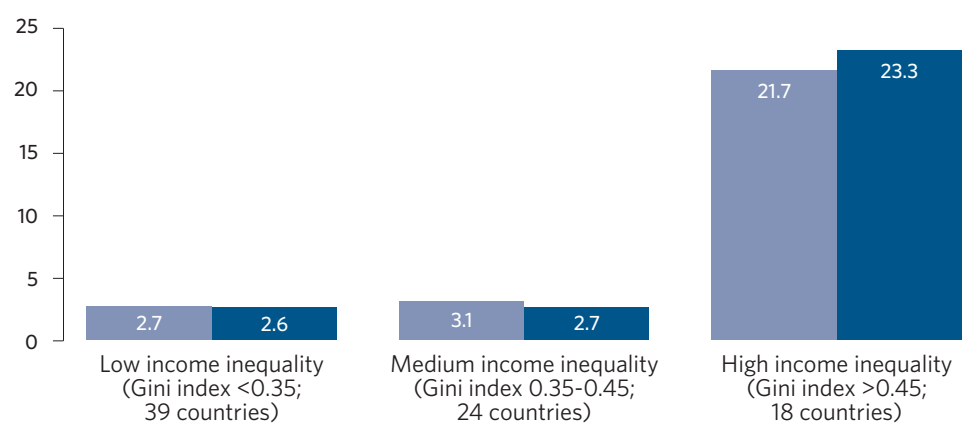

High income inequality (Gini index $>0.45$;
18 countries) 2005

\section{Homicide rates are higher in countries with high income inequality}

Countries with higher levels of income inequality tend to have higher rates of intentional homicide-a phenomenon that cuts across countries and regions. Since 2005, homicide rates have actually increased in a number of countries with high levels of income inequality, even while overall trends continued downward. Moreover, in 2015, these countries had, on average, a homicide rate that was nine times greater than countries where income was more evenly distributed.

Note: Gini index measures the extent to which the distribution of income among individuals or households within an economy deviates from a perfectly equal distribution, with 0 representing perfect equality and 1 representing perfect inequality. 


\section{Violent forms of child discipline are pervasive}

Violent forms of discipline, including methods that rely on physical punishment, verbal intimidation and psychological aggression, are pervasive. Different forms of violent discipline tend to overlap and frequently occur together, exacerbating the short- and long-term harm they inflict. Such harm ranges from immediate effects to long-term damage that children carry well into adulthood. Despite their detrimental and long-lasting impact, violent forms of discipline are widespread. In 76 countries with available data from 2005 to 2016, on average, about 8 in 10 children aged 1 to 14 years were subjected to some form of psychological aggression and/or physical punishment on a regular basis. In all but seven of these countries, more than half of children experienced some form of psychological aggression and/or physical punishment at home.
Proportion of children aged 1 to 14 years who experienced any violent form of discipline (psychological aggression and/or physical punishment) in the past month, 2005-2016 (percentage)

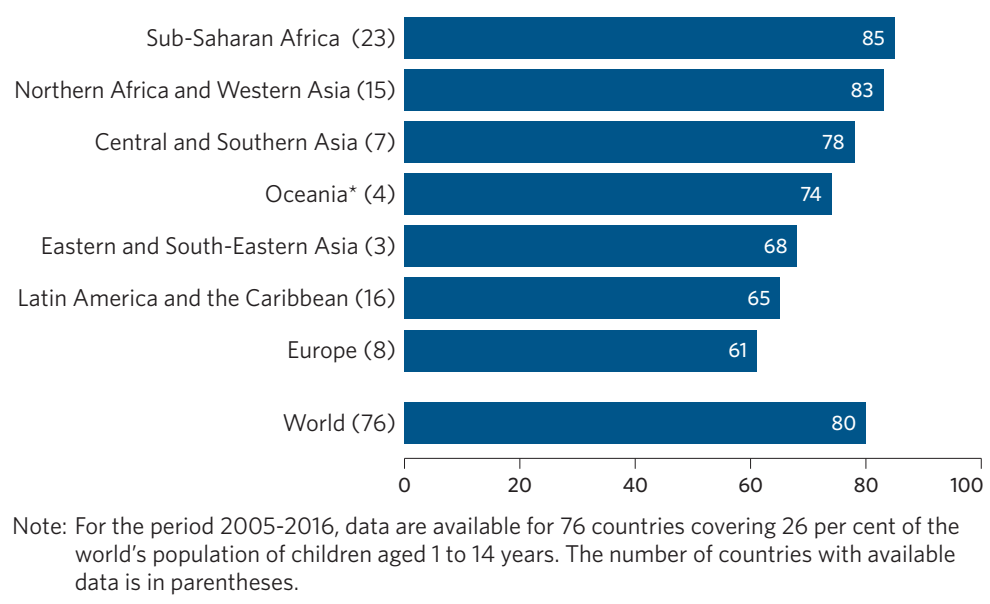

\section{No region is immune from human trafficking}

More than 570 different trafficking flows, which criss-cross the globe, were identified by law enforcement officers between 2012 and 2014. While trafficking affects all regions, many transnational flows involve the movement of victims from lowerto higher-income countries. Globally, more women and girls than men and boys were identified as victims of trafficking in 2014. However, the share of women and girls slowly declined, from 84 per cent in 2004 to 71 per cent in 2014 . And while the share of victims trafficked for sexual exploitation has also fallen, the proportion of those trafficked for forced labour has increased. More than a quarter of all trafficking victims detected in 2014 were children, with girls outnumbering boys (20 per cent of total victims versus 8 per cent). In sub-Saharan Africa and Central America and the Caribbean, the majority of detected victims were children.
Main destinations of transregional trafficking flows and their significant origins, 2012-2014

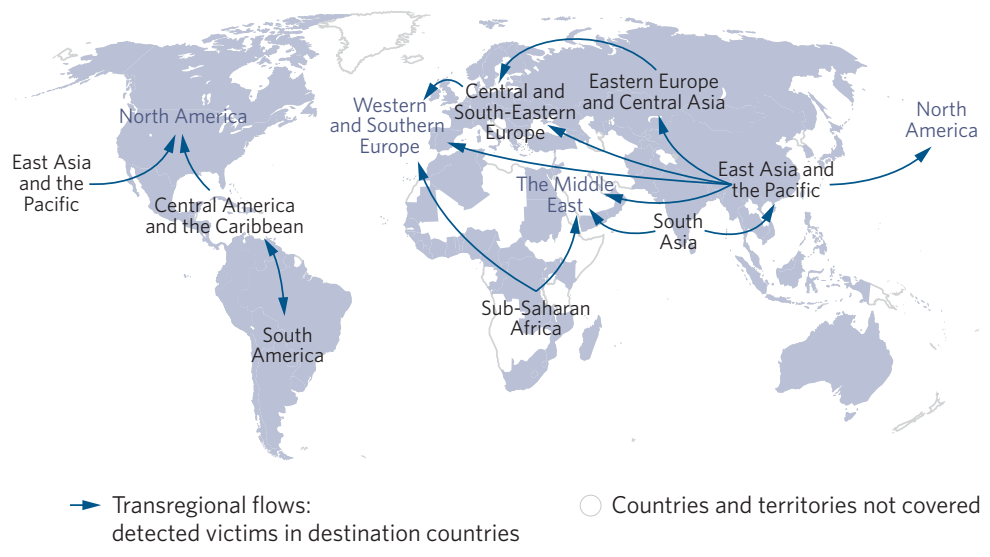

Note: The arrows show the flows that represent 5 per cent or more of the total victims detected in destination subregions. The global map is for illustrative purposes only and does not imply the expression of any opinion whatsoever concerning the legal status of any country or territory, or concerning the delimitation of its frontiers or boundaries.

\section{One third of the world's prisoners are being held without sentencing}

Rates of pretrial detention suggest that progress with respect to the rule of law and access to justice has been slow. Globally, the proportion of people held in detention without being tried or sentenced for a crime has remained almost unchangedfrom 32 per cent of total prisoners in 2003-2005 to 31 per cent in 2013-2015. This indicates that no significant progress has been made in the ability of judicial systems to process and try the accused in an efficient manner. Northern Africa and Western Asia, which had one of the highest proportions of unsentenced detainees a decade ago, has made the most progress. In contrast, the highest proportion of unsentenced detainees remains in Central and Southern Asia, where over 60 per cent of the total prison population are being detained without a trial.
Unsentenced detainees as a proportion of the overall prison population, 2003-2005 and 2013-2015 (percentage)

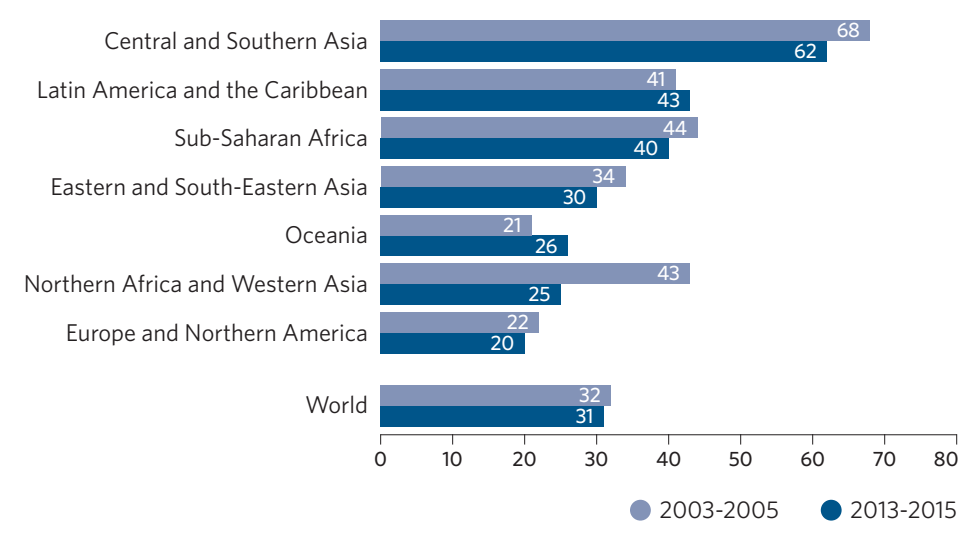

Note: Oceania includes Australia and New Zealand for this particular indicator. 
Proportion of firms that paid and were expected to pay a bribe, 2005-2016 (latest available) (percentage)

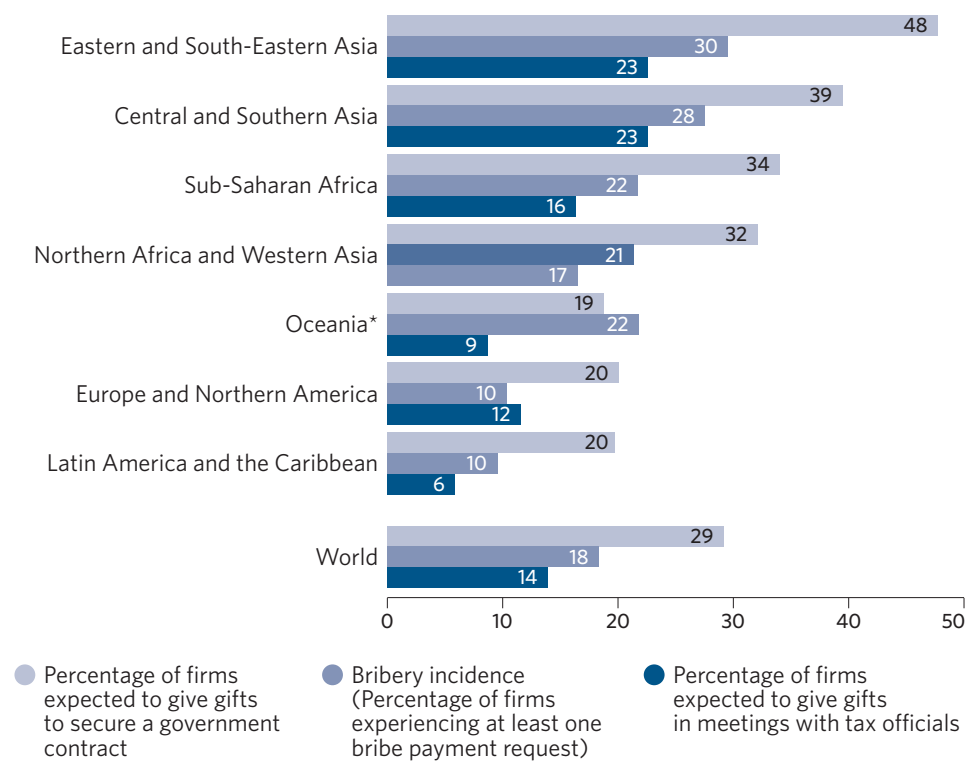

Note: Regional averages are computed by taking a simple average of country-level point estimates.
Firms in low-income countries are confronted by more bribery requests than those in richer countries

Opaque, burdensome and inefficient regulations and procedures provide a "cover" in which corrupt officials are able to extract bribes or unofficial payments. According to data from 2005 to 2016, over 18 per cent of firms worldwide reported receiving at least one bribery payment request. The share of firms in low- and lower-middle-income countries was 25 per cent, versus 4 per cent in high-income countries. Bribery often occurs in transactions necessary for a private firm to conduct business, such as paying taxes; obtaining an operating license, import license or construction permit; or obtaining an electrical or water connection. The data show that, across all regions, bribery is common when seeking to secure a government contract, with almost 30 per cent of firms reporting that they are expected to do so. In the worst-affected region, nearly one half of firms encounter bribery requests when engaging in public procurement.
Change in budget reliability score of countries assessed more than one time, various years, 2005-2016 (percentage of countries)

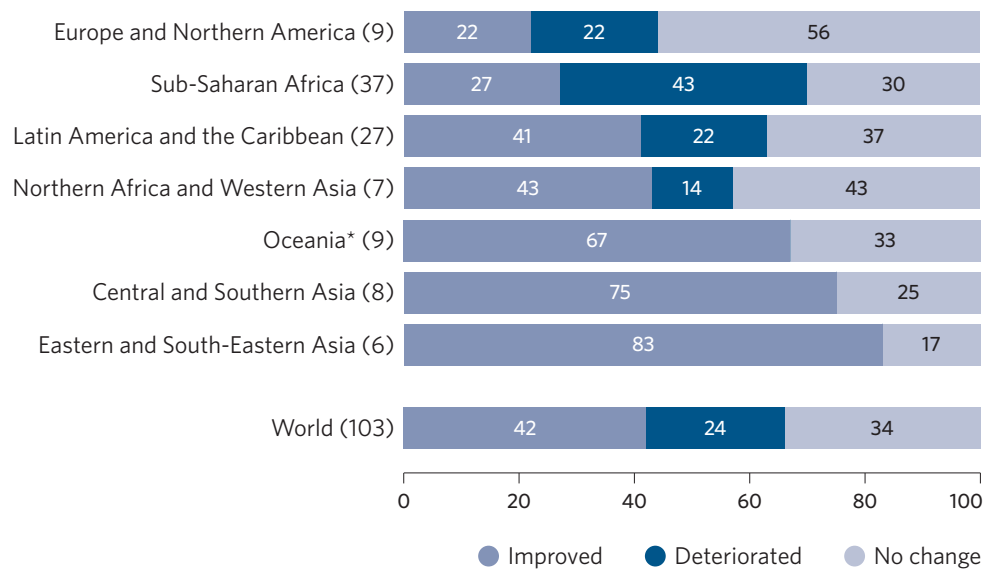

Note: The number of countries with available data is in parentheses.

Proportion of children under age 5 whose births have been registered, 2010-2016 (percentage)

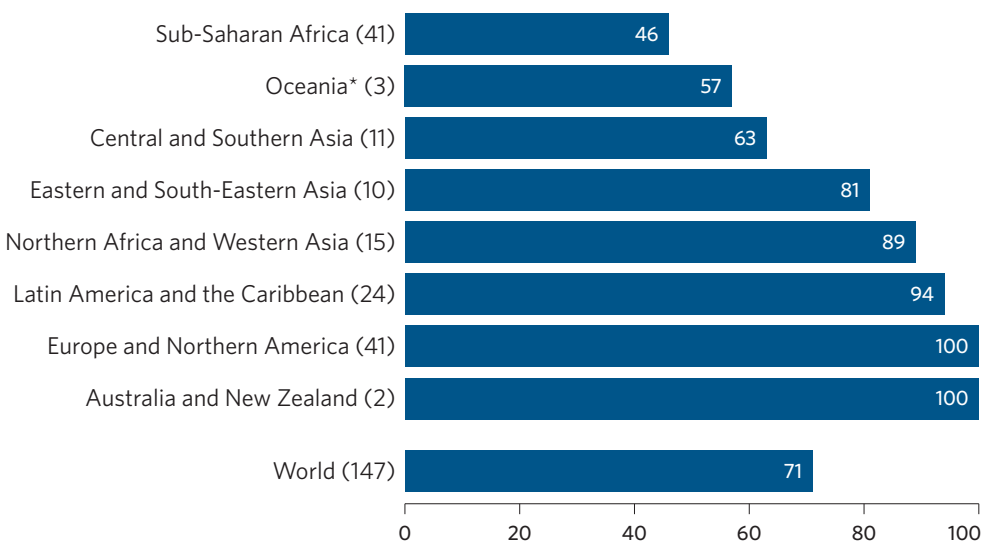

Note: For the period 2010-2016, data are available for 147 countries covering 80 per cent of the world's population of children under age 5 . The number of countries with available data is in parentheses.

\section{More than forty per cent of countries assessed improved the reliability of their national budgets}

To provide a sound basis for development, government budgets should be comprehensive, transparent and realistic. Since 2005, 147 countries had carried out at least one assessment on government budget execution, with 103 of them having carried out multiple assessments. The results show that expenditures in nearly 2 out of 3 countries that completed at least one assessment were within 10 per cent of their original national budget estimates, and more than one third of the countries were within 5 per cent of their budgets. For the 103 countries that completed multiple assessments, budget reliability has improved over time in some regions, with about 80 per cent of countries in Eastern and South-Eastern Asia showing improvement. Implementing realistic budgets is particularly challenging in sub-Saharan Africa, where more than three quarters of countries were more than 5 per cent off, and about 40 per cent of countries experienced a deterioration in the reliability of their budget execution estimates.

\section{Birth registration is still limited in some regions}

Birth registration is a first step towards safeguarding individual rights and providing every person with access to justice and social services. While some regions have reached universal or near-universal birth registration, globally the average is just 71 per cent, based on available data reported for 147 countries from 2010 to 2016 and covering 80 per cent of the world's population of children under age 5 . Less than half ( 46 per cent) of all children under age 5 in sub-Saharan Africa have had their births registered, while in Central and Southern Asia, and Oceania excluding Australia and New Zealand, the births of fewer than two in three children have been registered. 


\section{Of the 102 journalists killed in 2016, nearly a third were in the Arab States}

In 2016, 102 journalists lost their lives while attempting to do their jobs. This is a decrease from 2015, when 115 journalists were killed, but an increase from 2014 and 2013, when 98 and 90 journalists, respectively, lost their lives. The highest number of deaths (32) in 2016 occurred in the Arab States region, home to several armed conflicts. Earlier reports suggest that fewer than 1 in 10 cases of journalists killed between 2006 and 2015 led to a conviction; statistics are not yet available for the 2016 cases.
Number of journalists killed in 2016

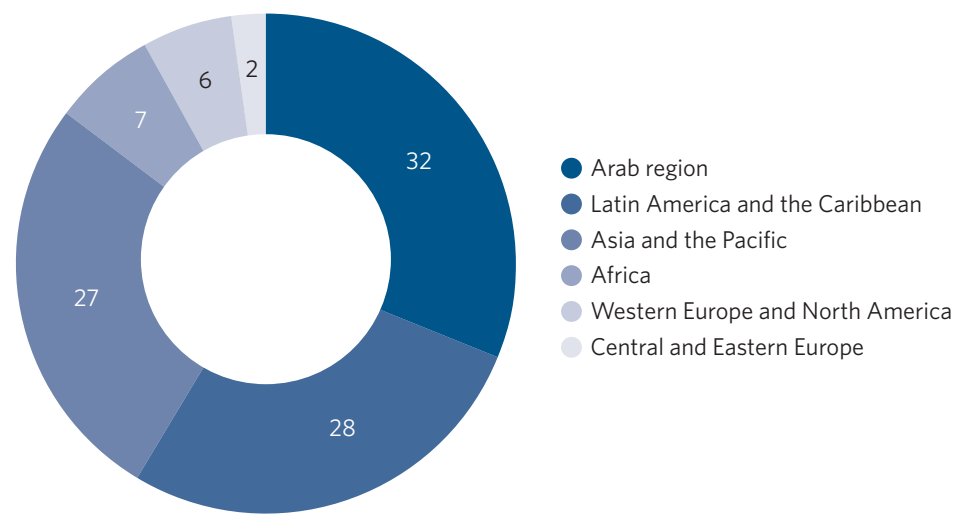

Note: Regional groupings are those used by the United Nations Educational, Scientific and Cultural Organization.

\section{More countries have adopted freedom-of-information legislation, but implementation lags behind}

Freedom-of-information laws and policies have been adopted by 111 countries, with at least 15 countries adopting such laws over the past four years. Expert assessments, however, suggest that implementation remains a challenge. Among the 109 countries with implementation data, only 62 countries had clear legal provisions for exceptions to the right of access to information in 2016. Similarly, only 62 countries had sufficient provisions for promotional materials, including those relating to effective public awareness-raising. This means that in around 40 per cent of countries with freedom-ofinformation laws in place, the public may not be aware of their existence.
Number of countries with freedom-of-information laws/policies and degree of implementation, 2016

Countries with clearer
promotional measures

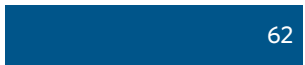

Countries with more specific legal exceptions
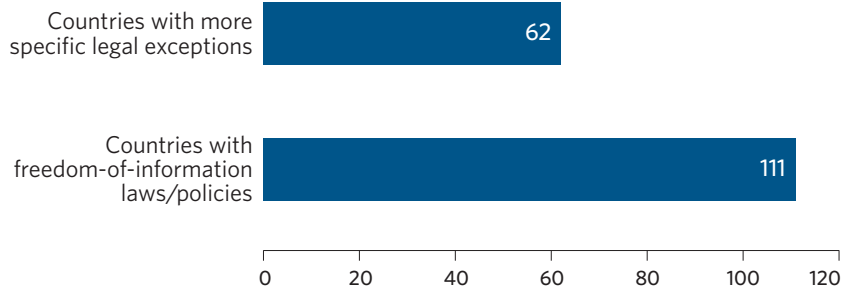

\section{More work is needed to ensure that human rights institutions are compliant with international standards}

Independent national human rights institutions (NHRIs) encourage States to deliver on their human rights obligations, protect people from violence, and ensure that no one is left behind. By the end of 2016, 57 per cent of countries had an NHRI that had been reviewed for compliance with internationally agreed standards (the Paris Principles) by their peers and 37 per cent of countries were found to be compliant. Compliance was highest in Australia and New Zealand at 100 per cent. Compliance was higher than the global average in Europe and Northern America at 46 per cent. The values for all regions represent a significant global increase since 2000 , when only 21 per cent of countries had been reviewed for compliance, and 16 per cent had an NHRI that was compliant. However, the low rates of compliance in some regions highlight the need for further capacity-building and international cooperation.
Proportion of countries with a national human rights institution that applied for review of compliance with international standards and proportion deemed compliant by the end of 2016 (percentage)

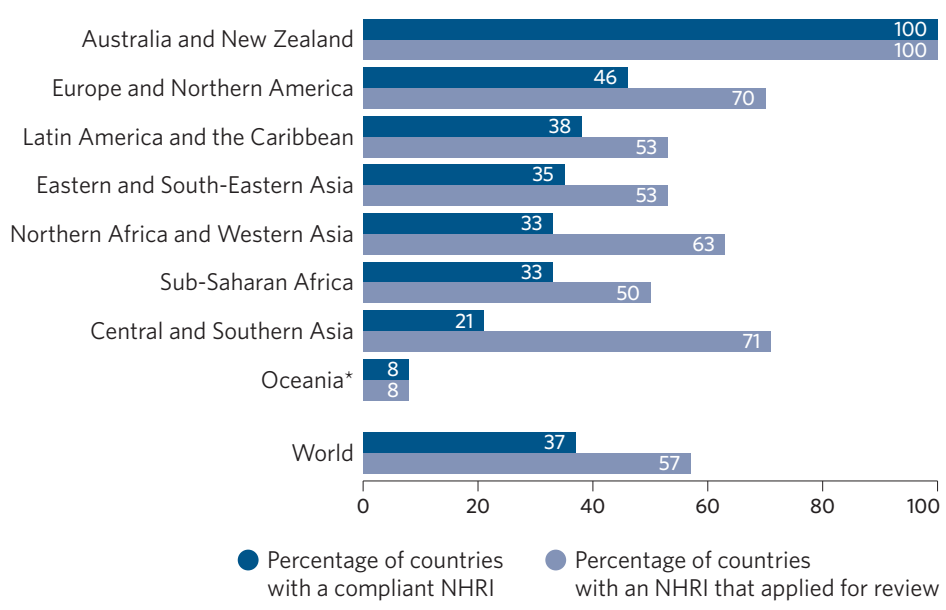




\section{Goal 17: Strengthen the means of implementation and revitalize the Global Partnership for Sustainable Development}

A stronger commitment to partnership and cooperation is needed to achieve the SDGs. Attaining the Goals will require coherent policies, an enabling environment for sustainable development at all levels and by all actors, and a reinvigorated Global Partnership for Sustainable Development. Towards this end, United Nations Member States have identified the following areas as critical: resource mobilization, technology, capacitybuilding, trade, policy and institutional coherence, multistakeholder partnerships, and data, monitoring and accountability. Meeting the means of implementation targets is key to realizing the Agenda for Sustainable Development, as is the full implementation of the Addis Ababa Action Agenda. Incremental progress has been made in these areas, but more is needed.

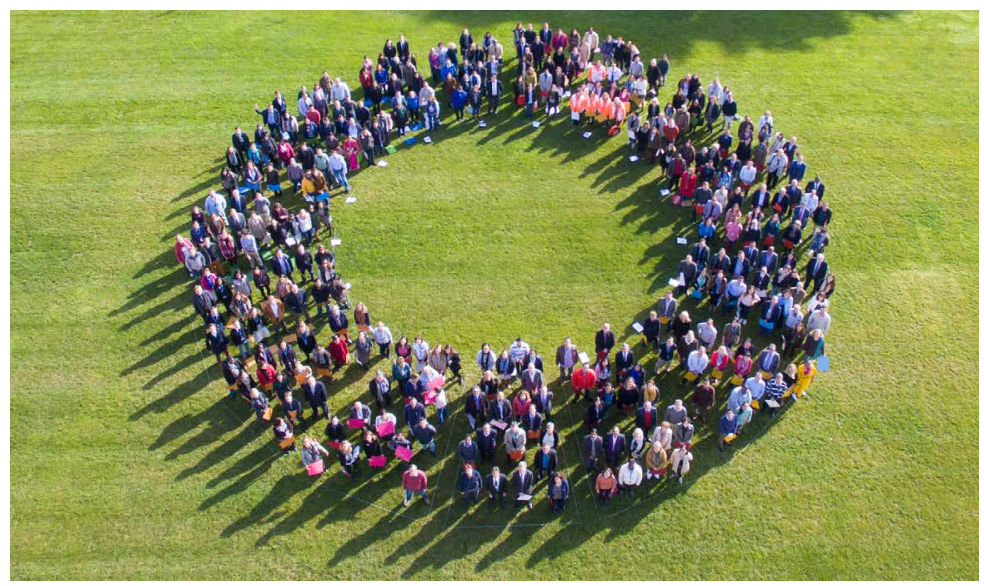

Net official development assistance from OECD-DAC countries, 2000-2016 (billions of constant 2015 US dollars)

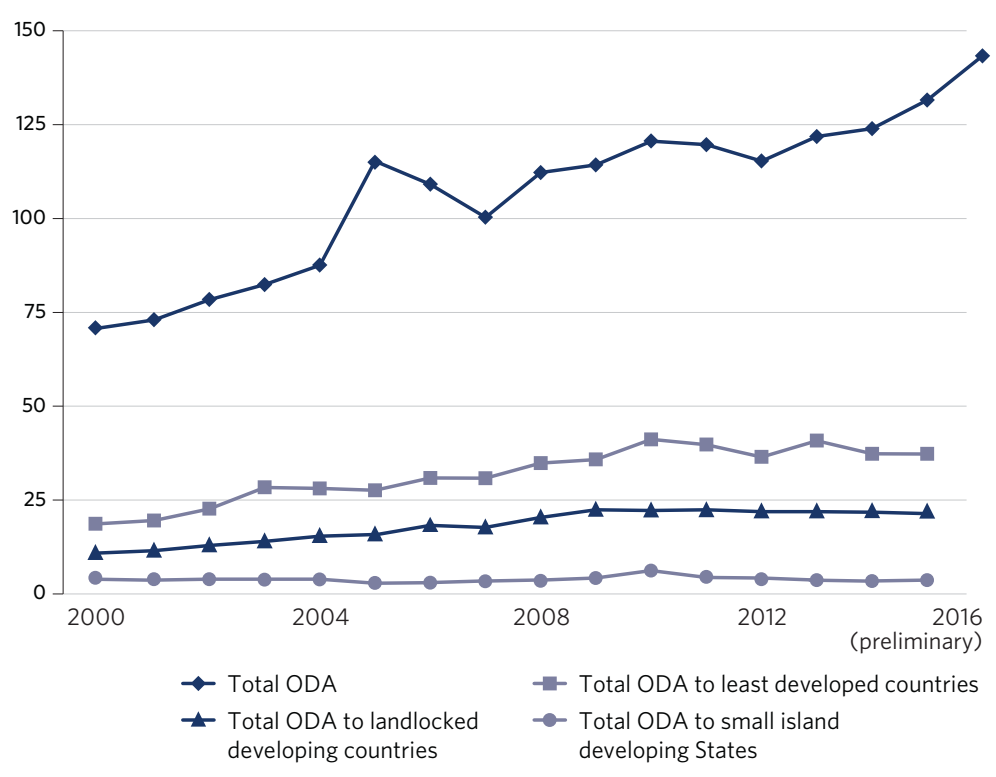

Debt service as a proportion of total exports of goods and services, 2000-2015 (percentage)

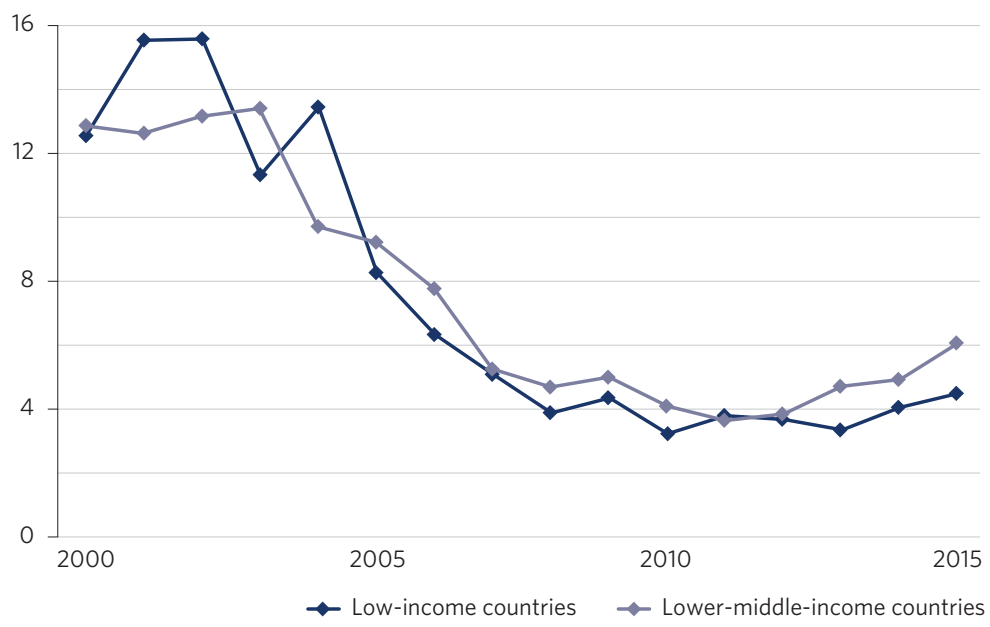

Official development assistance reaches a new high, but aid to the poorest countries stalls

In 2016, net official development assistance (ODA) from member countries of the OECD-DAC rose by 8.9 per cent in real terms to 142.6 billion US dollars, reaching a new peak. ODA as a percentage of member countries' gross national income (GNI) was 0.32 per cent, up from 0.30 per cent in 2015. A rise in aid spent on refugees in donor countries boosted the total. Even without refugee costs taken into account, aid rose 7.1 per cent. In 2016, Germany joined five other countriesDenmark, Luxembourg, Norway, Sweden and the United Kingdomin meeting the United Nations target for ODA of 0.7 per cent of GNI. Despite this progress, 2016 data show that bilateral (country-tocountry) aid to LDCs fell by 3.9 per cent in real terms from 2015. Aid to Africa fell by 0.5 per cent as some DAC members backtracked on a commitment to reverse past declines in flows to the poorest countries. ODA spent on hosting refugees inside donor countries jumped by 27.5 per cent in real terms from 2015 to reach 15.4 billion US dollars. The DAC is working to adjust ODA reporting rules to help ensure that funding for development is not diverted to in-donor refugee costs.

\section{The debt service burden is on the rise again for low- and lower-middle-income countries}

For a decade, starting in 2000, debt service as a proportion of exports of goods and services declined significantly for low- and lowermiddle-income countries. Increased export earnings, enhanced debt management and attractive borrowing conditions in international markets contributed to this improvement. Outright debt relief also eased the burden for countries eligible for the Heavily Indebted Poor Country Initiative: 36 out of 39 countries received debt relief of around 136 billion US dollars from official creditors.

However, debt service has been trending upward in recent years. From 2000 to 2011, debt service in lower-middle-income countries fell from 12.9 per cent to 3.6 per cent before rising slowly to 6.1 per cent in 2015 In low-income countries, debt service hit a low of 3.2 per cent in 2010 before increasing in subsequent years, reaching 4.5 per cent in 2015. 


\section{In 2016, remittances to developing countries fell for a second consecutive year}

Remittances sent by international migrants to their home countries in the form of personal transfers and compensation of employees have a profound impact on individual families, communities and countries. In 2016, international remittances totalled 575 billion US dollars, 75 per cent of which (429 billion US dollars) went to developing countries, according to the latest estimates. However, remittances to developing countries in 2016 fell for a second consecutive year, declining by 2.4 per cent over 2015. Low oil prices and weak economic growth in the Gulf Cooperation Council countries and the Russian Federation are taking a toll on remittance flows to Central and Southern Asia, while weak growth in Europe has reduced flows to Northern and sub-Saharan Africa. The contribution of remittances to the income of countries has been growing significantly over the last 15 years and exceeded 4 per cent of GDP for LDCs in 2015.
Volume of remittances (in US dollars) as a proportion of total GDP, 2000 and 2015 (percentage)

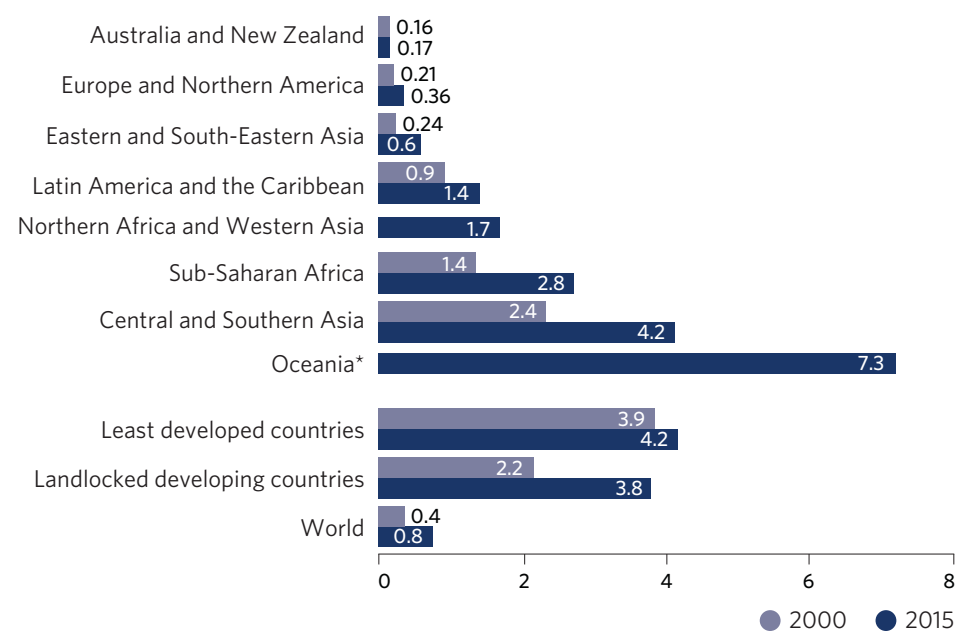

Note: 2000 figures for Northern Africa and Western Asia and Oceania* are not available.

\section{Internet services remain inaccessible across large swaths of the developing world}

Fixed-broadband services remain largely unaffordable and unavailable across large segments of the developing world. In 2016, fixed-broadband penetration reached 30 per cent in developed countries, but only 8.2 per cent and 0.8 per cent in developing regions and LDCs, respectively. In the developed regions, about 80 per cent of the population are online, compared to 40 per cent in developing regions and 15 per cent in LDCs. Although Internet use in LDCs has tripled over the last five years, the percentage of users today reaches the level enjoyed by developed countries in 1998. However, the LDC average hides large disparities, with some countries doing much better than others. In 2016, levels of Internet use worldwide were 12 per cent lower for women than for men; the gender gap remains even larger in LDCs at 31 per cent. Both globally and in LDCs, this gender gap has widened in recent years.
Individuals using the Internet, 2000 and 2015 (percentage)

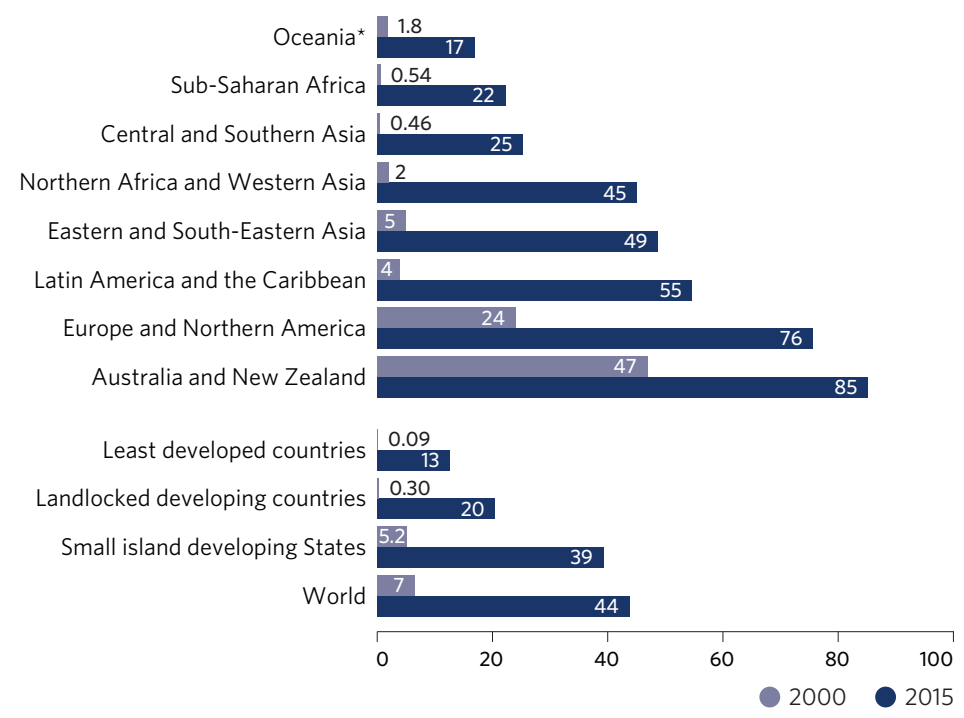

\section{Least developed countries' share of global exports is declining in merchandise trade but increasing in services}

Over the past 15 years, developing regions have represented a growing share of international trade, with their world merchandise exports increasing from 31 per cent in 2001 to 45 per cent in 2015. Moreover, developing regions overall have maintained a trade surplus vis-à-vis the rest of the world. However, the share in world merchandise exports from LDCs decreased from 1.1 per cent to 0.9 per cent between 2011 and 2015. Much of this change can be attributed to a fall in commodity prices, since exports from many LDCs are concentrated in primary commodities, such as minerals, ores and fuels. On the other hand, the share of LDCs in world services exports increased from 0.5 per cent to 0.8 per cent from 2001 to 2015.
Share of global merchandise and service exports from least developed countries, 2001-2015 (percentage)

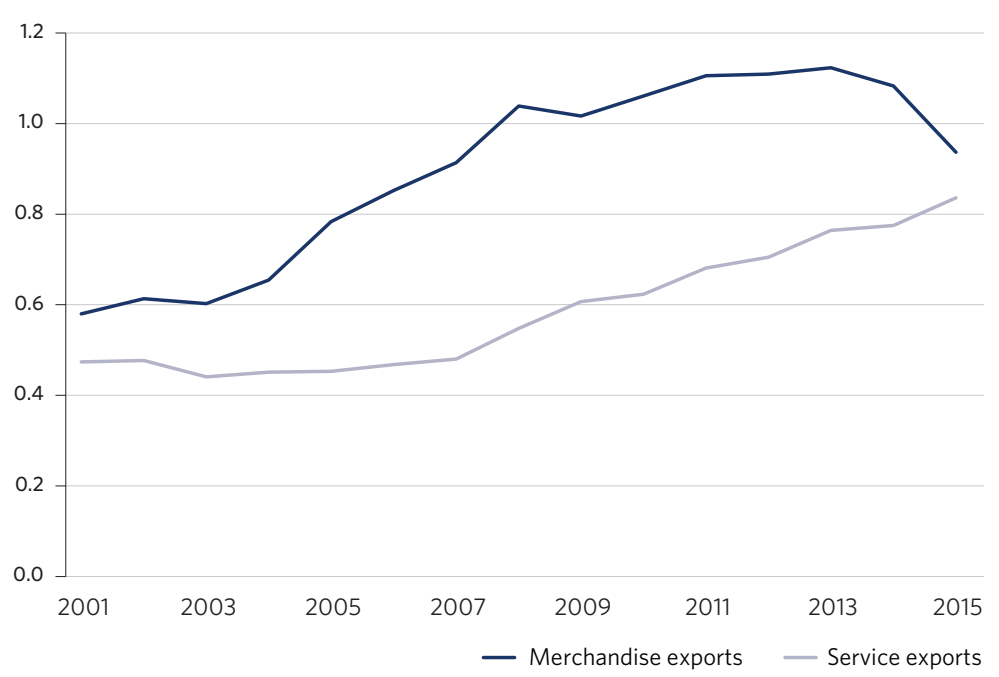


Average tariffs levied by developed countries on key products exported by developing countries and least developed countries, 2011-2015 (percentage)

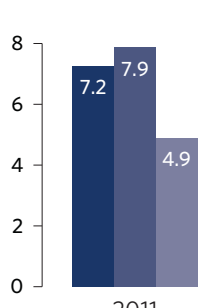

2011

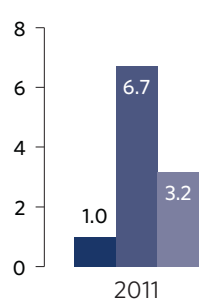

Exports by developing countries

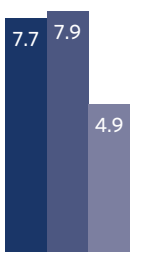

2012

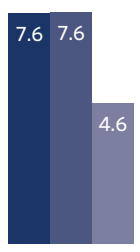

2013

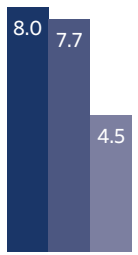

2014

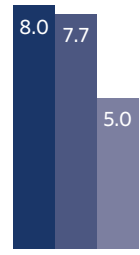

2015
Exports by least developed countries
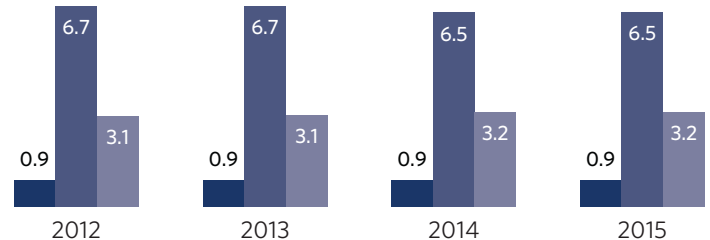

2015
Textiles
Average tariffs levied by developed countries on key products of developing countries and LDCs have remained stable

From 2011 to 2015, average tariffs applied by developed countries to imports from LDCs remained very stable. In 2015, they stood at 0.9 per cent for agricultural products, 6.5 per cent for clothing and 3.2 per cent for textiles. Tariffs applied to imports from developing countries also remained largely unchanged in recent years, but were higher than those applied to major exports of LDCs, at 8.0 per cent for agricultural products, 7.7 per cent for clothing and 5.0 per cent for textiles in 2015. A slight increase in applied tariffs to products from developing countries is largely explained by the exclusion of China and Thailand from the European Union's Generalised Scheme of Preferences, which took effect in January 2015. The textile sector is most affected by this change.

Extent of use of country-owned results frameworks and planning tools by providers of development cooperation, 2015 (percentage)

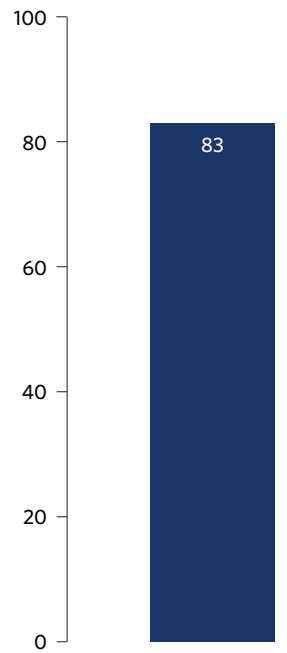

Alignment of objectives with national priorities

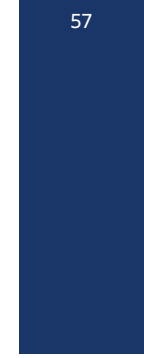

Alignment with country results frameworks

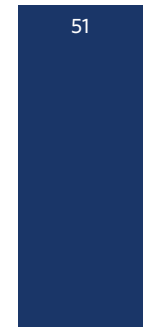

Use of government data and systems in monitoring results
Progress is ongoing in the monitoring of development effectiveness and in respecting countries' policy space

In 2016, 125 countries engaged in country-led monitoring of development effectiveness, demonstrating their commitment to strengthening SDG implementation and multi-stakeholder partnerships. Of these countries, 54 reported overall progress towards those commitments. For instance, countries reported progress in recording development cooperation on national budgets submitted for parliamentary oversight, and in tracking budget allocations for gender equality and women's empowerment.

Countries' own results frameworks were used to identify 83 per cent of new interventions supported by donor countries in 2016. Fifty-seven per cent of results indicators in these new interventions were drawn from country-led results frameworks and about half (51 per cent) used data from national monitoring systems to track results. The extent to which development partners use country-led results frameworks is one indication of the respect accorded to a country's policy "space" and its leadership in establishing its own path towards sustainable development.
Number and proportion of countries with a national statistical plan that is fully funded and under implementation, 2016 (percentage)

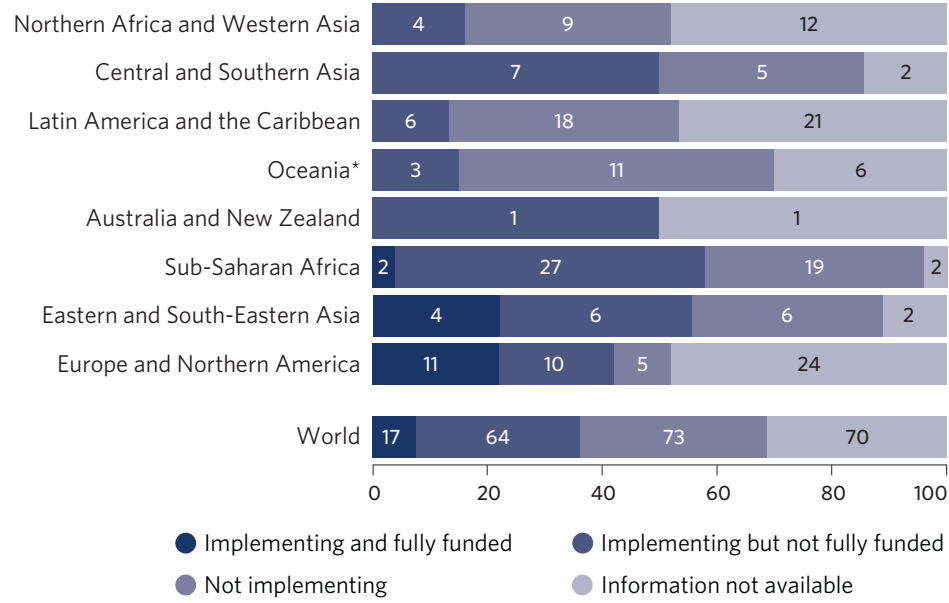

\section{Only 17 countries, mostly in Europe and Northern America, have fully funded national statistical plans}

More than half of the countries or areas for which information is available (81 out of 154) were implementing national statistical plans in 2016. Among the 17 countries with fully funded plans, 11 are located in Europe and Northern America. Such plans lay out the strategy by which a country can develop statistical capacity throughout its entire national statistical system. By designing, implementing and monitoring this strategic vision, countries can better respond to the growing demand for high-quality, timely, disaggregated and accessible data.

Only 37 out of 83 countries or areas with relevant information had national statistical legislation in place that complied with all 10 Fundamental Principles of Official Statistics. Solid and politically backed statistical legislation is required to ensure that the Fundamental Principles and other professional and scientific standards are being followed in the production of official statistics. 


\section{Financial support for statistics from official development assistance remains low}

In 2014, developing countries received 338 million US dollars in financial support for statistics. While this represented an increase of nearly 2.9 per cent from 2010, it accounted for only 0.18 per cent of total ODA. The main beneficiaries in 2014 were countries in sub-Saharan Africa (214 million US dollars), followed by countries in Latin America and the Caribbean (73 million US dollars). Continued effort and financial support are needed to ensure that developing countries have the capacity to better monitor progress on their own national policy objectives and international initiatives. To meet the data needs of the SDGs, developing countries will need an estimated 1 billion US dollars in statistical support annually from domestic and donor sources.
Total official development assistance to developing regions dedicated to statistical capacity-building activities, 2010 and 2014 (millions of US dollars)

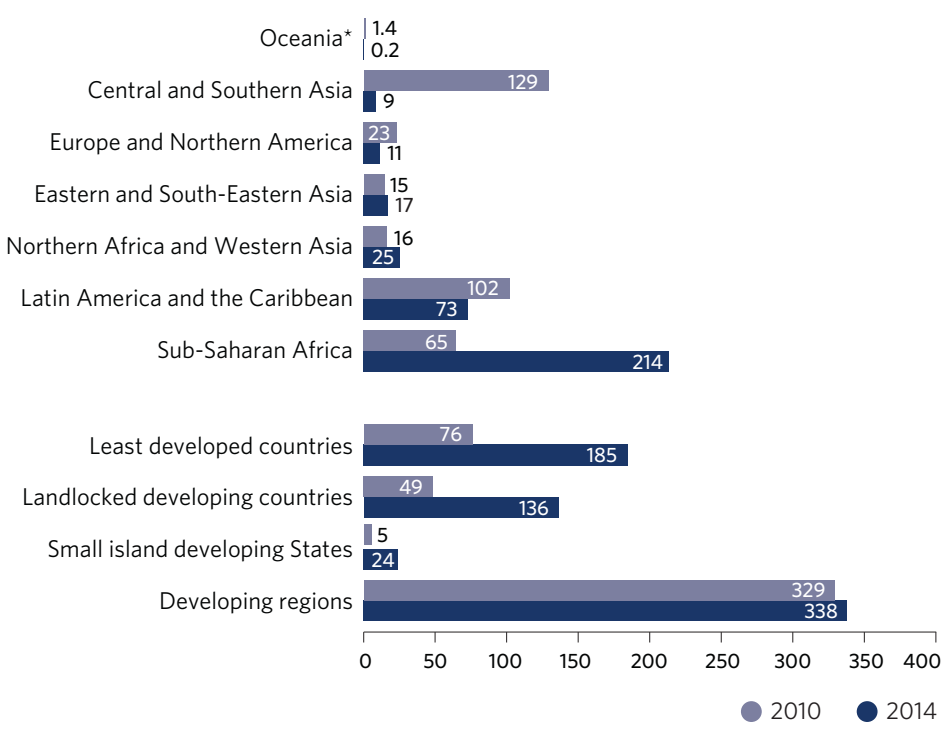

\section{While the population and housing census remains a key data source, 25 countries failed to conduct one in the period 2007-2016}

Population and housing censuses are a primary source of disaggregated data needed to formulate, implement and monitor development policies and programmes. During the period from 2007 to 2016,89 per cent of countries or areas around the world conducted at least one population and housing census. Owing to a variety of factors, 25 countries or areas failed to conduct a census over the same period. These included financial constraints, technical difficulties encountered in their preparation, natural disasters, and political and social instability. Among these countries or areas, nine were in subSaharan Africa and seven were in Northern Africa and Western Asia.
Proportion of countries that conducted at least one population and housing census over the period 2007-2016 (latest available) (percentage)

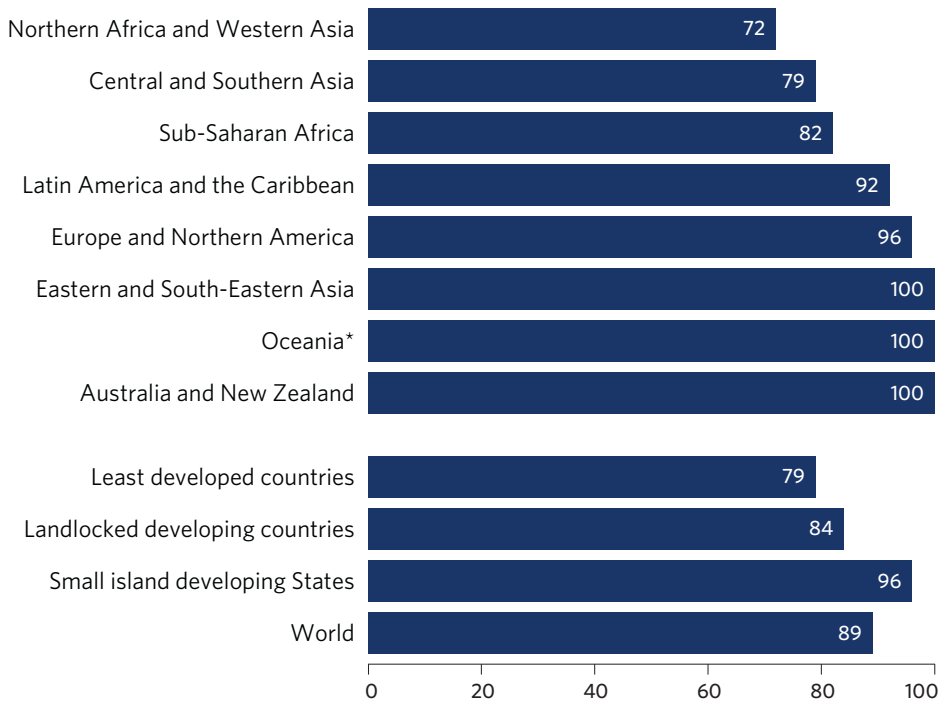

\section{Complete birth and death registration is far from universal, especially in sub-Saharan Africa}

From 2010 to 2015, 56 per cent of the world's countries or areas (138 out of 246) had birth registration data that were at least 90 per cent complete. In sub-Saharan Africa, only 8 out of 53 countries achieved this coverage. A child who is not registered at birth risks being denied the right to an official identity and is more likely to join the millions facing discrimination and lack of access to basic services. Over the same six years, 144 countries or areas, or 59 per cent, had death registration data that were at least 75 per cent complete. In sub-Saharan Africa, only 9 in 53 countries met this standard. Death registration data are crucial for many health indicators and for policy planning purposes. Even in countries with functioning civil registration systems, coverage of birth and death registration, and complete reporting of vital statistics remain a challenge.
Proportion of countries with death registration data that are at least 75 per cent complete and proportion of countries with birth registration data that are at least 90 per cent complete, 2010-2015 (latest available) (percentage)

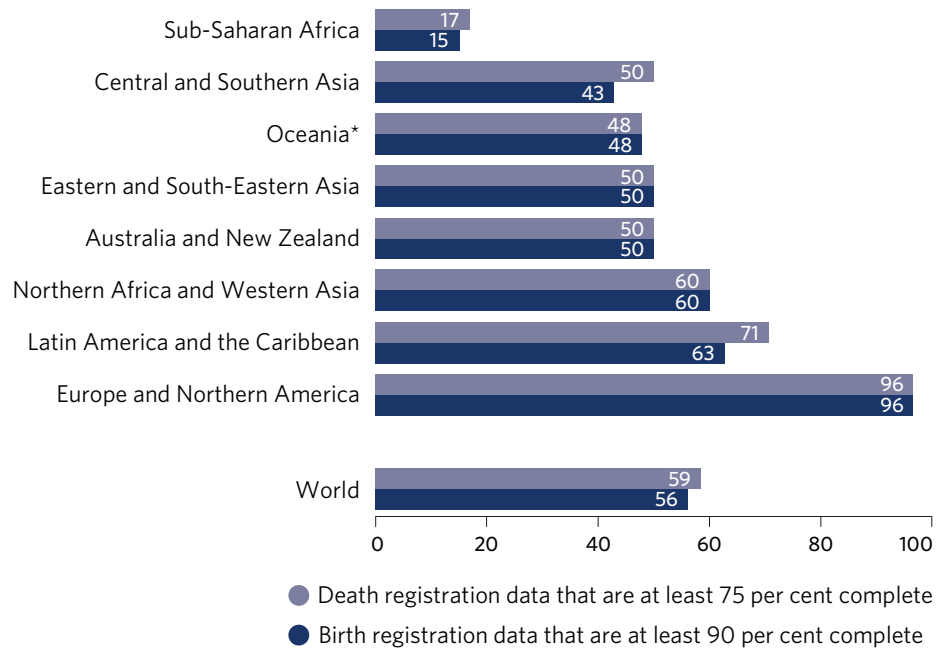




\section{A note to the reader}

\section{Global indicator framework for the follow-up and review of the SDGs}

The information presented in this report is based on the latest available data as of June 2017 on selected indicators of the global SDG framework. The indicators presented are those for which there are sufficient data available to provide an overview at the regional and global levels. The global indicator framework ${ }^{1}$ was developed by the Inter-Agency and Expert Group on SDG Indicators (IAEG-SDGs) and adopted by the United Nations Statistical Commission in March 2017 and by the United Nations General Assembly in July 2017. This set of indicators is intended for the review of progress at the global level.

\section{Data sources and the basis for this analysis}

For most of the indicators presented in this report, values represent regional and/or subregional aggregates. In general, the figures are weighted averages of country data, using the population of reference as a weight. They are calculated from national data collected by international agencies, based on their respective mandates and specialized expertise, from national statistical systems. The national data provided to the international statistical system are often adjusted for international comparability and, where lacking, are estimated. As decided by the Statistical Commission and in accordance with United Nations Economic and Social Council resolution 2006/6, estimates used for the compilation of global indicators are to be produced in full consultation with national statistical authorities.

\section{Improving data quality and availability}

Quality data are vital for Governments, international organizations, civil society, the private sector and the general public to make informed decisions and to ensure an accurate review of the implementation of the 2030 Agenda. That said, tracking progress on the SDGs requires the collection, processing, analysis and dissemination of an unprecedented amount of data and statistics at subnational, national, regional and global levels, including those derived from official statistical systems and from new and innovative data sources.

Many national statistical systems across the globe face serious challenges in this regard. As a result, accurate and timely information about certain aspects of people's lives are unknown, numerous groups and individuals remain "invisible", and many development challenges are still poorly understood. In resolution 70/1, Member States recognized the crucial role of strengthened data collection and capacity-building and committed to addressing the data gap (paragraph 57).
The selection of indicators in this report does not intend to represent a selection of the targets based on their importance, as all Goals and targets are equally important and will need to be addressed by the appropriate indicators.

The composition of regions and subregions in this report is based on United Nations geographical divisions with some modifications necessary to create, to the extent possible, groups of countries for which a meaningful analysis could be carried out. ${ }^{2}$

A database of available global, regional and country data and metadata for the SDG indicators accompanying this report is being maintained by the United Nations Statistics Division and will be available at https://unstats.un.org/sdgs.

Although the aggregate figures presented are a convenient way to track progress, the situation of individual countries within a given region may vary significantly from regional averages. Presenting aggregate figures for all regions also obscures another reality: the lack in many parts of the world of adequate data to assess national trends and to inform and monitor the implementation of development policies.

Where possible, global monitoring should be based on comparable and standardized national data obtained through well-established reporting mechanisms from countries to the international statistical system. Such mechanisms can be improved by strengthening the coordination function of national statistical offices and/or other national institutions. To fill data gaps and improve international comparability, countries will need to adopt internationally agreed upon standards, while the international statistical community will need to work closely with development partners and other stakeholders to strengthen national statistical capacities and improve reporting mechanisms. International and regional organizations and regional mechanisms play a significant role in facilitating these processes.

The success of these global initiatives will require capacity-building efforts and the mobilization of resources. In addition, new data sources and technologies for data collection and for the integration of different sources of data will need to be explored, including through partnerships with civil society, the private sector and academia. The integration of geospatial information and statistical data will be particularly important for the production of a number of indicators.

1 The complete list of indicators is presented in Annex III of the Report of the Inter-agency and Expert Group on Sustainable Development Goal Indicators (E/CN.3/2017/2) (see https://unstats.un.org/sdgs/indicators/indicators-list for details).

2 The composition of these subregions is shown in the next section, "Regional groupings". 


\section{Regional groupings}

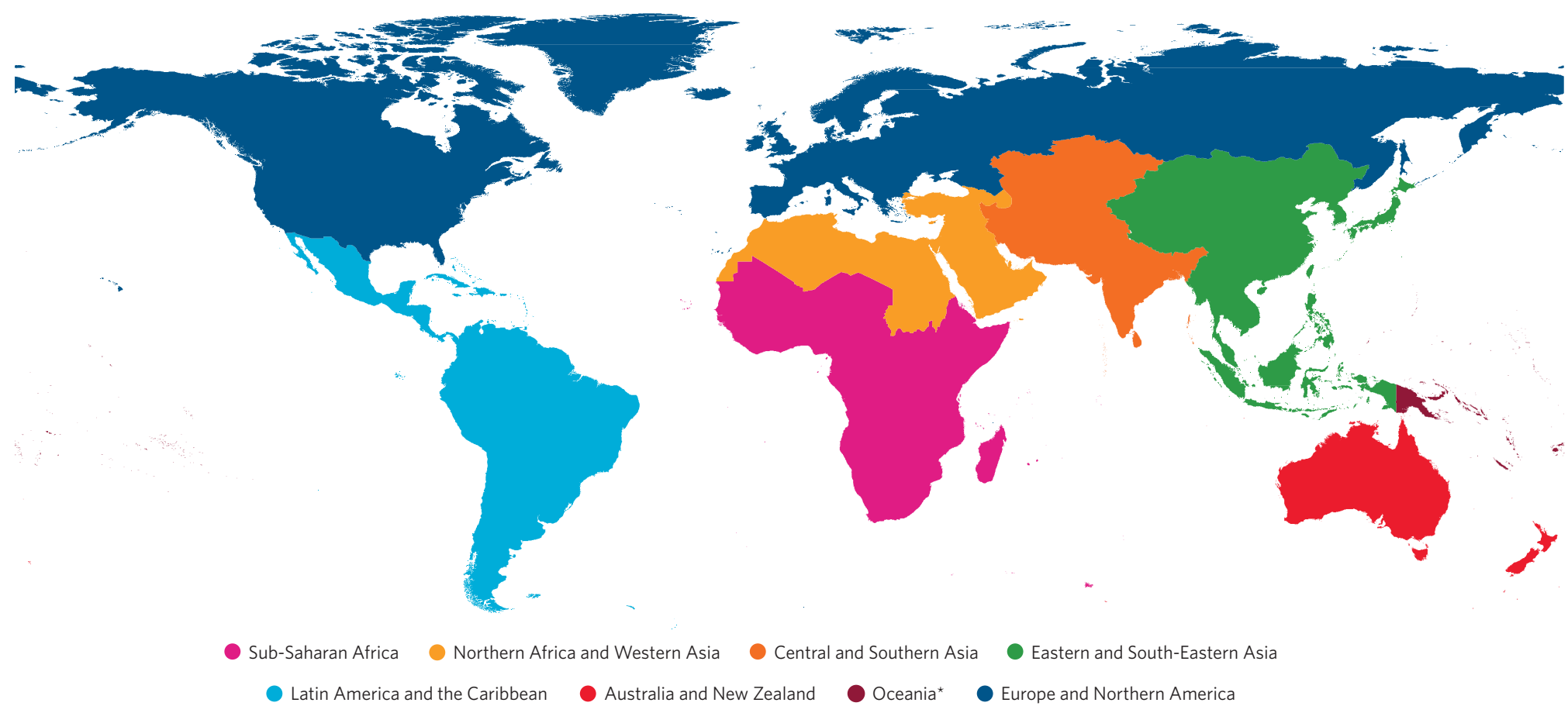

Notes: - Oceania* refers to Oceania excluding Australia and New Zealand throughout the publication.

- The boundaries and names shown and the designations used on this map do not imply official endorsement or acceptance by the United Nations.

This report presents data on progress towards the Sustainable Development Goals for the world as a whole and for various groups. The country groupings are based on the geographic regions defined under the Standard Country or Area Codes for Statistical Use (known as M49) 3 of the United Nations Statistics Division. The geographic regions are shown on the map above. For the purpose of presentation, some of the $\mathrm{M} 49$ regions have been combined.

The use of geographic regions as the basis for country groupings is a major change from The Sustainable Development Goals Report 2016 and the progress reports on the Millennium Development Goals. Previously, data were presented for countries in "developed" regions and countries in "developing" regions, which were further broken down into geographic subregions. Although there is no established convention for the designation of "developed" and "developing" countries or areas in the United Nations system, data for some indicators in this report are still being presented for developed and developing regions for the purpose of statistical analysis only, and are based on the practice employed by the international agencies that provided the data. 4

In addition, the text and figures present, to the extent possible, data for least developed countries, landlocked developing countries and small island developing States, which are country groups requiring special attention.

A complete list of countries included in each region and subregion and country group is available at https://unstats.un.org/sdgs/indicators /regional-groups.

The designations employed and the presentation of the material in this publication do not imply the expression of any opinion whatsoever on the part of the Secretariat of the United Nations concerning the legal status of any country, territory, city or area or of its authorities, or concerning the delimitation of its frontiers or boundaries.

3 Full details of the M49 standard can be found on the United Nations Statistics Division website at https://unstats.un.org/unsd /methodology/m49.

4 A discussion note, "Update of the regional groupings for the SDG report and database," of 31 October 2016 describes the details of this change and is available at https://unstats.un.org/sdgs/indicators/regional-groups. 
Photo credits:

Cover (c) The World Bank/Dominic Chavez

Page 16 (c) The World Bank/Mohamad Al-Arief

Page 18 (c) UN Photo/Albert González Farran

Page 20 (C) UN Photo/Eskinder Debebe

Page 24 (C) The World Bank/Dominic Chavez

Page 26 (C) The World Bank/Mousa Sabury/Rumi Consultancy

Page 30 C UN Photo/Albert González Farran

Page 32 (c) UN Photo/Sophia Paris

Page 34 (C) The World Bank/Graham Crouch

Page 36 (c) The World Bank/Gerardo Pesantez

Page 38 (c) The World Bank/Mohamed Azakir

Page 40 (C) UN Photo/Kibae Park

Page 42 (C) UN Photo/B. Wolff

Page 44 (c) UN Photo/UNICEF/Marco Dormino

Page 46 (C) UN Photo/Martine Perret

Page 48 (C) UN Photo/Kibae Park

Page 50 (c) UN Photo/Helena Mulkerns

Page 54 (C) UN Photo/Emmanuel Hungrecker

Map credits: Map on page 46 is from UNEP-WCMC January 2017.

Map on page 47 is from the Transboundary Waters Assessment Programme (GEF/UNEP/IOC-UNESCO).

Map on page 51 is from the UNODC Global Report on Trafficking in Persons 2016.

Infographic icons credit: Infographic icons from pages 3 to 11 and 14 to 15 are from thenounproject.com under a NounPro license.

Design: United Nations Graphic Design Unit/DPI

Additional report design, graphics design, typesetting and copy-editing: Copy Preparation and Proofreading Section/DGACM

Editor: Lois Jensen

Copyright (C) 2017 United Nations

All rights reserved worldwide

Requests to reproduce excerpts or to photocopy should be addressed to the Copyright Clearance Center at http://www.copyright.com.

All other queries on rights and licenses, including subsidiary rights, should be addressed to:

United Nations Publications, 300 East 42nd Street, New York, NY, 10017, United States of America.

Email: publications@un.org; website:www.un.org/publications

United Nations publication issued by the Department of Economic and Social Affairs (DESA)

ISBN: 978-92-1-101368-9

e-ISBN: 978-92-1-361715-1

ISSN: 2518-3958

Sales No. E.17.I.7 
The report is based on a master set of data prepared by the Department of Economic and Social Affairs of the United Nations Secretariat with inputs from a large number of international and regional organizations in response to General Assembly resolution 70/1 (para. 83) to provide an annual assessment of progress towards the Sustainable Development Goals. The international and regional organizations that contributed to the report are listed below. A number of national statisticians, experts from civil society and academia also contributed.

ALLIANCE OF SMALL ISLAND STATES

ASIAN DEVELOPMENT BANK

ECONOMIC AND SOCIAL COMMISSION FOR ASIA AND THE PACIFIC

ECONOMIC AND SOCIAL COMMISSION FOR WESTERN ASIA

ECONOMIC COMMISSION FOR AFRICA

ECONOMIC COMMISSION FOR EUROPE

ECONOMIC COMMISSION FOR LATIN AMERICA AND THE CARIBBEAN

FOOD AND AGRICULTURE ORGANIZATION OF THE UNITED NATIONS

INTERNATIONAL CIVIL AVIATION ORGANIZATION

INTERNATIONAL ENERGY AGENCY

INTERNATIONAL LABOUR ORGANIZATION

INTERNATIONAL MONETARY FUND

INTERNATIONAL RENEWABLE ENERGY AGENCY

INTERNATIONAL TELECOMMUNICATION UNION

INTERNATIONAL TRADE CENTRE

INTERNATIONAL UNION FOR CONSERVATION OF NATURE

INTER-PARLIAMENTARY UNION

JOINT UNITED NATIONS PROGRAMME ON HIV/AIDS

OFFICE OF THE UNITED NATIONS HIGH COMMISSIONER FOR HUMAN RIGHTS

OFFICE OF THE UNITED NATIONS HIGH COMMISSIONER FOR REFUGEES

ORGANISATION FOR ECONOMIC CO-OPERATION AND DEVELOPMENT

PARTNERSHIP IN STATISTICS FOR DEVELOPMENT IN THE 21ST CENTURY / PARIS21

SECRETARIAT OF THE CONVENTION ON BIOLOGICAL DIVERSITY

SUSTAINABLE ENERGY FOR ALL

UNITED NATIONS CAPITAL DEVELOPMENT FUND

UNITED NATIONS CHILDREN'S FUND

UNITED NATIONS CONFERENCE ON TRADE AND DEVELOPMENT

UNITED NATIONS CONVENTION TO COMBAT DESERTIFICATION

UNITED NATIONS DEPARTMENT OF ECONOMIC AND SOCIAL AFFAIRS

UNITED NATIONS DEVELOPMENT PROGRAMME

UNITED NATIONS DIVISION FOR OCEAN AFFAIRS AND THE LAW OF THE SEA

UNITED NATIONS EDUCATIONAL, SCIENTIFIC AND CULTURAL ORGANIZATION

UNITED NATIONS ENTITY FOR GENDER EQUALITY AND THE EMPOWERMENT OF WOMEN / UN-WOMEN

UNITED NATIONS ENVIRONMENT PROGRAMME

UNITED NATIONS FRAMEWORK CONVENTION ON CLIMATE CHANGE

UNITED NATIONS HUMAN SETTLEMENTS PROGRAMME

UNITED NATIONS INDUSTRIAL DEVELOPMENT ORGANIZATION

UNITED NATIONS INTERNATIONAL STRATEGY FOR DISASTER REDUCTION

UNITED NATIONS MINE ACTION SERVICE

UNITED NATIONS OFFICE FOR DISASTER RISK REDUCTION

UNITED NATIONS OFFICE OF RULE OF LAW AND SECURITY INSTITUTIONS

UNITED NATIONS OFFICE OF THE HIGH REPRESENTATIVE FOR THE LEAST DEVELOPED COUNTRIES,

LANDLOCKED DEVELOPING COUNTRIES AND SMALL ISLAND DEVELOPING STATES

UNITED NATIONS OFFICE OF THE SECRETARY-GENERAL'S ENVOY ON YOUTH

UNITED NATIONS OFFICE OF THE SPECIAL REPRESENTATIVE OF THE SECRETARY-GENERAL ON VIOLENCE AGAINST CHILDREN

UNITED NATIONS OFFICE ON DRUGS AND CRIME

UNITED NATIONS PEACEBUILDING SUPPORT OFFICE

UNITED NATIONS POPULATION FUND

UN-ENERGY

UN-OCEAN

UN-WATER

THE WORLD BANK GROUP

WORLD HEALTH ORGANIZATION

WORLD METEOROLOGICAL ORGANIZATION

WORLD TOURISM ORGANIZATION

WORLD TRADE ORGANIZATION

For more information, visit the United Nations Statistics Division Sustainable Development Goals website at https://unstats.un.org/sdgs. 
"Two years ago, world leaders adopted the ambitious 2030 Agenda for Sustainable Development, with seventeen Sustainable Development Goals at its heart. The Agenda is our shared plan to transform the world in fifteen years and, crucially, to build lives of dignity for all."

- UN SeCRETARY-General ANTÓNIo GUTERRES

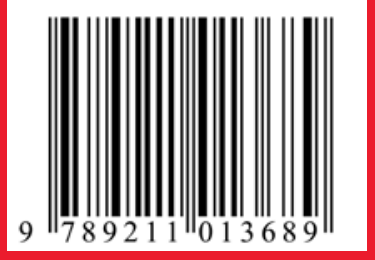

